\title{
WestVirginiaUniversity
}

THE RESEARCH REPOSITORY @ WVU

Graduate Theses, Dissertations, and Problem Reports

2005

\section{Influence of a thermal denuder on diesel exhaust particle size distributions}

Bobby John

West Virginia University

Follow this and additional works at: https://researchrepository.wvu.edu/etd

\section{Recommended Citation}

John, Bobby, "Influence of a thermal denuder on diesel exhaust particle size distributions" (2005). Graduate Theses, Dissertations, and Problem Reports. 1631.

https://researchrepository.wvu.edu/etd/1631

This Thesis is protected by copyright and/or related rights. It has been brought to you by the The Research Repository @ WVU with permission from the rights-holder(s). You are free to use this Thesis in any way that is permitted by the copyright and related rights legislation that applies to your use. For other uses you must obtain permission from the rights-holder(s) directly, unless additional rights are indicated by a Creative Commons license in the record and/ or on the work itself. This Thesis has been accepted for inclusion in WVU Graduate Theses, Dissertations, and Problem Reports collection by an authorized administrator of The Research Repository @ WVU. For more information, please contact researchrepository@mail.wvu.edu. 


\title{
Influence of a Thermal Denuder on Diesel Exhaust
}

Particle Size Distributions

\author{
Bobby John
}

\author{
Thesis submitted to the \\ College of Engineering and Mineral Resources \\ at West Virginia University \\ in partial fulfillment of the requirements \\ for the degree of
}

\author{
Master of Science \\ in \\ Mechanical Engineering
}

Mridul Gautam, Ph.D., Chair

Nigel N. Clark, Ph.D. Michael McCawley, Ph.D.

Department of Mechanical and Aerospace Engineering

\author{
Morgantown, West Virginia \\ 2005
}

Keywords: Thermal Denuder, Particle Sizing, Nanoparticles, Crankcase Emission 


\section{ABSTRACT \\ Influence of a Thermal Denuder on Diesel Exhaust Particle Size Distributions}

\section{Bobby John}

Particle size distributions in diesel exhaust were studied using a thermal desorption technique to determine the volatile and non-volatile fractions. A thermal denuder was designed and characterized for optimal operating parameters and its influence on the exhaust chemistries studied using diesel engine exhaust. The study was conducted on a 1992 DDC Series 60 engine mounted on a heavy-duty direct current dynamometer and exercised over steady state and transient cycles. The particle size distributions were recorded upstream and downstream of the denuder maintained at different temperatures to determine the behavior of the volatile fraction. The volatilization technique was also applied to the crankcase emissions in light of the 2007/2010 EPA regulations. The SMPS was used to obtain the particle size distributions from the sample gases diluted by an ejector diluter system. With the removal of the volatile fraction from the sample exhaust a shift in the size distribution towards the lower end of the spectrum was observed. With the engine running at $1810 \mathrm{rpm}$ and $380 \mathrm{~N}-\mathrm{m}$ (280 ft-lb), the upstream denuder distribution showed a Count Median Diameter of 40nm, which shifted to $20.9 \mathrm{~nm}$ at a denuder temperature of $200^{\circ} \mathrm{C}$ and to $14.6 \mathrm{~nm}$ at $400^{\circ} \mathrm{C}$. At $1220 \mathrm{rpm}$ and $475 \mathrm{~N}-\mathrm{m}$ (350 ft-lb), the Count Median Diameter shifted from 41.4nm to $12.2 \mathrm{~nm}$ at a denuder temperature of $400^{\circ} \mathrm{C}$. This suggests the particle size distribution with a CMD of 40nm was characterized by a carbonaceous core with an adsorbed organic fraction. At a denuder temperature of $400^{\circ} \mathrm{C}$ the organic fraction was desorbed, and nanoparticles comprising of the non-volatile solid carbon fraction and/or ash were measured. 


\section{ACKNOWLEDGEMENTS}

Great effort and much time have been spent on this work with help all along the way. It is now the moment in time to remember all those who positively influenced me and helped me become a better person.

I would like to express my deepest gratitude to Dr Mridul Gautam for being my advisor and for the faith he placed in me. I respect you for the patience and the guidance and for helping me out in all situations.

Dan, I can never express how grateful I am for everything; you taught me more in a year than what I learned in my entire life.

I would like to thank Tom Spencer for teaching me patience and for all the fun in ERC. If it were not for your support, I would have still been a graduate student. Richard, thanks for answering my silly questions all the time.

Special thanks to my committee members Dr Clark and Dr McCawley for agreeing to do my defense at short notice.

Thanks to all my room mates- Anthony, Ram, Sam, and Vinu with whom I had so much fun drinking. I would also like to express my gratitude to my office matesHemanth, Karthik, Mohan and Sasi. Karthik, I owe you for all the late night testing, without which I would not have been able to finish my thesis on time. Special thanks to Mohan for all the advice and help he offered without even asking.

I would also like to express my gratitude to my family for supporting me in my decisions and letting me follow my dreams always; and to Jency, my greatest friend and wife now, who has been my inspiration since we met six years ago. I acknowledge The Almighty that kept me going through thick and thin. 


\section{TABLE OF CONTENTS}

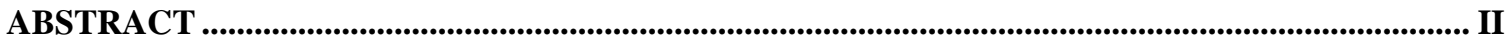

ACKNOWLEDGEMENTS ....................................................................................................................II

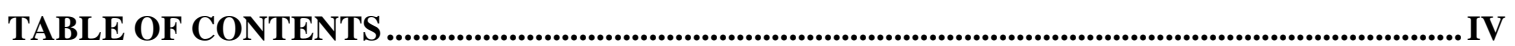

LIST OF TABLES......................................................................................................................................... VII

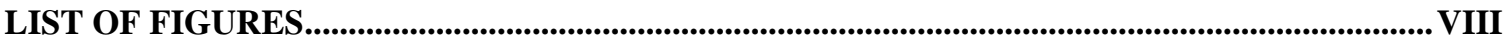

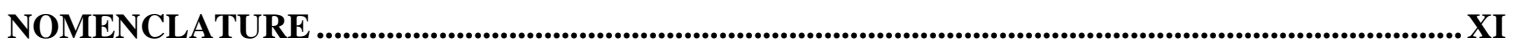

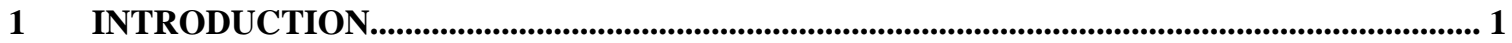

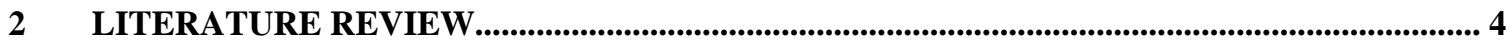

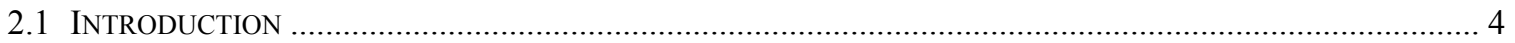

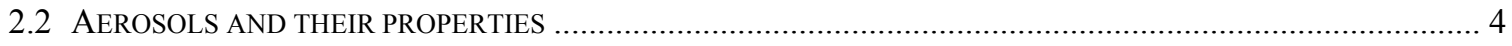

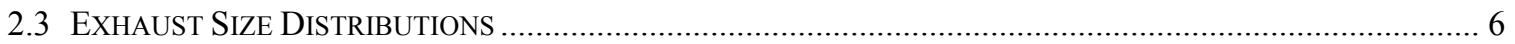

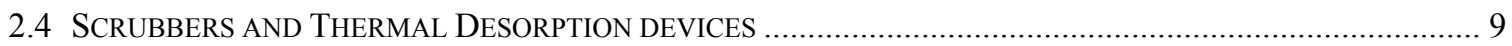

3 INSTRUMENTAL DESIGN AND DEVELOPMENT .................................................................... 17

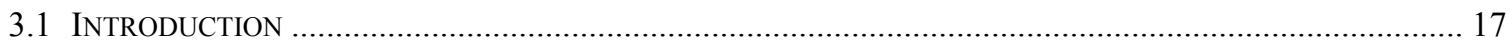

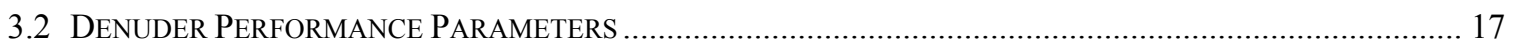

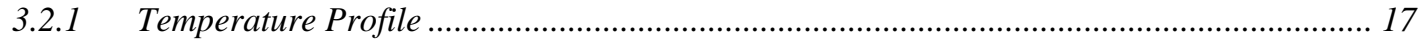

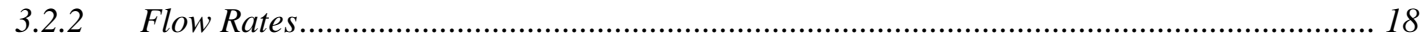

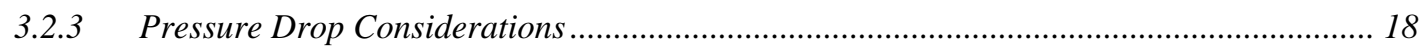

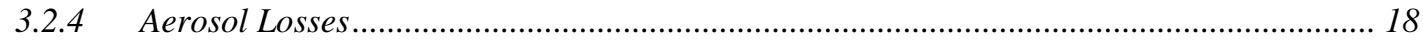

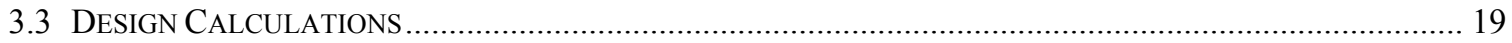

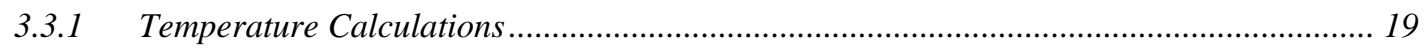

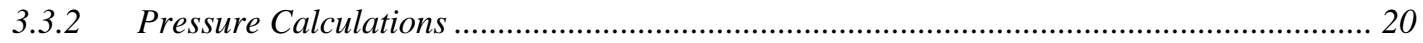

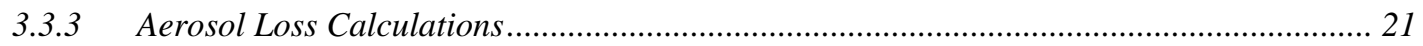

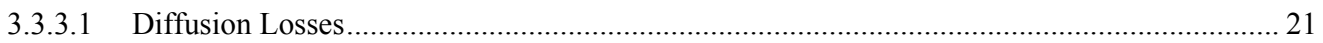

3.3.3.2 Thermophoretic Losses ……………………………………………………………... 22 


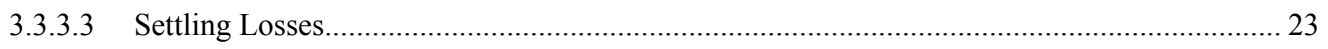

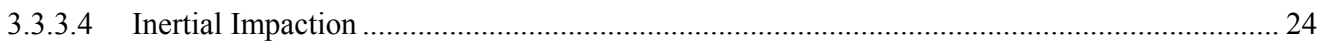

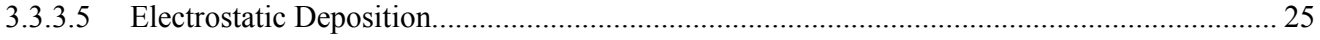

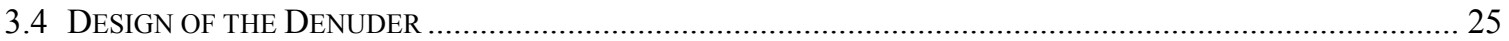

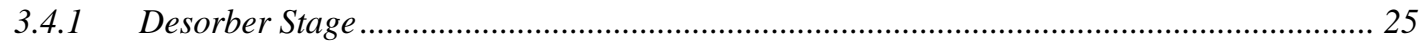

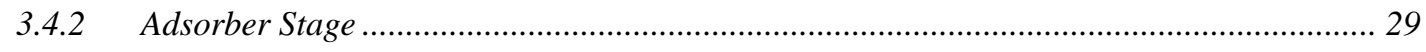

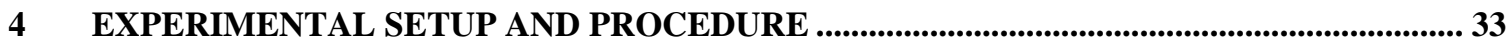

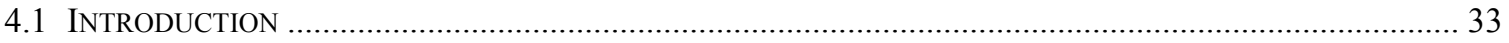

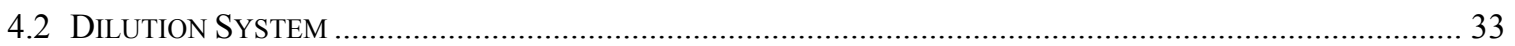

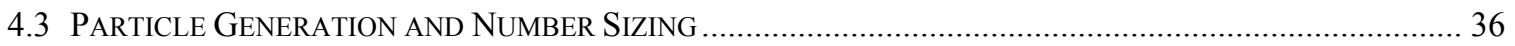

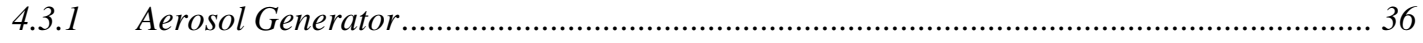

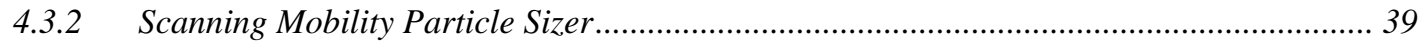

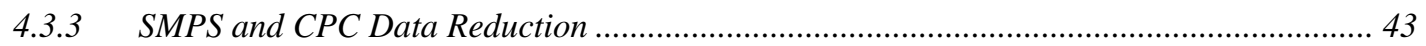

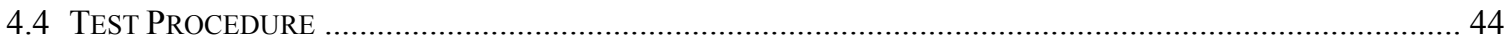

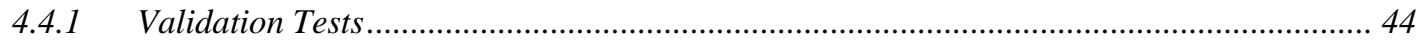

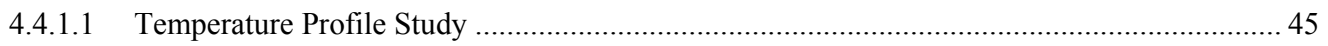

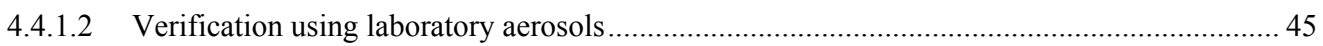

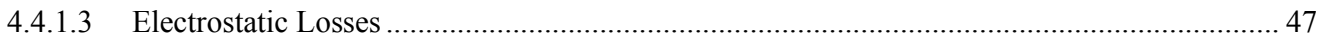

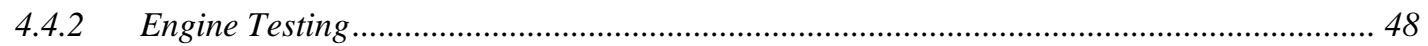

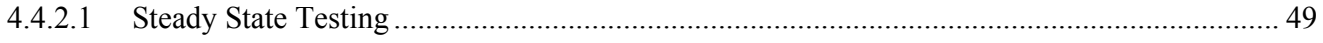

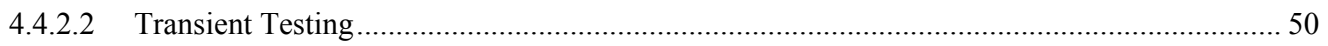

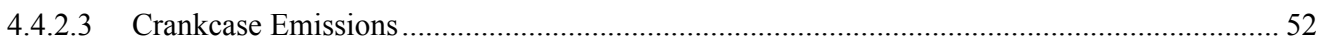

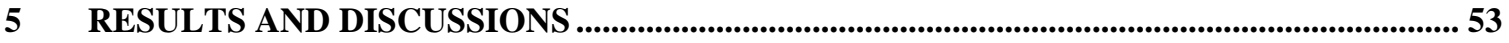

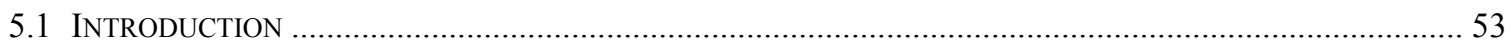

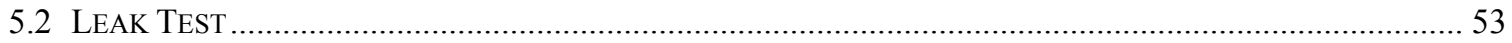

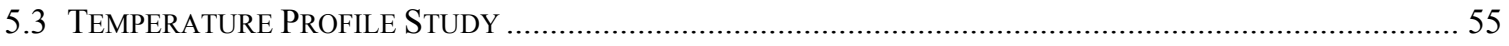

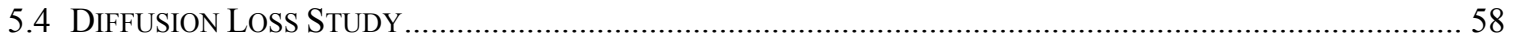

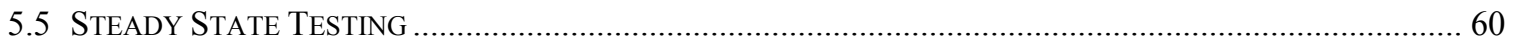

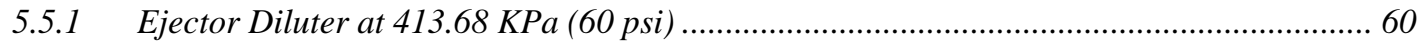




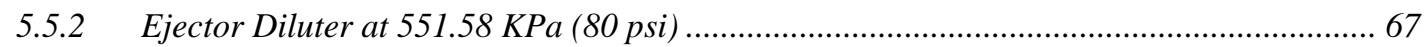

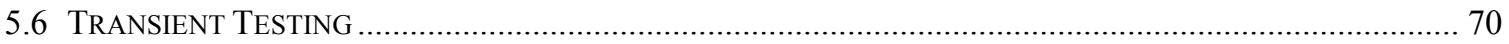

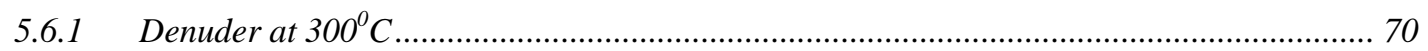

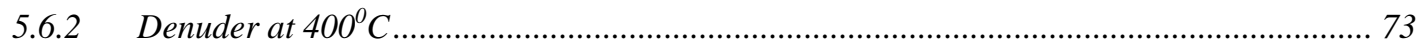

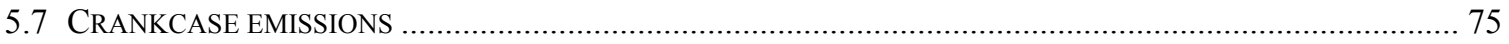

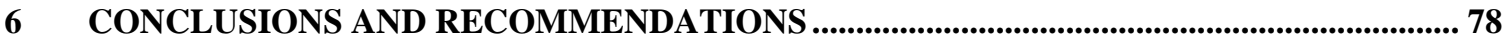

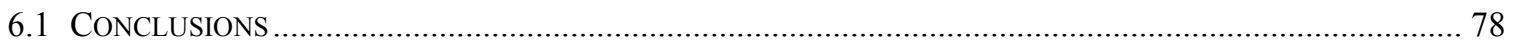

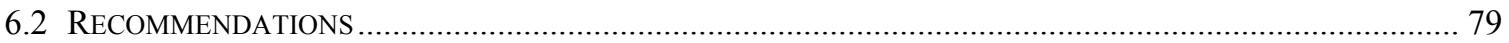

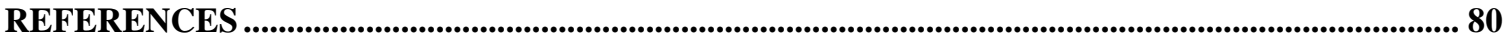

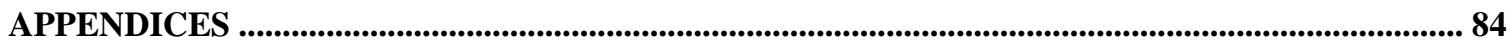

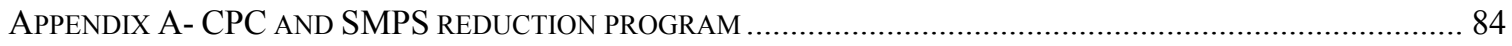

APPENDIX B-TSI MODEL 3936 SCANNING MOBILITY PARTICLE SIZER SPECIFICATIONS ........................ 87

APPENDIX C- TSI MODEL 3480 ElECTROSPRAY AEROSOL GENERATOR SPECIFICATIONS ...................... 88 


\section{LIST OF TABLES}

Table 2.1 Specifications of the TSI Model 3065 Thermodenuder [25]............... 12

Table 2.2 Specifications of the Dekati Thermodenuder [26] ............................ 13

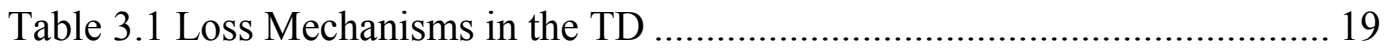

Table 3.2 Heating Tape Specifications .......................................................... 26

Table 4.1 Dilution Ratios at different pressures ......................................... 35

Table 4.2 Steady State Set Points for 92 DDC S60 …....................................... 49

Table 5.1 Diffusion Loss Summary ............................................................. 59

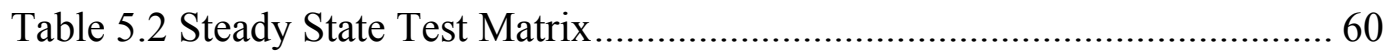




\section{LIST OF FIGURES}

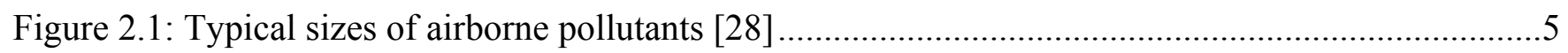

Figure 2.2: Typical Composition of Diesel Exhaust (Kittelson, 1998) ………………….........................

Figure 2.3: Exhaust Size Distributions for a 1992 DDC S60 Engine.......................................................

Figure 2.4: Lung Deposition curve based on particle size (Gautam, 2000) .............................................

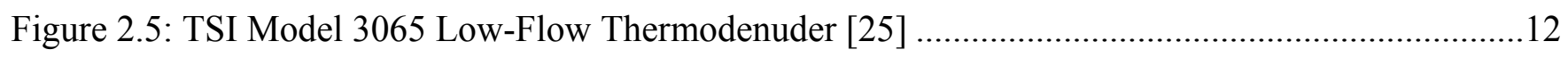

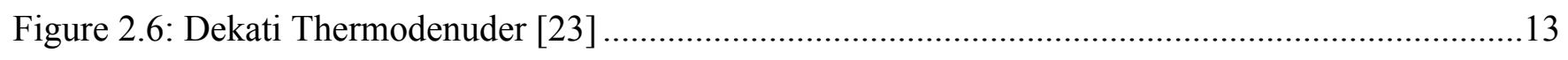

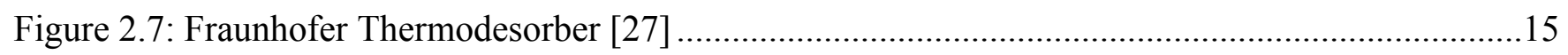

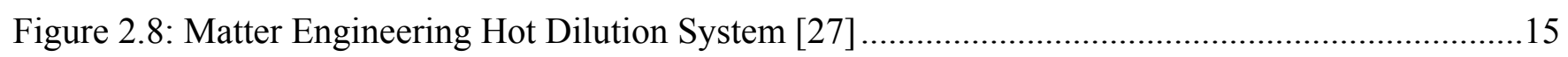

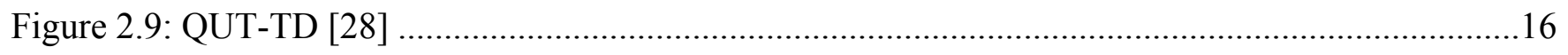

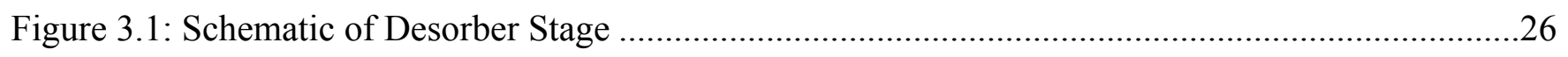

Figure 3.2: Desorber Stage showing heating tape and thermocouples ..................................................27

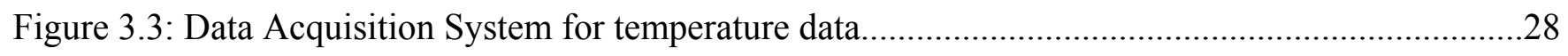

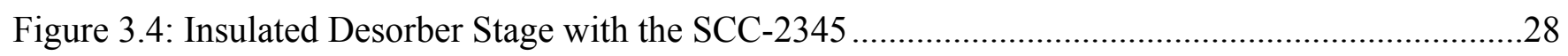

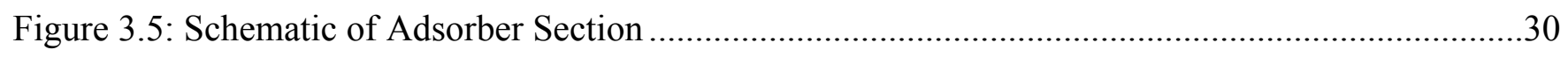

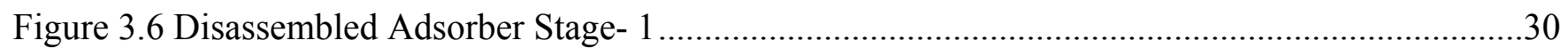

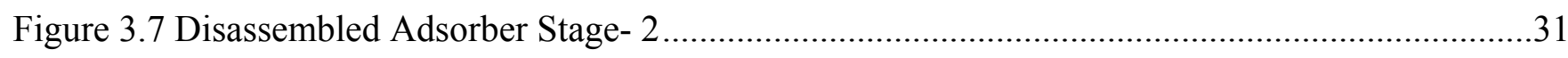

Figure 3.8 Assembled Adsorber Stage with the heated stage ....................................................................

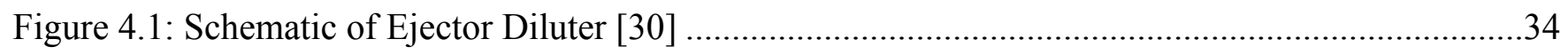

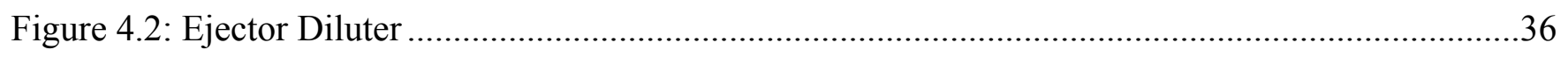

Figure 4.3: TSI Model 3480 Electrospray Aerosol Generator [34] ........................................................

Figure 4.4: Schematic of TSI Model 3480 Electrospray Aerosol Generator [34] .....................................38

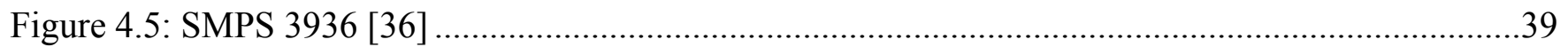


Figure 4.6: Schematic of Classifier with NDMA [36].

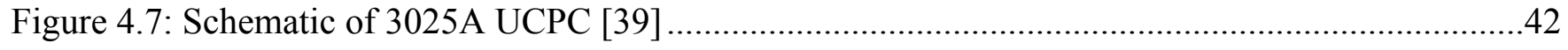

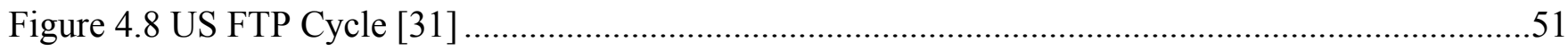

Figure 5.1: TD under Pressure ........................................................................................................54

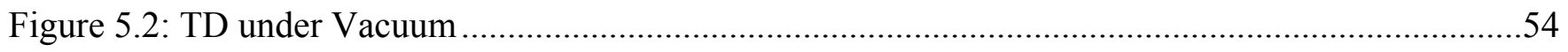

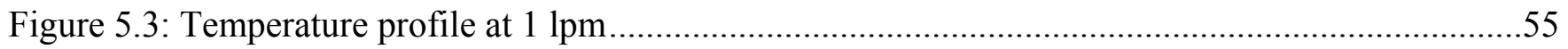

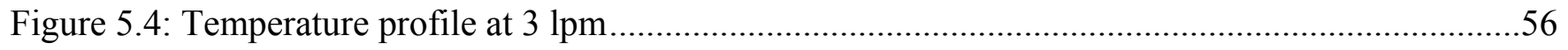

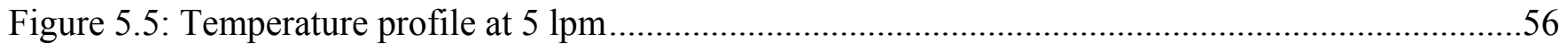

Figure 5.6: Penetration Efficiency Curve at different Flow rates .........................................................59

Figure 5.7: Particle Size Distribution for 1992 DDC S60 Operating at 25\% Load at Rated Speed and Different Denuder Temperatures $(\mathrm{DR}=70)$

Figure 5.8: Particle Size Distribution for 1992 DDC S60 operating at 25\% Load at Intermediate

Speed and Different Denuder Temperatures $(\mathrm{DR}=70)$

Figure 5.9: Particle Size Distribution for 1992 DDC S60 operating at 50\% Load at Rated Speed and Different Denuder Temperatures $(\mathrm{DR}=70)$

Figure 5.10: Particle Size Distribution for 1992 DDC S60 Operating at 50\% Load at Intermediate Speed and Different Denuder Temperatures $(\mathrm{DR}=70)$

Figure 5.11: Particle Size Distribution for 1992 DDC S60 Operating at 100\% Load at Rated Speed and Different Denuder Temperatures $(\mathrm{DR}=70)$ .66

Figure 5.12: Particle Size Distribution for 1992 DDC S60 Operating at 100\% Load at Intermediate Speed and Different Denuder Temperatures $(\mathrm{DR}=70)$ .66

Figure 5.13: Particle Size Distribution for 1992 DDC S60 Operating at 25\% Load at Rated Speed and Different Denuder Temperatures $(\mathrm{DR}=104)$ .68 
Figure 5.14: Particle Size Distribution for 1992 DDC S60 Operating at 100\% Load at Rated Speed and Different Denuder Temperatures $(\mathrm{DR}=104)$

Figure 5.15: Particle Size Distribution for 1992 DDC S60 Operating at 100\% Load at Intermediate Speed and Different Denuder Temperatures $(\mathrm{DR}=104)$ .69

Figure 5.16: Concentration Variation for 70nm Particle over the FTP Cycle-Denuder at $300^{\circ} \mathrm{C} \ldots \ldots \ldots \ldots . . . .71$

Figure 5.17: Concentration Variation for 30nm Particle over the FTP Cycle-Denuder at $300^{\circ} \mathrm{C}$...............71

Figure 5.18: Concentration Variation for $15 \mathrm{~nm}$ Particle over the FTP Cycle-Denuder at $300^{\circ} \mathrm{C} \ldots \ldots \ldots \ldots . . .72$

Figure 5.19: Concentration Variation for 70nm Particle over the FTP Cycle-Denuder at $400^{\circ} \mathrm{C} \ldots \ldots \ldots \ldots . . . .73$

Figure 5.20: Concentration Variation for 30nm Particle over the FTP Cycle-Denuder at $400^{\circ} \mathrm{C} \ldots \ldots \ldots \ldots . . . .74$

Figure 5.21: Concentration Variation for $15 \mathrm{~nm}$ Particle over the FTP Cycle-Denuder at $400^{\circ} \mathrm{C} \ldots \ldots \ldots \ldots . . . .74$

Figure 5.22: Particle size distributions for Crankcase Emissions under Different Engine

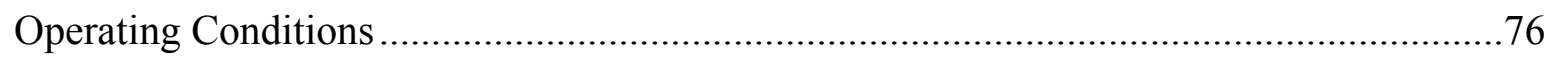

Figure 5.23: Concentration variation of $118 \mathrm{~nm}$ Particle in the Crankcase Emissions over the FTP Cycle .77

Figure 5.24: Concentration variation of 136nm Particle in the Crankcase Emissions over the FTP Cycle...... .77 


\section{NOMENCLATURE}

\begin{tabular}{|c|c|}
\hline AIM & Aerosol Instrument Manager \\
\hline CMD & Count Median Diameter \\
\hline $\mathrm{C}_{\mathrm{c}}$ & Cunningham Slip Correction Factor \\
\hline$d$ & Tube diameter \\
\hline$d_{p}$ & Particle diameter \\
\hline $\mathrm{D}$ & Diffusion Coefficient \\
\hline DDCS60 & Detroit Diesel Corporation Series 60 Engine \\
\hline DD & Denuder Downstream \\
\hline DL & Diffusion Losses \\
\hline DMA & Differential Mobility Analyzer \\
\hline $\mathrm{DPF}$ & Diesel Particulate Filter \\
\hline DU & Denuder Upstream \\
\hline DR & Dilution ratio \\
\hline $\mathrm{EC}$ & Electrostatic Classifier \\
\hline EERC & Engines and Emissions Research Center \\
\hline EPA & Environmental Protection Agency \\
\hline FTP & Federal Test Procedure \\
\hline HDDE & Heavy Duty Diesel Engine \\
\hline
\end{tabular}




\begin{tabular}{|c|c|}
\hline $\mathrm{k}_{\mathrm{g}}$ & Thermal Conductivity of the gas \\
\hline $\mathrm{k}_{\mathrm{p}}$ & Thermal Conductivity of the particle \\
\hline NDMA & Nano Differential Mobility Analyzer \\
\hline $\mathrm{nm}$ & Nanometer \\
\hline $\mathrm{Nu}_{\mathrm{d}}$ & Nusselt Number \\
\hline OD & Outer Diameter \\
\hline $\mathrm{P}$ & Penetration \\
\hline PM & Particulate Matter \\
\hline $\operatorname{Pr}$ & Prandtl Number \\
\hline $\operatorname{Re}_{\mathrm{d}}$ & Reynolds Number \\
\hline SCC & Signal Conditioning Connector Block \\
\hline SMPS & Scanning Mobility Particle Sizer \\
\hline $\mathrm{SO}_{4}$ & Sulphate Fraction \\
\hline SOF & Soluble Organic Fraction \\
\hline SOL & Solid Fraction \\
\hline TAC & Toxic Air Contaminant \\
\hline $\mathrm{TD}$ & Thermal Denuder \\
\hline $\mathrm{TL}$ & Thermophoretic Losses \\
\hline $\mathrm{TP}$ & Total Particulate Matter \\
\hline
\end{tabular}




$\begin{array}{ll}\text { UCPC } & \text { Ultrafine Condensation Particle Counter } \\ \mathrm{V}_{\mathrm{TS}} & \text { Terminal Settling Velocity } \\ \text { WVU } & \text { West Virginia University } \\ \# / \mathrm{cm} 3 & \text { Particles per cubic centimeter } \\ \mu & \text { Deposition Parameter } \\ \eta & \text { Viscosity of the gas } \\ \rho_{\mathrm{g}} & \text { Density of the gas } \\ \mu \mathrm{m} & \text { Micrometer } \\ \theta & \text { Inclination of the tube }\end{array}$




\section{INTRODUCTION}

Classification of Particulate Matter (PM) as a "Toxic Air Contaminant (TAC) by the California Air Resources Board and the Office of Environmental Health Hazard Assessment [1] has lead to stringent regulations being imposed by the regulatory bodies on emissions from diesel engines. This is quite evident from the EPA imposed mandatory reduction in particulate matter emissions in the US from $0.6 \mathrm{~g} / \mathrm{bhp}$-hr in 1988 to the 2007 limit of $0.01 \mathrm{~g} / \mathrm{bhp}-\mathrm{hr}$. The Heavy Duty Diesel Engine (HDDE) manufacturers have been able to meet these severe regulations with improved engine combustion techniques and after treatment devices such as PM traps and DPF's. While, cleaner engine technologies will meet the mass-based 2007 PM regulations, they do not necessarily reduce the number concentrations in the submicrometer range as innumerable aerosol studies on diesel exhaust have indicated [2-5].

Aerosols are generally characterized by a log-normal distribution. Diesel particulate matter distributions have been observed to exhibit unimodal, bimodal and trimodal distributions depending upon engine technology, mode of operation, dilution methodology, dilution air temperature and saturation ratios. The nuclei mode consists of metallic compounds, elemental carbon and semi-volatile organics and sulphur compounds that form nanoparticles during exhaust dilution and range in diameter from 5$50 \mathrm{~nm}$. The nuclei mode contains $1-20 \%$ of the particle mass but more than $90 \%$ by particle number. The accumulation mode consists of particles in the range $50-500 \mathrm{~nm}$ consisting of carbonaceous agglomerates and adsorbed materials that contribute towards mass in PM collection. The coarse mode is mainly particles that are formed by the re- 
entrainment of particles [12]. After treatment devices have efficiencies of the order of $99 \%$ for particles in the accumulation mode, but as the trap is close to the engine where exhaust temperatures are still high, most of the volatile part which contributes towards nanoparticle formation escape and depending on the dilution conditions, operating point etc., form particles in the submicron range [9].

The genotoxic and mutagenic effects of fine particles and their health issues have been identified extensively in research works globally $[6,7,8]$. The health effects will not be dealt with in any detail in this report.

The current PM measurement methodology stipulates collecting PM on a filter from a stream of exhaust that has been cooled and diluted to a temperature of $52^{0} \mathrm{C}$. Negative or positive artifacts on the filter can misrepresent the results depending on the sampling conditions leading to decreased sensitivity. Moreover, with modern engines emitting very low mass of particulates, sampling times would have to be compromised to ensure sufficient collection on filters.

Regulatory bodies have been studying potential candidate measurement systems that replace or enhance the current methodology and give adequate weight to the number concentrations considering the penetration efficiency and deposition of ultrafine particles in the lungs $[10,11]$. A PM number-count based standard may not replace the mass based standard in the near future, but it may certainly complement it. However, to ensure repeatability in number counting, suppression of the nuclei mode particles is required as they are generally volatile in nature, and these particles exhibit different characteristics under different sampling conditions. 
Thus, the thermal denuder (TD) forms an essential element of any field measurement system in order to condition the exhaust in the ultrafine particle regime and to ensure repeatability.

The thermal denuder consists of a heated section and a cooled section having activated carbon. The heated section heats the exhaust to temperatures ranging from $30^{\circ} \mathrm{C}$ to $400^{\circ} \mathrm{C}$ followed by the cooled adsorbent section where the volatile fraction is adsorbed preventing re-adsorption onto particles. Measurements made with and without the TD allow real time measurements of the total, volatile and non-volatile concentrations in diesel exhaust.

The work presented herein discusses the design and fabrication of a thermal denuder and its effect on diesel exhaust particle size distributions. The influence of the thermal denuder on the exhaust was studied using a 1992 Detroit Diesel Corporation Series 60 Engine exercised over steady state and transient operating conditions. Crankcase emissions were also studied in accordance with the 2007 regulations. 


\section{LITERATURE REVIEW}

\subsection{Introduction}

Diesel engine PM is a complex mixture of carbonaceous, ultrafine and volatile fractions. With the EPA tightening regulation of total particulate matter (TPM), engines have become cleaner, with less carbonaceous material being emitted. This compliance with the standards based on mass, does not necessarily imply a reduction in the nanoparticle number fractions. A thermal desorption technique was examined to speciate the volatile and non volatile fractions in the exhaust and to throw light on the nanoparticle formation in the exhaust. The following sections discuss published literature on topics related to the thermal desorption technique.

\subsection{Aerosols and their properties}

An aerosol is defined as a suspension of solid or liquid particles in a gaseous medium [14]. This entails a two-phase system consisting of the particles and the gas in which it is suspended. All atmospheric particulate pollutants are aerosols and their behavior varies depending on the prevailing conditions. Understanding of the aerosol behavior requires a microscopic approach, with explanations derived from the fundamentals of physics, chemistry and engineering. Cloud, dust, fume, mist, fog, smoke, spray etc are examples of some aerosols occurring in nature. Particle size is an important parameter used when defining aerosol properties. The particle diameter, expressed in terms of micrometers and nanometers, can be used to explain the behavior of aerosols to a greater extent. Figure 2.1 shows some typical airborne pollutants with their sizes. 


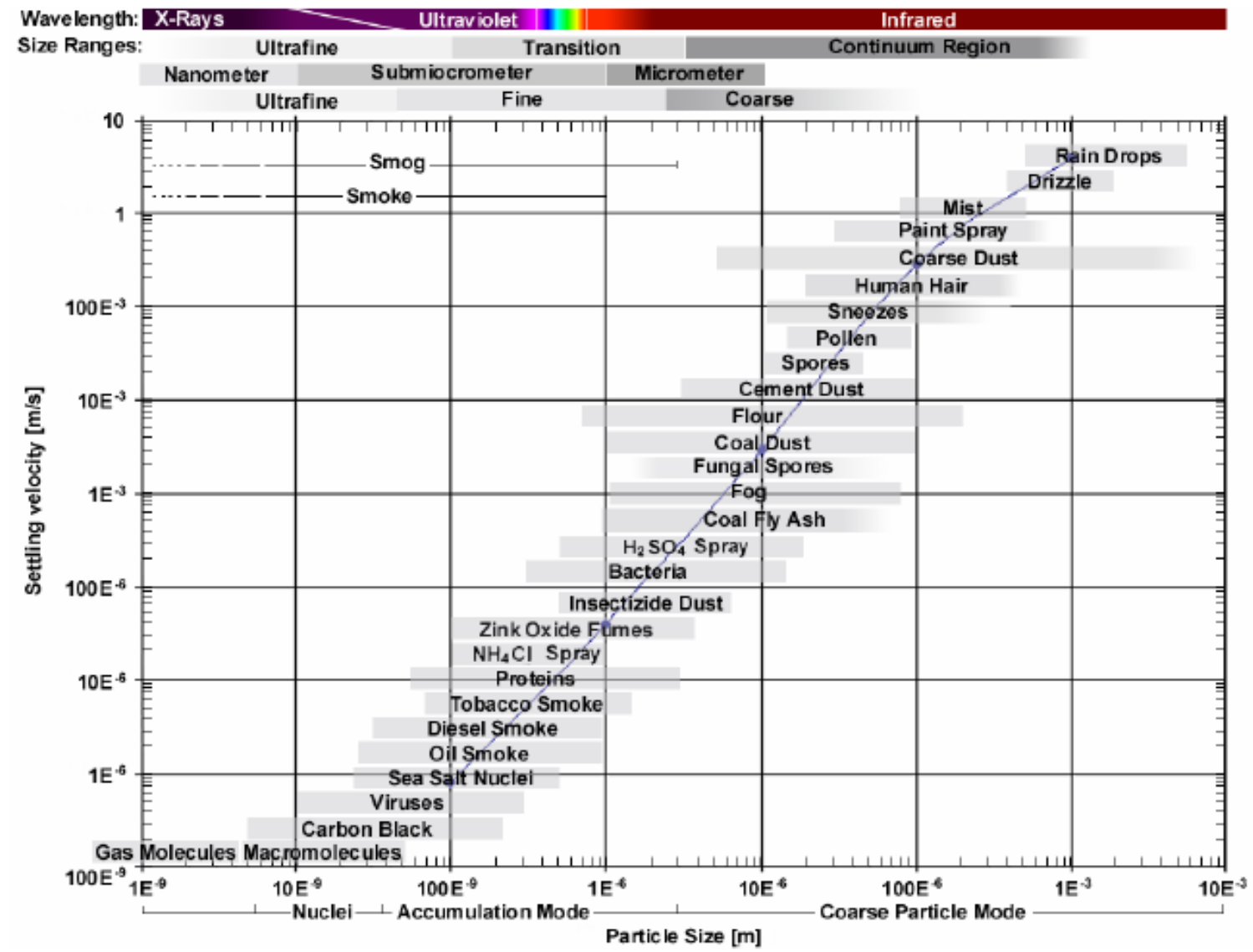

Figure 2.1: Typical sizes of airborne pollutants [28]

The kinetic theory of gases is used to understand the interaction between the suspended particles and the medium and to explain particle motion. However, the submicrometer range aerosols neither follow the continuum region of the kinetic gas theory nor the transition region. For these aerosols the viscous forces dominate the inertial forces and the Stoke's law is used to explain their behavior. The Stoke's Law is a derivation of the Navier-Stokes equations with simple assumptions which eliminates the higher order terms and yields solvable linear equations. These laws form the fundamental basis for describing the factors and parameters that influence particle behavior.

The nanometer sized PM in diesel exhaust is termed ultrafine particles and nanoparticles, and may exist primarily as agglomerates. The formation of nanoparticles 
from diesel engines is being studied extensively and reduction strategies are being implemented because of their carcinogenic nature and deposition efficiency in the lungs $[10,11,16]$.

\subsection{Exhaust Size Distributions}

Nanoparticle formation is enhanced in the absence of carbonaceous agglomerates which act as sites of sorption for the volatile fraction being generated. Homogeneous and heterogeneous nucleation occurs when the volatile compounds in the exhaust reach supersaturation due to cooling down. Nanoparticle formation is dependant on various factors, such as dilution conditions, humidity, temperatures, and residence times [15].

The diesel aerosol consists of highly agglomerated solid carbonaceous material and ash and volatile organic and sulphur compounds. Combustion in locally fuel rich regions produces carbon which is subsequently oxidized and exhausted as solid agglomerates. PM consists of three fractions-SOL, $\mathrm{SOF}$ and $\mathrm{SO}_{4}$ [31]. The Solid Fraction (SOL) consists of elemental carbon and ash, Soluble Organic Fraction (SOF) consists of organics, primarily derived from the lube oil and those derived from the fuel. The sulfate fraction $\left(\mathrm{SO}_{4}\right)$ consists of the hydrated sulfuric acid from the sulfur content in the fuel. Figure 2.2 shows the typical particle composition of a heavy duty diesel engine exhaust. 


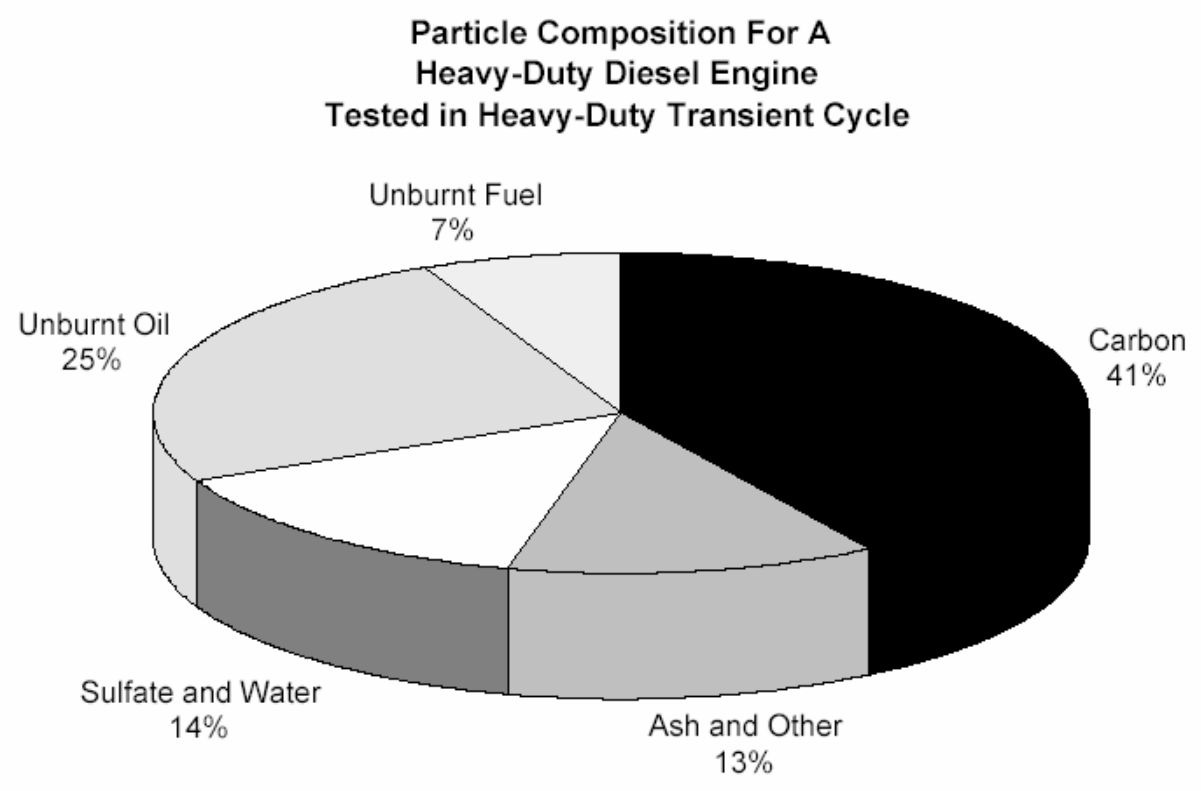

Figure 2.2: Typical Composition of Diesel Exhaust (Kittelson, 1998)

The gases exiting the stack consist of the carbonaceous material, gas phase organics and the sulphur compounds. Once these gases are vented into the atmosphere, they encounter dilution air which causes condensation of the gas phase organics and sulphate fraction. Heterogeneous and homogeneous nucleation occur leading to formation of new particles or growth of the existing agglomerates. The volatile fraction is formed from the lube oil escaping the piston rings during low load conditions [4] and the sulphate fraction in the exhaust from the sulphur content in the fuel. The nanoparticle formation in engines varies with engine design and the operating parameters. The typical exhaust particle size distributions for a 1992 DDC S60 engine for different operating setpoints are shown in Figure 2.3. The deposition efficiency of fine particles in the lungs is shown in Figure 2.4. 


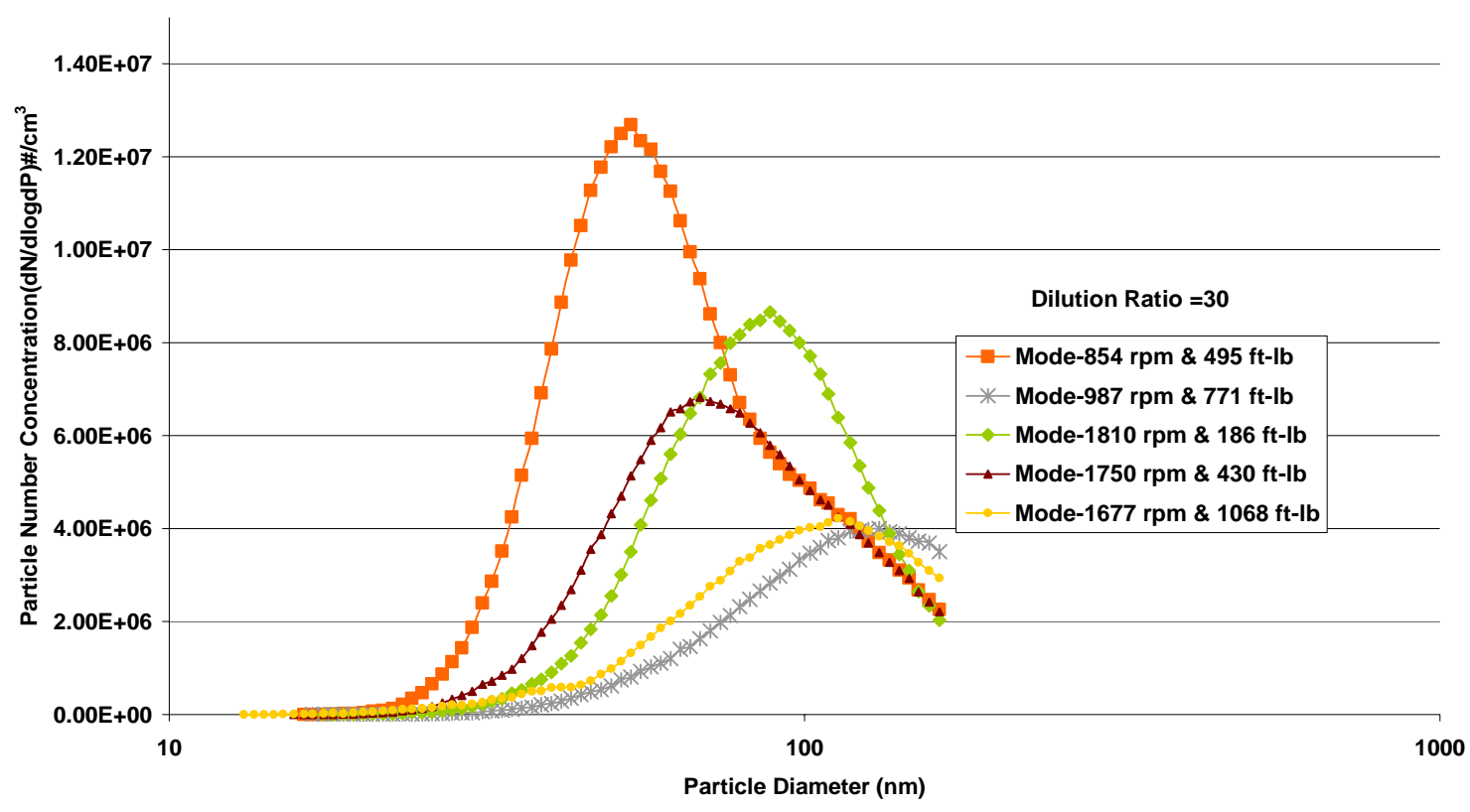

Figure 2.3: Exhaust Size Distributions for a 1992 DDC S60 Engine

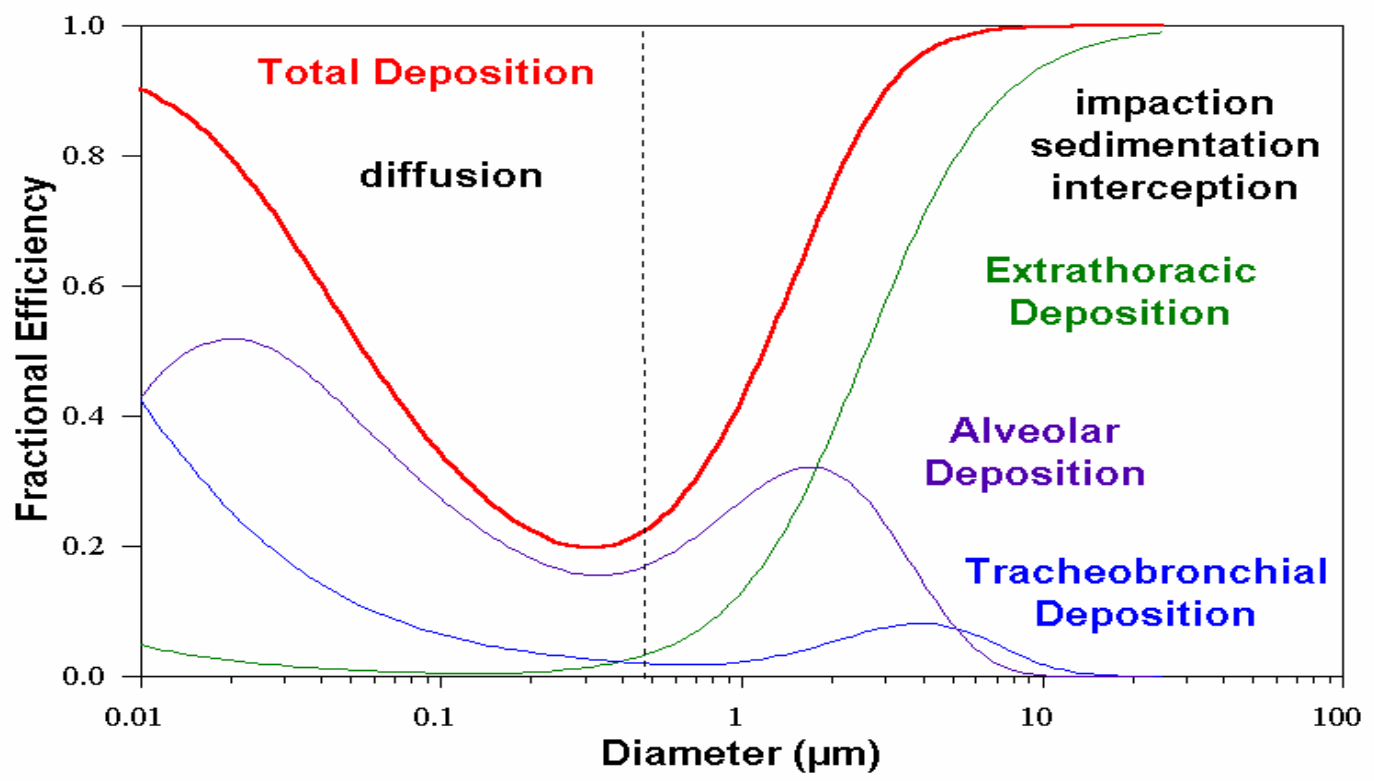

Figure 2.4: Lung Deposition curve based on particle size (Kobrich, 1994) 


\subsection{Scrubbers and Thermal Desorption devices}

Diffusion scrubbers or denuders have been used extensively for many years now in sampling and analysis of atmospheric air pollutants. They were used mainly for atmospheric monitoring studies where the gaseous pollutants were collected on suitable sorbents. More recently diffusion denuders are being used for ambient particulate matter sampling to prevent "negative" and "positive" artifacts on the filter for increased sensitivity of the whole measurement process. The particulate matter consists of organic material as well as elemental carbon, of which the most of the organic material are semivolatile. These semi-volatile organic compounds can be lost from the particles during sampling (negative artifact) or adsorbed onto the filters or the particles (positive artifact) during the measurement process. Either of these processes can occur during the sampling and /or the subsequent handling, storage, conditioning and weighing process. Hence the removal of the volatile fraction in the sample stream is an undeniable requirement for accurate data representation.

Koutrakis et al. [17] designed a personal sampling device with a glass impactor, an annular denuder and a filter pack for sampling atmospheric gases. The impactor had a cut point of 2.5 micrometer and coated with mineral oil to prevent particle bounce. The denuder was coated with citric acid to collect ammonia and nicotine vapors and the filter pack to measure fine particulates in the atmosphere. The flow rates used were $21 \mathrm{pm}$ to 4 lpm. The device was used as a personal sampler to quantify the human exposure to acid aerosols.

Coutant et al. [18] designed a "high-volume compound annular denuder" to be used with a personal sampler with higher efficiencies at flow rates 10-20 times than those 
of the scrubbers in use. The denuder was made of nested series of cylindrical tubes and was used for the adsorption of polynuclear aromatic hydrocarbons with $100 \%$ transmission of the ambient particulates.

Koutrakis et al. [17, 19] improved the denuder filter pack technology with a two stage glass honeycomb denuder which was more compact than the previous one and also had the capability of using several denuders for simultaneous collection of a variety of atmospheric pollutants. The first stage of the denuder assembly was for the adsorption of acidic gases and the second for basic gases. A Teflon filter was used for the collection of fine particulates less than 2.1 micrometer.

Eatough et al. [20, 21, 22] designed a diffusion denuder sampler called the Particle Concentrator-Brigham Young University Organic Sampling System (PC-BOSS) for removal of the gas phase organics before collecting the PM on a quartz filter. The denuder desorbs the sample stream of the semi-volatile organics and nitrates preventing negative or positive artifacts during particulate mass collection. The system was optimized for flow rates of 120-150 Lpm and rigorously tested in the field.

Thermal desorption techniques have recently been used to study the exhaust particle size distributions to ascertain the contribution of volatile fraction to nanoparticle formation. Kittelson et al. [23] used a catalytic stripper to study the volatile and nonvolatile concentrations in the engine exhaust. The catalytic stripper, $125 \mathrm{~mm}$ long and 38 $\mathrm{mm}$ in diameter, was a small section of a diesel catalytic converter from Engelhard Corporation, housed in a stainless steel tube. The whole system was heated using a ceramic electric heater to $300^{\circ} \mathrm{C}$ followed by a cooled section. The catalytic stripper was characterized for the losses and penetration efficiencies using particles generated by a 
Collision Atomizer and a Differential Mobility Analyzer. Particle size distributions were made with a TSI Model 3030 Electrical Aerosol Analyze and a TSI Model 3020 Condensation Nucleus Counter. It was used to study the exhaust from a single cylinder conversion of a John Deere $4045 \mathrm{~T}$ diesel engine as well as a gasoline engine. Bimodal size distributions with a nuclei mode between $30 \mathrm{~nm}$ and $50 \mathrm{~nm}$ and an accumulation mode in the $150 \mathrm{~nm}$ range was reported for the diesel engine at light loads and a strong dependence of particle emissions on the equivalence ratio for the gasoline engine.

Burtscher et al. [24] designed a thermodesorption device with the heated section separate from the cooled section containing activated charcoal for adsorption of the volatile fraction. The operating parameters were determined theoretically and experimentally before studying exhaust distributions. The desorber section or the heated section was made of stainless steel of length $50 \mathrm{~cm}$ and diameter $2 \mathrm{~cm}$ and was heated using a coaxial heating element which increased the temperatures in steps up to $400^{\circ} \mathrm{C}$. The adsorbent section consisted of a stainless steel mesh housed in a cylindrical metal casing containing activated charcoal. The optimum flow rate in the device was $3 \mathrm{lpm}$. Exhaust studies were conducted on a 1.8 liter gasoline engine at steady state conditions with a dilution ration of 1:40 and measurements made with and without the denuder. Efficient removal of the volatile fraction was reported.

Thermal Desorption devices are available from TSI Inc. and Dekati Ltd. Figure 2.5 shows the TSI denuder and Table 2.1 gives the specifications [25]. The Low Flow Model 3065 Thermodenuder is optimized for flow rates of $0.2 \mathrm{lpm}$ to $2 \mathrm{lpm}$ and uses activated charcoal as the adsorbent. The temperature setting can be increased in steps to 
$400^{\circ} \mathrm{C}$ to achieve separation of the volatile fraction from the non-volatile fraction in the exhaust. Glass, ceramics and stainless steel are used for the construction.

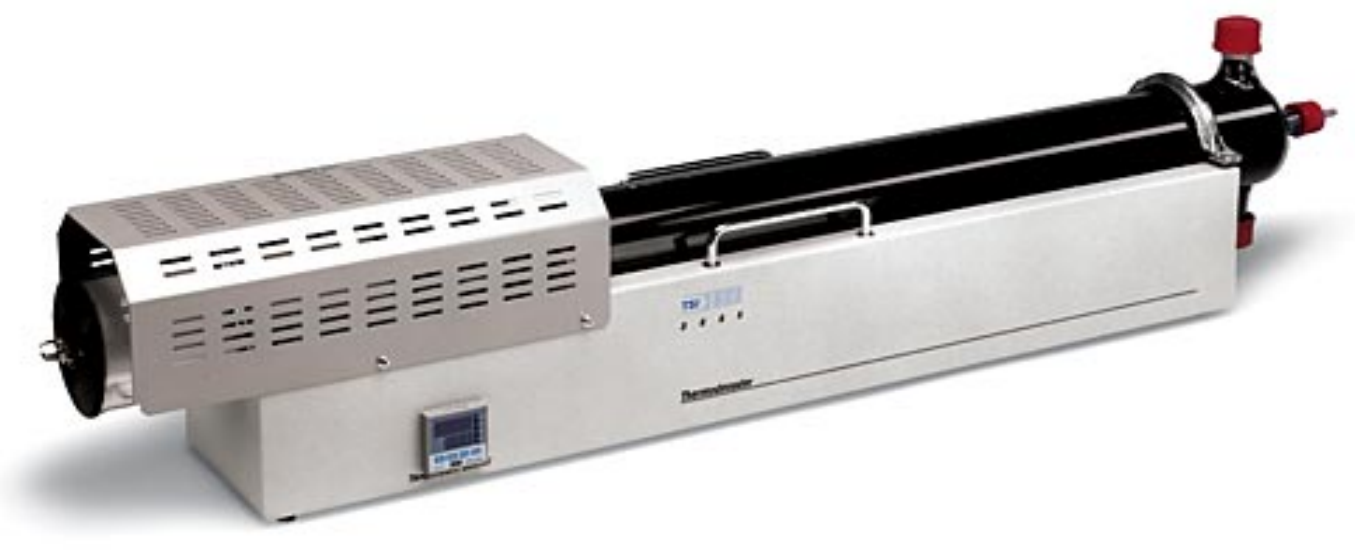

Figure 2.5: TSI Model 3065 Low-Flow Thermodenuder [25]

Table 2.1 Specifications of the TSI Model 3065 Thermodenuder [25]

\begin{tabular}{|c|c|}
\hline Adsorption Material & Activated carbon \\
\hline $\begin{array}{c}\text { Adsorption Material } \\
\text { Volume }\end{array}$ & $6 \mathrm{~L}$ \\
\hline Temperature Range & 0 to $400^{\circ} \mathrm{C} \pm 1^{\circ} \mathrm{C}$ \\
\hline Temperature Controller & WIKA GCS \\
\hline Flow Range & $\begin{array}{c}0.2 \text { to } 2 \text { L/min, } \\
\text { optimal } 0.5 \text { to } 1 \text { L/min }\end{array}$ \\
\hline Sampling Line Connector & $\begin{array}{c}6-\mathrm{mm} \mathrm{Swagelok}{ }^{\circledR} \\
\text { fitting }\end{array}$ \\
\hline Power Supply & $\begin{array}{c}230 \mathrm{VAC} \text { standard, } \\
110 \mathrm{VAC}\end{array}$ \\
\hline Dimensions (LWH) & $\begin{array}{c}110 \mathrm{~cm} \times 26 \mathrm{~cm} \times 17 \\
\mathrm{~cm}\end{array}$ \\
\hline Weight & $11.5 \mathrm{~kg} \mathrm{(25} \mathrm{lb)}$ \\
\hline
\end{tabular}


The Dekati Thermodenuder (ELA-111, ELA-230), manufactured by Dekati Ltd in Finland, works on the same principle of thermal desorption with activated charcoal as the adsorbent.[26] Figure 2.6 shows the Dekati Thermodenuder and Table 2.2 gives the specifications. The denuder is optimized for flow rates of 10-20 lpm and temperatures of $250^{0} \mathrm{C}$.

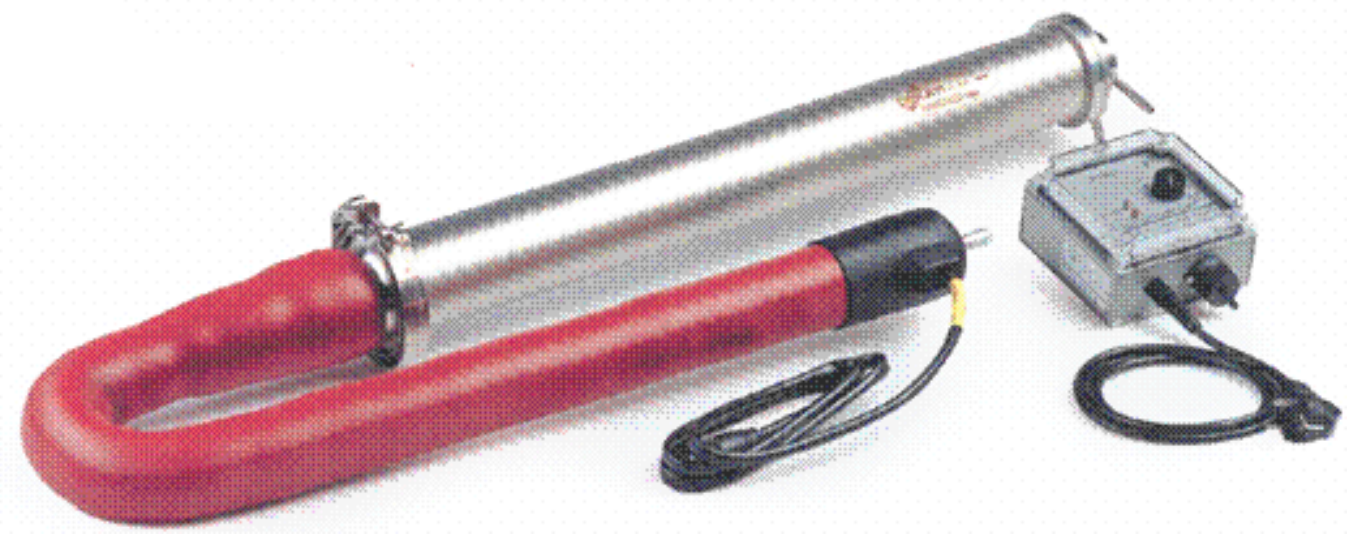

Figure 2.6: Dekati Thermodenuder [23]

Table 2.2 Specifications of the Dekati Thermodenuder [26]

\begin{tabular}{|c|c|}
\hline Flow rate & $10-20 \mathrm{lpm}$ \\
\hline Maximum operating temperature & $300^{\circ} \mathrm{C}$ \\
\hline Cooling medium & Air or water \\
\hline Adsorber material & Active charcoal \\
\hline Weight & $7.5 \mathrm{~kg}$ without filter cartridges \\
\hline Dimensions & L95 cm x W22 cm \\
\hline Electric Power & $230 \mathrm{~V} / 230 \mathrm{~W}, 110 \mathrm{~V} / 230 \mathrm{~W}$ \\
\hline
\end{tabular}

Fierz et al. [27] evaluated the performance of three thermodesorbers and a hot dilution system for application in type approval tests of diesel engines. The thermodesorption devices tested were TSI Thermodenuder, Dekati Thermodenuder, a 
design from the Fraunhofer Institute of Toxicology and Experimental Medicine and a hot dilution system built by Matter Engineering. Figures 2.5 and 2.6 show the TSI Thermodenuder and Dekati Thermodenuder respectively. The Fraunhofer thermodesorber [Figure 2.7] is a novel design which uses a honeycomb ceramic trap instead of activated charcoal as the adsorber. The operating flow rate is $1 \mathrm{Lpm}$ and temperatures used are $400^{\circ} \mathrm{C}$. The Matter Engineering Hot Dilution system, shown in Figure 2.8 was just a heated tube added to the commercially available MD-19 rotating disk diluter. The operating flow rate is $1 \mathrm{lpm}$ and the temperatures set to $200^{\circ} \mathrm{C}$. Penetration measurements were conducted with particles generated with a CAST flame soot generator. The generated particles were size selected using a differential mobility analyzer and particle concentrations measured upstream and downstream of the devices using Condensation Particle Counters. Volatile particle behaviors in the devices were studied using Triacontane and Tetracontane generated by an aerosol generator. Finally chassis dynamometer tests were performed on a VW Passat gasoline car exercised over steady state conditions and the ETC cycle. Efficient removal of volatile fraction in the exhaust was reported, however further optimization of the devices was suggested for better efficiency. 


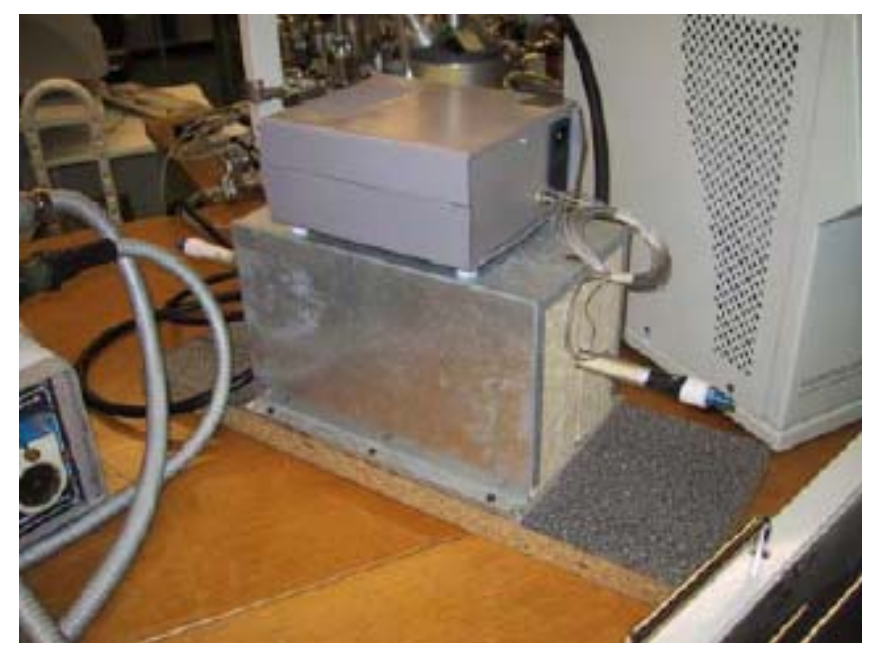

Figure 2.7: Fraunhofer Thermodesorber [27]

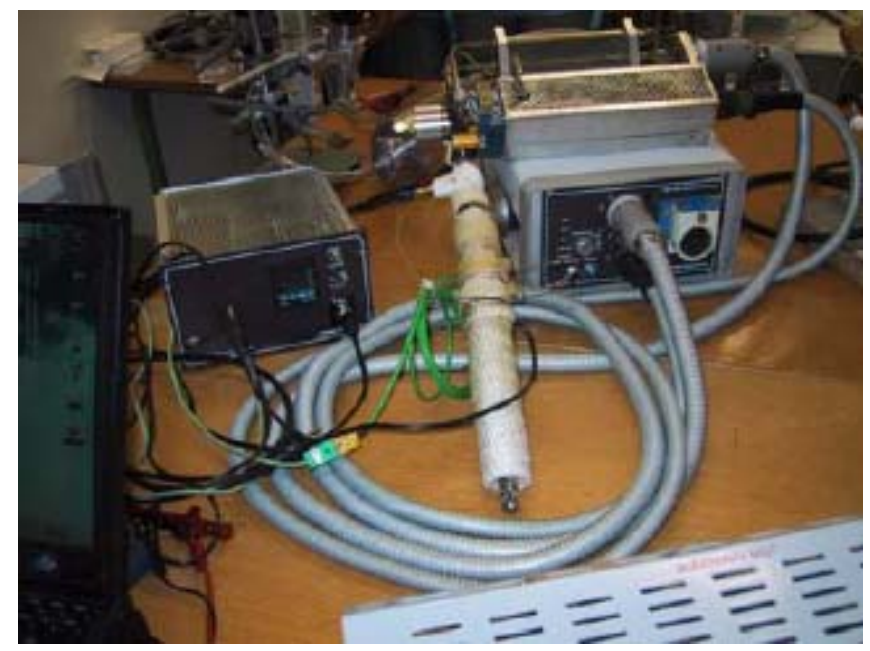

Figure 2.8: Matter Engineering Hot Dilution System [27]

Madl [28] in a collaborative research work between the Institute of Physics and Biophysics of Salzburg University, Austria and the Center of Medical Health and Physics at the Queensland University of Technology in Australia developed a Thermodenuder for conditioning the exhaust. The system incorporated a direct heating system for better temperature control in the heated section resulting in stable temperature profiles with positive gradients. The QUT TD, with an optimal flow rate of 2- $2.5 \mathrm{lpm}$ is shown in 
Figure 2.9. The system was divided into two stages with the heated stage separate from the adsorber stage containing the activated charcoal.

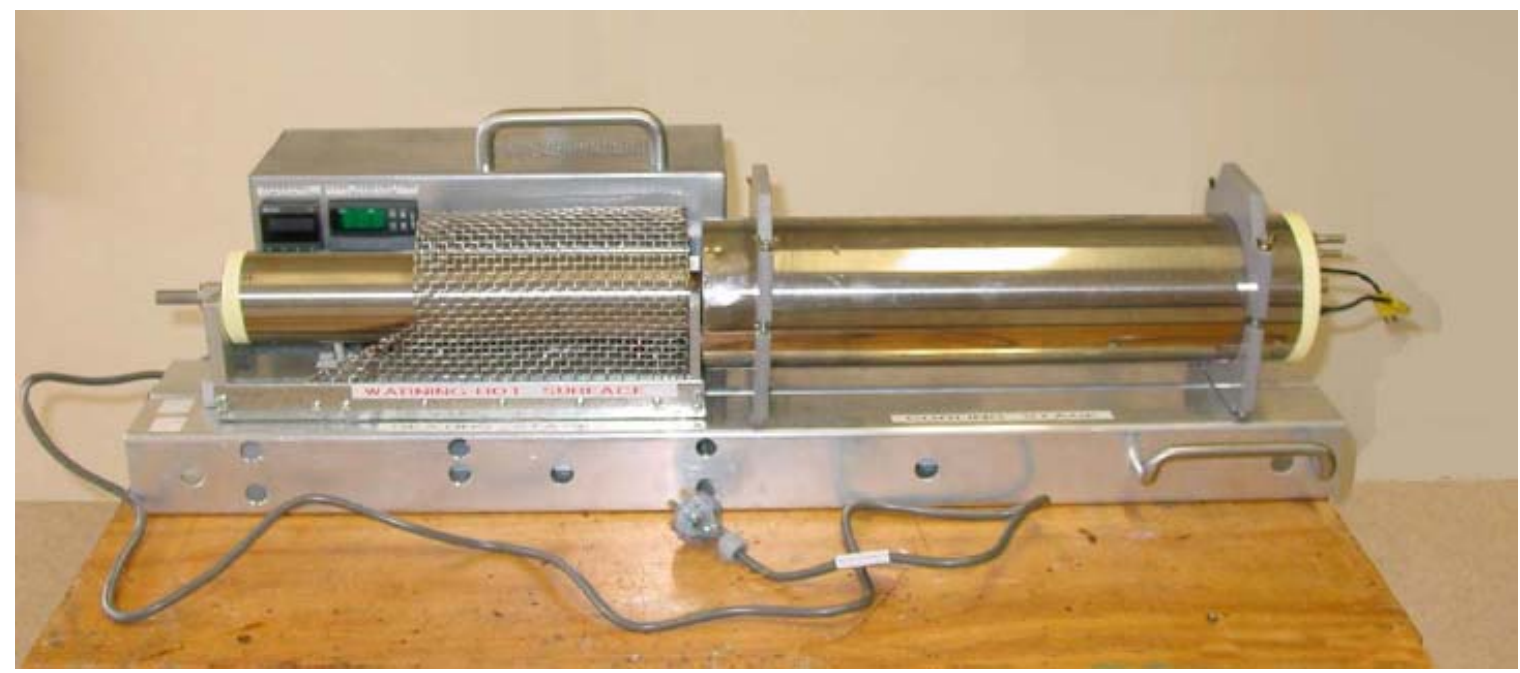

Figure 2.9: QUT-TD [28]

Extensive tests were performed on the QUT-TD and compared with the TSI Thermodenuder for penetration efficiencies and losses using test aerosols generated by a CMAG. Desorption of the volatile fraction in gasoline and diesel exhaust was studied and reported.

The development and use of a carbon denuder was reported in the E-66 ProjectPhase I [29] in January, 2005. The denuder was a coated honeycomb ceramic substrate in stainless steel housing. However due to inconsistent performance of the stripping mechanism, the use of the denuder was abandoned in the early stages of the project. 


\section{INSTRUMENTAL DESIGN AND DEVELOPMENT}

\subsection{Introduction}

The thermal denuder is a device that is used to remove volatile material in the exhaust by the thermal desorption technique. It consists of two stages-a heated section for desorption of the volatile fraction and a cooled stage with a sorbent for adsorbing the volatiles. Ideally, transmission of the volatile material should be zero and penetration of the stripped particles, $100 \%$.

This chapter describes in details the various parameters considered, and the design of the thermal denuder. The theoretical calculations performed to arrive at the final configuration used for studying the influence on particle size distributions in the diesel exhaust is described in detail.

\subsection{Denuder Performance Parameters}

The various parameters affecting the stripping performance of the thermal denuder are given in the following sections.

\subsubsection{Temperature Profile}

The temperature profile inside the desorber tube or the heated section is critically important because it has a significant effect on the entire process of nanoparticle formation and defines the volatilization behavior of particles. It is desirable to have a uniform profile in the heating zone or else re-adsorption of volatile material onto particles or homogeneous nucleation or even thermal degradation of the exhaust components may occur. Hence set temperatures should be maintained till the adsorber section is reached. 
Theoretical temperature calculations were conducted for different combinations of flow rates and diameters of the volatilization tube and are described in detail in Section 3.3.1.

\subsubsection{Flow Rates}

Determination of the optimal flow rate through the denuder required an extensive experimental effort. The denuder is to be used with aerosol size spectrometers, such as the Scanning Mobility Particle Sizer (SMPS) which operates at flow rates of $0.3 \mathrm{lpm}$ to 1.5 Lpm. A higher sample flow rate in the denuder would decrease the particle losses associated with the denuder, but may not ensure uniform heating of the sample gases. Hence an optimized flow rate is essential.

\subsubsection{Pressure Drop Considerations}

Pressure drop in the denuder is another important factor to be considered as higher pressure drops would be detrimental to the sampling pump. Pressure drop calculations are described in Section 3.3.2.

\subsubsection{Aerosol Losses}

Aerosol deposition mechanisms, namely interception, inertial impaction, diffusion, gravitational settling and electrostatic attraction are generally associated with flows in a tube. These deposition mechanisms dictate the efficiency of the denuder and theoretical calculations are necessary to determine the optimal operating characteristics of the denuder. The aerosol losses associated with the denuder and their theoretical calculations are presented in detail in Section 3.3.3. The loss mechanisms are summarized in Table 3.1 
Table 3.1 Loss Mechanisms in the TD

\begin{tabular}{|c|c|c|}
\hline Loss Mechanism & Effect & Countermeasure \\
\hline Diffusion Losses & $\begin{array}{c}\text { Important for } \\
\text { small } \\
\text { particles<1um }\end{array}$ & $\begin{array}{c}\text { High flow rate, short } \\
\text { residence time, shorter } \\
\text { length of tube }\end{array}$ \\
\hline $\begin{array}{c}\text { Thermophoretic } \\
\text { Losses }\end{array}$ & $\begin{array}{c}\text { Important in } \\
\text { adsorber stage }\end{array}$ & Correct data for losses \\
\hline Settling Losses & $\begin{array}{c}\text { Important for } \\
\text { large particles }\end{array}$ & $\begin{array}{c}\text { Shorter tubes, high gas } \\
\text { velocity, TD kept vertical }\end{array}$ \\
\hline Inertial Impaction & $\begin{array}{c}\text { Mainly important } \\
\text { for large } \\
\text { particles>1um }\end{array}$ & No bends in the tube \\
\hline $\begin{array}{c}\text { Electrostatic } \\
\text { Deposition } \\
\text { particles or } \\
\text { charges on the } \\
\text { transport tube }\end{array}$ & TD electrically grounded \\
\hline
\end{tabular}

\subsection{Design Calculations}

Theoretical calculations performed to arrive at the final design of the thermal denuder are presented below. The equations used were taken from Mills [13] and Hinds [14].

\subsubsection{Temperature Calculations}

The calculations were done with an assumed inlet temperature of $50^{\circ} \mathrm{C}\left(\mathrm{T}_{\mathrm{b}_{\text {in }}}\right)$. The average nusselt number is then calculated using the assumed bulk temperature for fluid properties.

Steps:

1. $\operatorname{Re}_{d}=\frac{(\dot{m} / A) d}{\eta} \quad$ Where, $m$ is in $\mathrm{kg} / \mathrm{s}, \mathrm{d}$ is in $\mathrm{m}, \mathrm{A}$ is in $\mathrm{m}^{2}$ and $\eta$ in $\mathrm{kg} / \mathrm{ms}$. 
The calculated Reynolds Number is used to determine the average Nusselt Number [13].

$$
\text { 2. } \overline{\mathrm{Nu}_{\mathrm{d}}}=3.66+\frac{0.065(\mathrm{~d} / \mathrm{L}) \mathrm{Re}_{\mathrm{d}} \operatorname{Pr}}{1+0.04\left[(\mathrm{~d} / \mathrm{L}) \operatorname{Re}_{\mathrm{d}} \operatorname{Pr}\right]^{2 / 3}}
$$

Where, $\overline{\mathrm{Nu}_{\mathrm{d}}}$ is the average nusselt number used to calculate the heat transfer coefficient.

$$
\begin{aligned}
& \text { 3. } \overline{\mathrm{h}_{\mathrm{c}}}=\frac{\mathrm{k}}{\mathrm{d}} \overline{\mathrm{Nu}_{\mathrm{d}}} \\
& \text { 4. } \mathrm{T}_{\mathrm{b}_{\text {out }}}=\mathrm{T}_{\mathrm{s}}-\left(\mathrm{T}_{\mathrm{s}}-\mathrm{T}_{\mathrm{b}_{\text {in }}}\right) \mathrm{e}^{-\overline{\mathrm{h}_{\mathrm{c}}} 2 \pi \mathrm{RL} / \mathrm{mC}_{\mathrm{p}}}
\end{aligned}
$$

The calculations were done for 2" and 1" diameter tubes with flow rates 1 lpm, 3 lpm and $5 \mathrm{lpm}$.

\subsubsection{Pressure Calculations}

The pressure drop across the length of the tube is given by $=\frac{\rho f L V^{2}}{2 d}$ (neglecting entrance effects)

Where, $\mathrm{f}=\frac{64}{\mathrm{Re}_{\mathrm{d}}}$ for laminar flows,

$\mathrm{V}$ is the flow velocity in $\mathrm{m} / \mathrm{s}, \mathrm{d}$ is the diameter of the pipe,

$\mathrm{L}$ is the length of the pipe and $\rho$ is the density of the fluid.

Decreasing the diameter and increasing the length results in a higher-pressure drop. 


\subsubsection{Aerosol Loss Calculations}

Losses that occur in the denuder are Brownian Diffusion losses, Thermophoretic losses, Settling Losses, Inertial Impaction losses and Electrostatic deposition losses.

\subsubsection{Diffusion Losses}

Brownian diffusion is the major mechanism for losses in transport tubes. It is the movement of particles due to a concentration gradient. The aerosol concentration at the surface of the transport tube is zero which results in a concentration gradient causing the particles to move towards the walls of the tube The diffusion of particles to the walls of the tube does not depend on the diameter of the tube for a given flow rate. The fraction of particles entering the tube that will exit the tube, called the penetration, $\mathrm{P}$ is given by Hinds [14] as a function of the deposition parameter, $\mu$.

$$
\mu=\frac{\mathrm{DL}}{\mathrm{Q}}
$$

Where, $\mathrm{D}$ is the diffusion coefficient,

$$
\begin{aligned}
& \mathrm{L} \text { is the length of the tube, } \\
& \mathrm{Q} \text { is the volumetric flow rate. }
\end{aligned}
$$

Penetration is given by the equation [14],

$$
\begin{array}{ll}
\mathrm{P}=1-5.5 \mu^{2 / 3}+3.77 \mu & \text { for } \mu<0.009 \\
\mathrm{P}=0.819 \exp (-11.5 \mu)+0.0975 \exp (-70.1 \mu) & \text { for } \mu \geq 0.009
\end{array}
$$

The diffusion coefficient $\mathrm{D}$,

$$
\mathrm{D}=\frac{\mathrm{kTC}_{\mathrm{c}}}{3 \pi \eta \mathrm{d}_{\mathrm{p}}}
$$


Where, $\mathrm{k}$ is the Boltzmann constant

$\mathrm{T}$ is the absolute temperature,

$\mathrm{C}_{\mathrm{c}}$ is the Cunningham slip correction factor,

$\mathrm{d}_{\mathrm{p}}$ is the particle diameter,

$\eta$ is the viscosity of the gas.

The Cunningham Slip Correction factor $\mathrm{C}_{\mathrm{c}}$,

$$
\begin{aligned}
& \mathrm{C}_{\mathrm{c}}=1+\mathrm{kn}[1.142+0.558 \exp (-0.999 / \mathrm{kn}) \\
& \mathrm{kn}=\frac{2 \lambda}{\mathrm{d}_{\mathrm{p}}}
\end{aligned}
$$

Where, $\mathrm{kn}$ is the Knudsen number and $\lambda$ is the mean free path.

The diffusive deposition depends on the factor $\frac{\mathrm{DL}}{\mathrm{Q}}$ where $\mathrm{D}$ is the diffusion coefficient and $\mathrm{L}$ is the length of the tube.

For a $100 \mathrm{~cm}$ (40 inches) length and a particle diameter of $10 \mathrm{~nm}$, the diffusion losses are $22.2 \%$, but for a $50 \mathrm{~cm}$ (20 inches) length, the losses are $1 \%$ (calculations made at NTP).

This means the diffusion losses can be significantly decreased if length is decreased or if the flow rate is increased.

\subsubsection{Thermophoretic Losses}

Thermophoresis is the motion of the particle due to asymmetrical forces that arise due to a thermal gradient. The thermal force and particle motion is in the direction of decreasing temperature gradient. Thermophoretic losses are more significant in the absorber tube as the walls are at a lower temperature than the incoming gas temperature. 
This causes a thermal gradient causing particles to drift towards the cooler surface. The thermal forces experienced by the particles depend on the properties of the gas and particles and the thermal gradient.

The thermophoretic velocity is given by Waldmann and Schmitt (1966) as,

For small particles, $d_{p}<\lambda$

$$
\mathrm{V}_{\mathrm{th}}=\frac{-0.55 \eta \Delta \mathrm{T}}{\rho_{\mathrm{g}} \mathrm{T}}
$$

For large particles, $d_{p}>\lambda$

$$
\mathrm{V}_{\mathrm{th}}=\frac{-3 \eta \mathrm{C}_{\mathrm{c}} \mathrm{H} \Delta \mathrm{T}}{2 \rho_{\mathrm{g}} \mathrm{T}}
$$

Where, $\mathrm{H}$ is the molecular accommodation coefficient and $\rho_{\mathrm{g}}$ is the density of the gas [14].

$$
\begin{aligned}
& \mathrm{H}=\left[\frac{1}{1+6 \lambda / \mathrm{d}_{\mathrm{p}}}\right]\left[\frac{\mathrm{k}_{\mathrm{a}} / \mathrm{k}_{\mathrm{p}}+4.4 \lambda / \mathrm{d}_{\mathrm{p}}}{1+2 \mathrm{k}_{\mathrm{a}} / \mathrm{k}_{\mathrm{p}}+8.8 \lambda / \mathrm{d}_{\mathrm{p}}}\right] \\
& \mathrm{k}_{\mathrm{g}} \text { and } \mathrm{k}_{\mathrm{p}} \text { are the thermal conductivities of the gas and the particle respectively. }
\end{aligned}
$$

Thus the thermophoretic loss is independent of the particle diameter for smaller particles.

\subsubsection{Settling Losses}

Gravitational settling losses increase with increasing particle sizes. For laminar flow in tubes, Fuch (1964) gave the settling losses as

$$
\frac{2}{\pi}\left(2 \mathrm{k}_{1} \mathrm{k}_{2}-\mathrm{k}_{1}^{1 / 3}+\arcsin \left(\mathrm{k}_{1}^{1 / 3}\right)\right)
$$


Where, $\mathrm{k}_{1}=\frac{3 \mathrm{~V}_{\mathrm{TS}} \mathrm{L}}{4 \mathrm{Ud}} \operatorname{Cos} \theta$ and $\mathrm{k}_{2}=\left(1-\mathrm{k}_{1}^{2 / 3}\right)^{1 / 2}$,

$\mathrm{U}$ is the gas velocity,

$\mathrm{V}_{\mathrm{TS}}$ is the settling velocity and

$d$ is the diameter of the tube.

The transport efficiency for gravitational settling for laminar flow in a tube is

dependant on the parameter $\frac{\mathrm{V}_{\mathrm{TS}} \mathrm{L}}{\mathrm{Ud}} \operatorname{Cos} \theta$, where the inclination of the tube with the horizontal is $\theta$ and $U$ is the gas velocity.

For a particle aerodynamic diameter of $1 \mu \mathrm{m}$, the settling losses are $4.2 \%$, which means a transport efficiency of $95.7 \%$.

Increasing the flow rate and decreasing the length will result in lower settling losses. Further, if the tube is kept vertical, i.e., $\theta=90^{\circ}$, the transport efficiency will be $100 \%$.

\subsubsection{Inertial Impaction}

Inertial impaction occurs from the inability of the particles to follow the fluid streamlines due to their inertia. Particles may be preferentially excluded or included from the sampling stream or lost to the walls by inertial impaction. Inertial impaction losses are associated with higher flow rates and bends in the sampling tubes. In the thermal denuder, the straight tube configuration and the low sampling flow rates negate the losses due to inertial impaction. 


\subsubsection{Electrostatic Deposition}

Electrostatic deposition occurs due to particles carrying a charge or due to charges on the transport tubes. In the thermal denuder, the electrostatic losses are prevented by electrically grounding the tube.

\subsection{Design of the Denuder}

Theoretical calculations performed for the temperature profile, pressure drop and aerosol losses were used to arrive at the final design of the thermal denuder. The device was divided into two stages with a heated section located upstream of the cooled adsorber section. All components of the TD were made of 316L Stainless Steel tubing with seamless inner surface to avoid particulate matter build-up in both the stages. The aerosol pathway was made of $2.5 \mathrm{~cm}(1 \mathrm{inch})$ diameter (OD) stainless steel tubing with a length of $50 \mathrm{~cm}$ ( $20 \mathrm{inch})$ for both the stages. The detailed description is given below.

\subsubsection{Desorber Stage}

The schematic of the desorber section is showed in Figure 3.1. The adsorber stage was made of $2.5 \mathrm{~cm}$ (1 inch) diameter (OD), 50cm (20 inch) length, $316 \mathrm{~L}$ stainless steel tubing with an Omega series heavy insulated heating tape wrapped around it in a uniform fashion. 


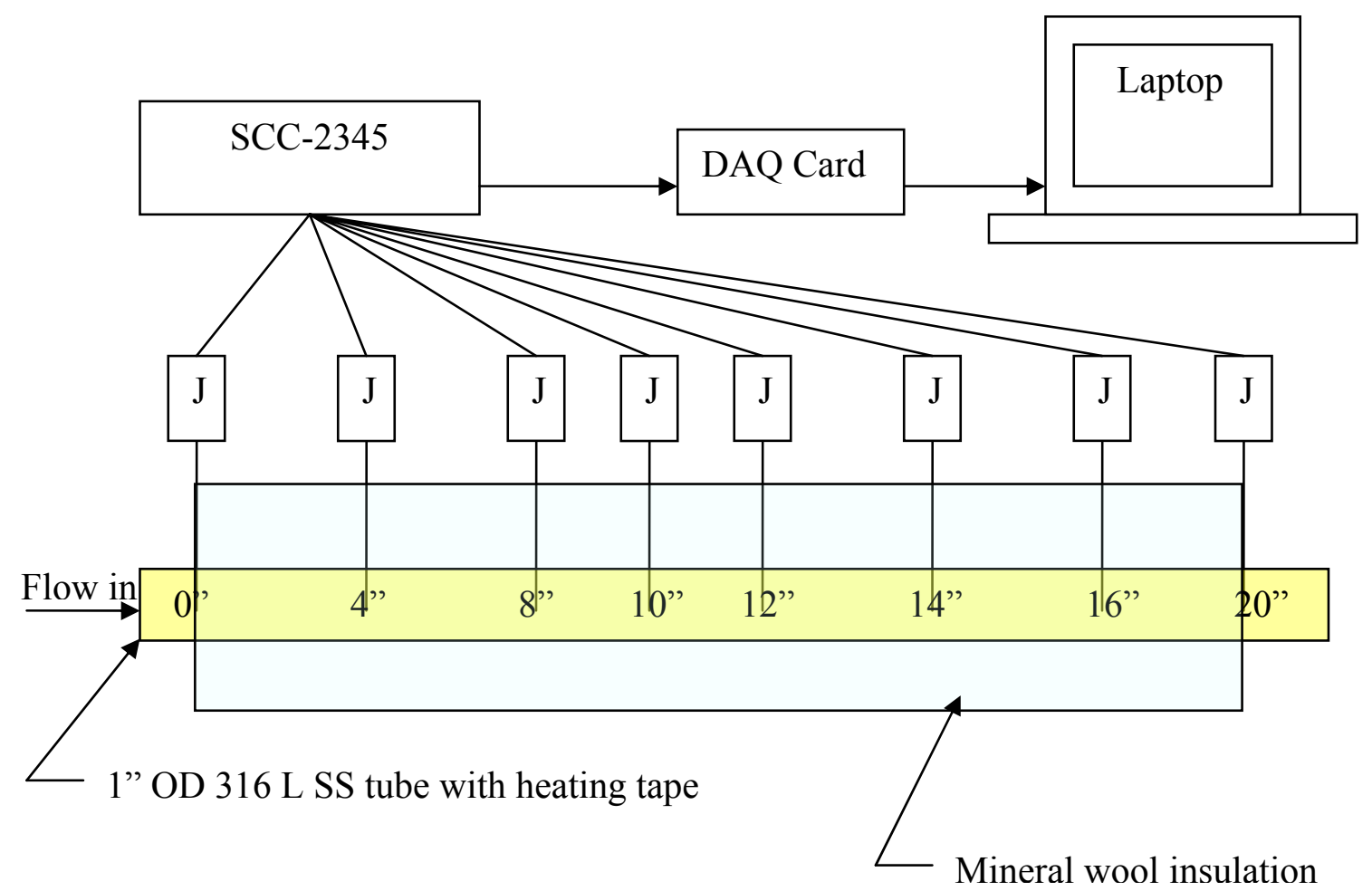

Figure 3.1: Schematic of Desorber Stage

The heating tape specifications are given in Table 3.2.

Table 3.2 Heating Tape Specifications

\begin{tabular}{|c|c|}
\hline Model No. & FGH051-080 \\
\hline Watts & 418 \\
\hline W/in & 8.6 \\
\hline Volts & 120 \\
\hline $\begin{array}{c}\text { Size } \\
\text { (Width X Length) }\end{array}$ & $1 / 2^{\prime \prime} \times 8^{\prime}$ \\
\hline
\end{tabular}


The Omega FGH series high temperature heating tape was rated to $482^{\circ} \mathrm{C}\left(900^{\circ}\right.$ F) continuous with a fast thermal response and is heavily insulated to withstand the high temperatures. The heating was controlled by a CNi3254-C24 1/32 DIN Micromega autotune PID temperature controller with input from a J-type thermocouple at the end of the heated section. It was decided to have real time temperature data during the measurement process to explain any deviations in the particle sizing data. For this purpose $7 \mathrm{~J}$-type thermocouples were fixed at $0,4,8,10,12,16$ and 20 inches along the length of the heated section, registering the core aerosol temperature. A thermocouple was also added at the end of the desorber section to measure the exit TD temperature of the sample stream. The desorber tube with heating tape and thermocouples are shown in Figure 3.2.

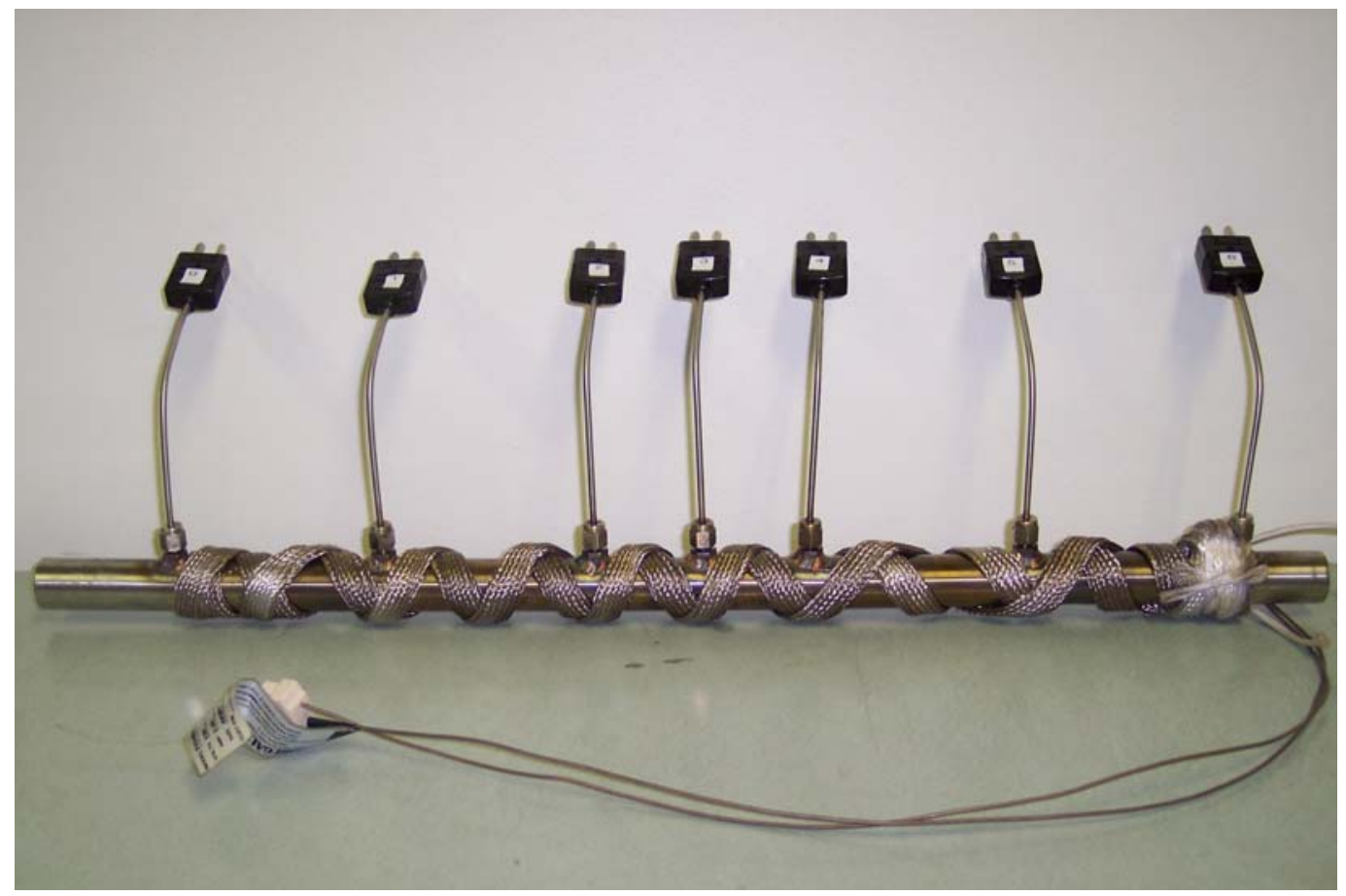

Figure 3.2: Desorber Stage showing heating tape and thermocouples 
A National Instruments SCC-2345 signal conditioning connector block with eight SCC TC02 signal conditioning modules were used to record the real time temperature data with a program written in Visual Basic which records data every 0.1 seconds. The data acquisition was enabled with a National Instruments PCMCIA Data Acquisition Card 6062E plugged into a laptop. This configuration was also helpful in saving time during the temperature profile study. Figure 3.3 shows the DAQ.

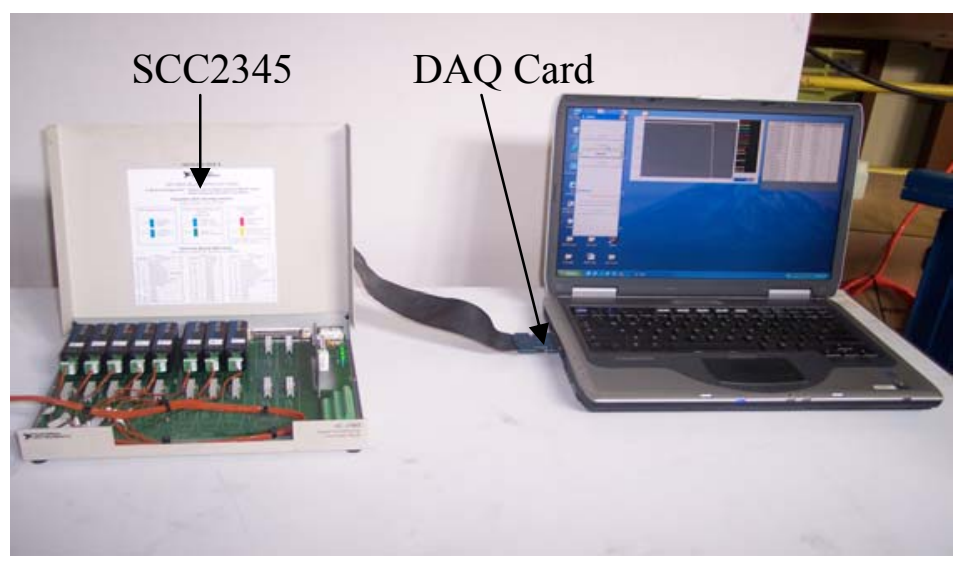

Figure 3.3: Data Acquisition System for temperature data

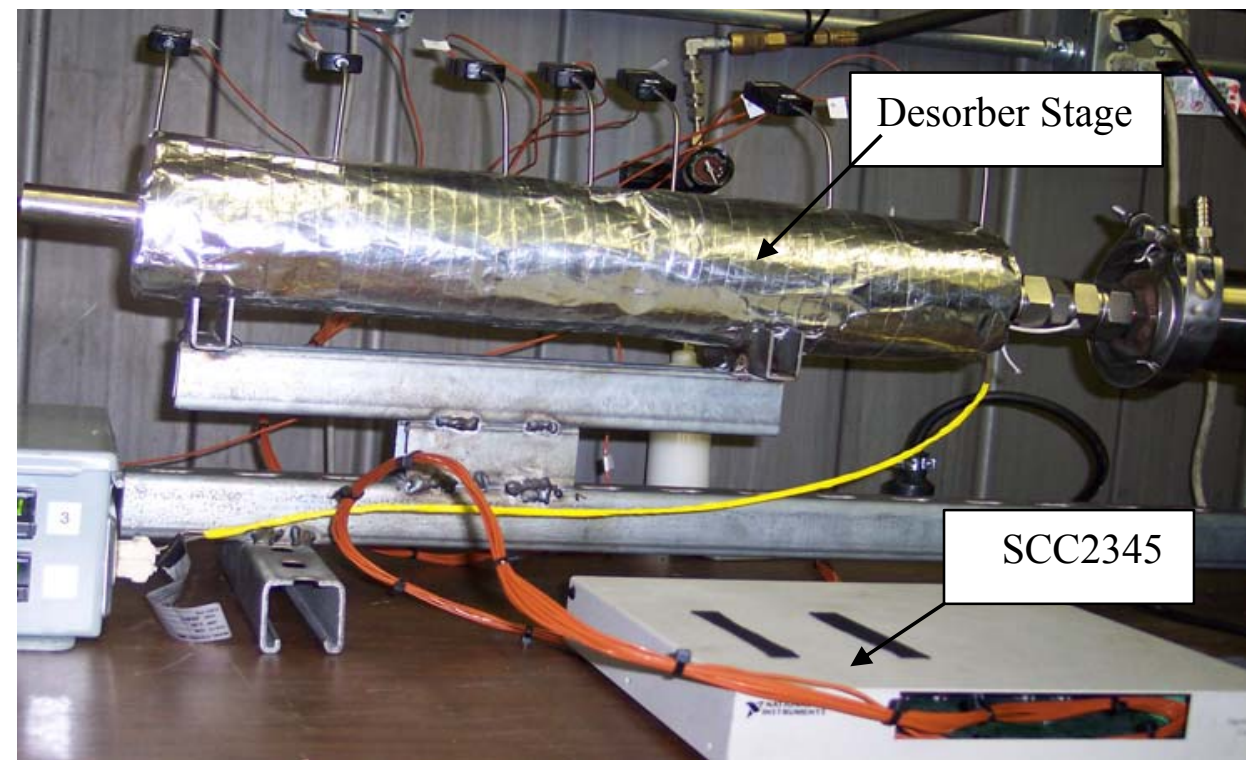

Figure 3.4: Insulated Desorber Stage with the SCC-2345 
The desorber stage was wrapped with mineral wool insulation to prevent heat loss from the heated section.

\subsubsection{Adsorber Stage}

A schematic of the adsorber section is shown in Figure 3.5.The adsorber section was made of three concentric tubes, with the outer two tubes welded together. The third tube $2.5 \mathrm{~cm}(1 \mathrm{inch})$ in diameter slides in and out easily. A removal plate at one end was used for charging and discharging the activated charcoal through a port. A Teflon O-ring with vacuum grease on the face plate and a band clamp ensure leak tight connections between the removable face plate and the desorber stage.

The aerosol pathway is $2.5 \mathrm{~cm}$ (1 inch) in diameter (OD) and $50 \mathrm{~cm}$ (20 inch) in length and has slots machined on it to accommodate a 316 L SS woven wire cloth sheet to enable adsorption of the volatile materials. The total adsorption area is $101.29 \mathrm{~cm}^{2}$

$\left(15.71 \mathrm{in}^{2}\right)$. The outer jacket circulates cooling air around the adsorption chamber to prevent re-adsorption of the volatiles on to the particles. The disassembled desorber stage is shown in Figures 3.6 and 3.7. 


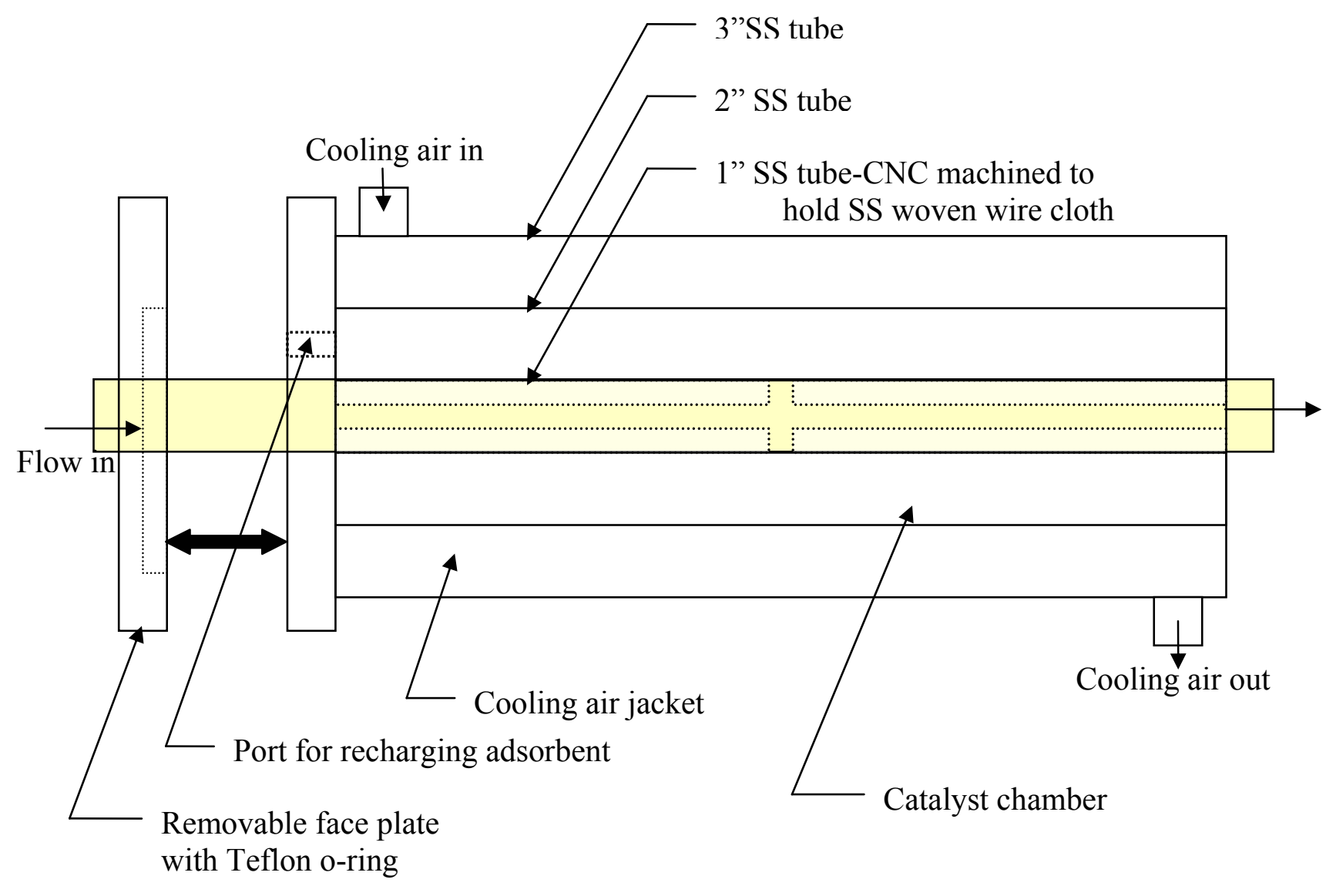

Figure 3.5: Schematic of Adsorber Section
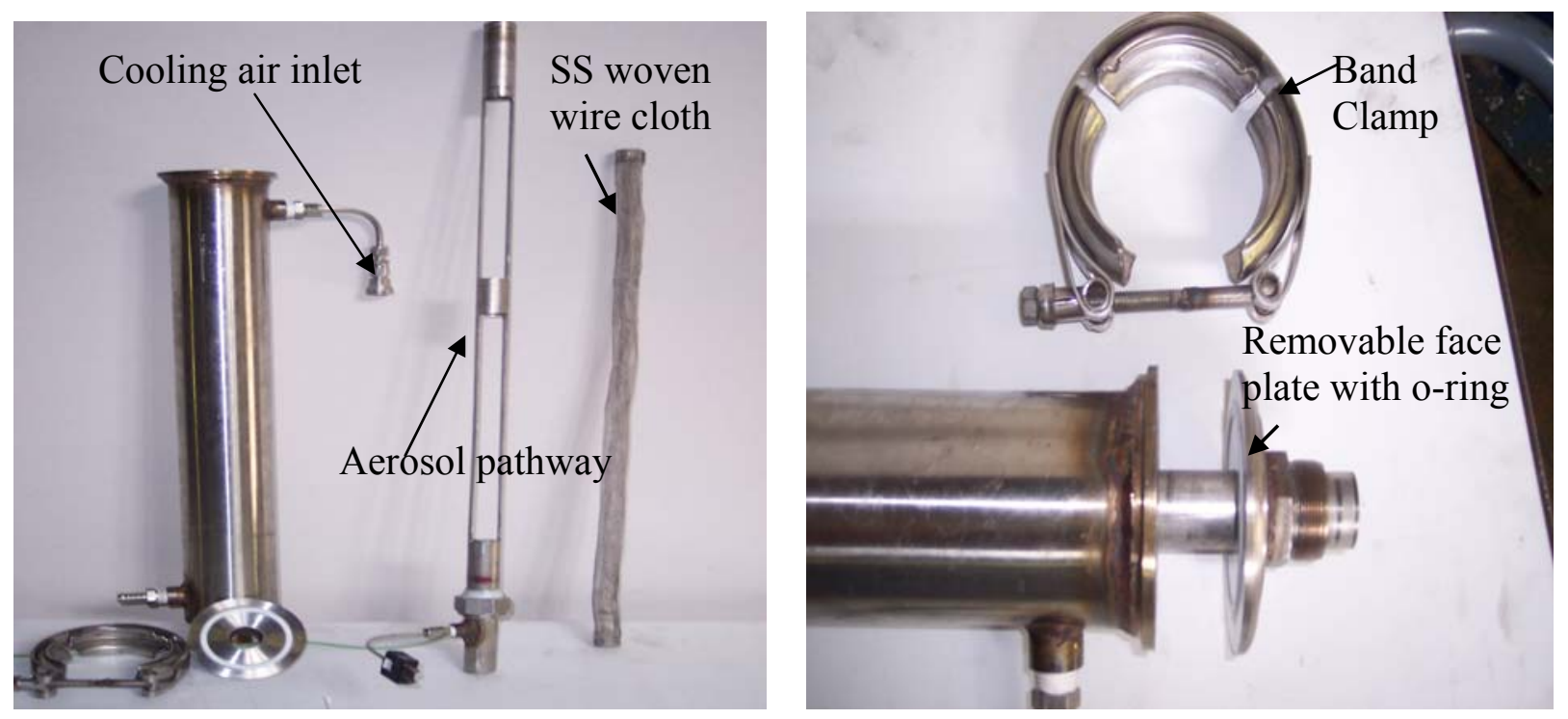

Figure 3.6 Disassembled Adsorber Stage- 1 
The different parts of the adsorber stage are shown in Figures 3.6 and 3.7. The aerosol pathway, woven wire cloth, removable face plate with Teflon o-ring, band clamp and the adsorber tube is shown. The final form after assembly is shown in Figure 3.8 and with the desorber stage.

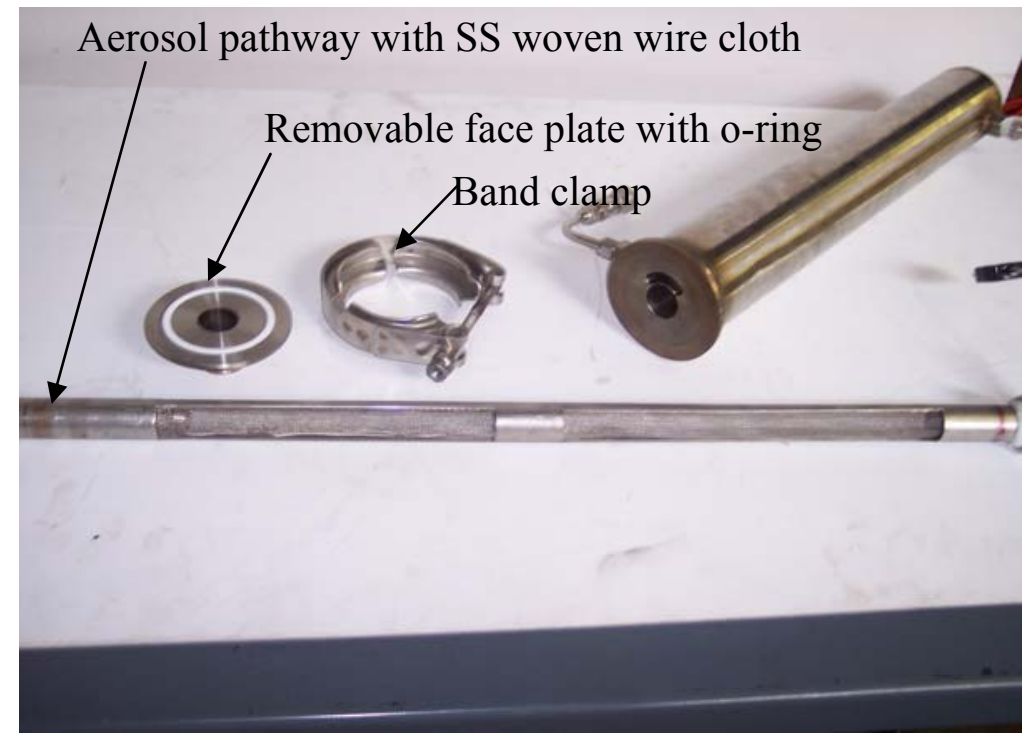

Figure 3.7 Disassembled Adsorber Stage- 2
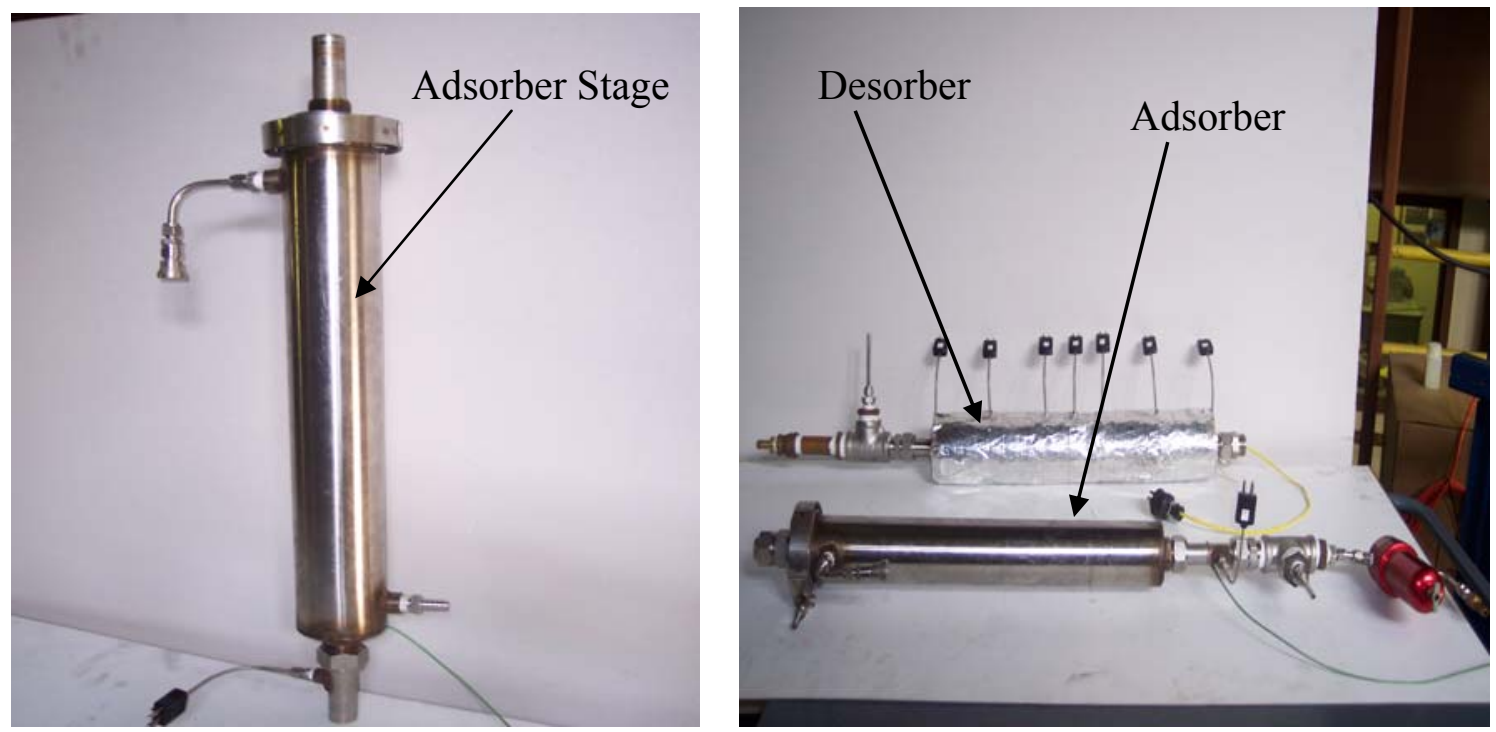

Figure 3.8 Assembled Adsorber Stage with the heated stage 
The key advantages of the thermal denuder design were:

1. Easy access to the components of the denuder.

2. Uniform temperature profile along the desorber tube.

3. Losses due to electrostatic deposition, gravitational settling and inertial impaction are negligible.

4. Real time temperature measurement across the denuder during the measurement process.

5. Robust in design. 


\section{EXPERIMENTAL SETUP AND PROCEDURE}

\subsection{Introduction}

The objective of the study was to design a thermal denuder optimized for operating characteristics and to study its influence on diesel exhaust particle size distributions. The thermal denuder was subjected to bench tests to determine the losses in the tube and the optimum flow rates and temperatures. The denuder was designed based on theoretical calculations and the flow rates and temperatures experimentally determined based on the bench tests. The influence of the denuder on diesel exhaust was evaluated over different engine operating conditions.

The entire thermal denuder study, from the fabrication stage to the testing phase was completed utilizing the resources available at the West Virginia University Engines and Emissions Research Center (WVU-EERC). The influence of the denuder on particle size distributions was studied using a 1992 DDC Series 60 diesel engine mounted on a DC dynamometer. The engine was exercised over steady state as well transient cycles. This chapter describes in detail the dilution system, particle sizing equipments, experimental setup and the test procedures employed for the project.

\subsection{Dilution System}

West Virginia University employs a mini dilution tunnel dedicated for particle sizing studies. The maximum dilution ratio achievable with the mini tunnel is of the order of 30. For this project an ejector diluter was used to achieve higher dilution ratios of up to 100, which would facilitate nanoparticle formation. The ejector diluter works on the 
principle of vacuum caused at the tip of an orifice through which the sample is flowing in $[30,31]$. Figure 4.1 shows the schematic of the diluter.

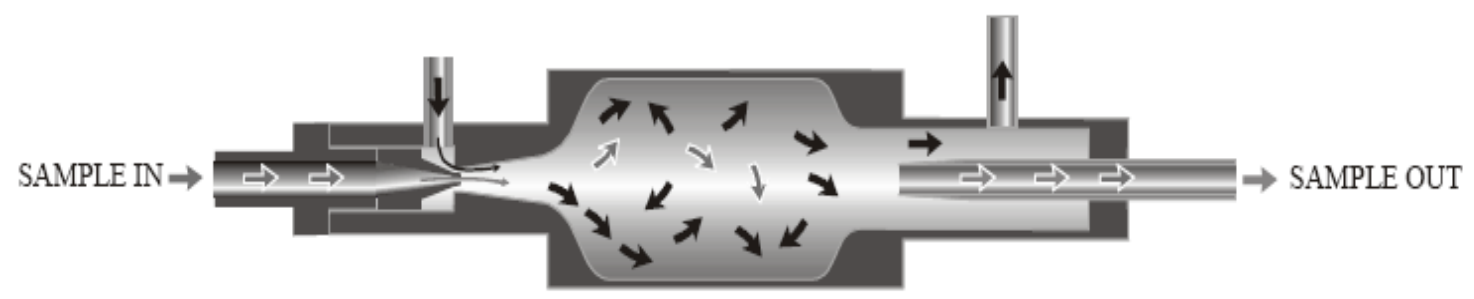

Figure 4.1: Schematic of Ejector Diluter [30]

The ejector diluter used for this study was a TD $110 \mathrm{H}$ vacuum pump from AirVac Engineering with a critical orifice at the inlet of the body. Pressure drop across the orifice causes sample flow into the diluter chamber where mixing occurs. Dry and regulated compressed air was used to achieve the desired dilution ratios.

The TD series vacuum pump is a single stage design with straight thru vacuum passages. Positive flow rate control was achieved by a critical orifice from BGI Incorporated at the inlet of the TD $110 \mathrm{H}$ vacuum pump. The critical orifi SO0 [32] which regulates the inlet sample flow to $2 \mathrm{lpm}$ was used with the vacuum pump to form the ejector diluter.

The dilution ratios were determined by taking the sample upstream and downstream of the ejector diluter with the engine running at a steady condition and tracking the concentration of a single particle using the Condensation Particle Counter. The dilution air pressures were varied to study the dilution ratios and the dilution ratios were calculated as

$$
\mathrm{DR}=\text { Upstream Average Concentration / Downstream Average Concentration }
$$


The dilution ratios with different dilution air pressures are summarized in Table

4.1

Table 4.1 Dilution Ratios at different pressures

\begin{tabular}{|c|c|c|c|}
\hline \multirow{2}{*}{$\begin{array}{c}\text { Dilution Air } \\
\text { Pressure }\end{array}$} & $\begin{array}{c}\text { Upstream } \\
\text { Average } \\
\text { Concentration }\end{array}$ & $\begin{array}{c}\text { Downstream } \\
\text { Average } \\
\text { Concentrations }\end{array}$ & $\begin{array}{c}\text { Dilution } \\
\text { Ratio }\end{array}$ \\
\hline $275.79 \mathrm{KPa}(40 \mathrm{psi})$ & & 1506 & 48 \\
\cline { 3 - 4 } $344.73 \mathrm{KPa}(50 \mathrm{psi})$ & \multirow{2}{*}{71912} & 1272 & 57 \\
\cline { 3 - 4 } $413.68 \mathrm{KPa}(60 \mathrm{psi})$ & & 1030 & 70 \\
\cline { 3 - 4 } $482.63 \mathrm{KPa}(70 \mathrm{psi})$ & & 768 & 94 \\
\cline { 3 - 4 } $551.58 \mathrm{KPa}(80 \mathrm{psi})$ & & 687 & 104 \\
\hline
\end{tabular}

The sample was drawn from the raw exhaust using a heated line, maintained at $191^{\circ} \mathrm{C}\left(375^{0} \mathrm{~F}\right)$ into the ejector diluter to prevent condensation of the heavier hydrocarbons. The dilution air pressures were regulated from $275.79 \mathrm{KPa}$ (40 psi) to $551.58 \mathrm{KPa}(80 \mathrm{psi})$ to achieve different dilution ratios. The diluted sample was drawn isokinetically into the denuder using a probe situated ten diameters downstream of the ejector to ensure proper mixing of the sample with the dilution air. Figure 4.2 shows the sampling system with the ejector diluter. 


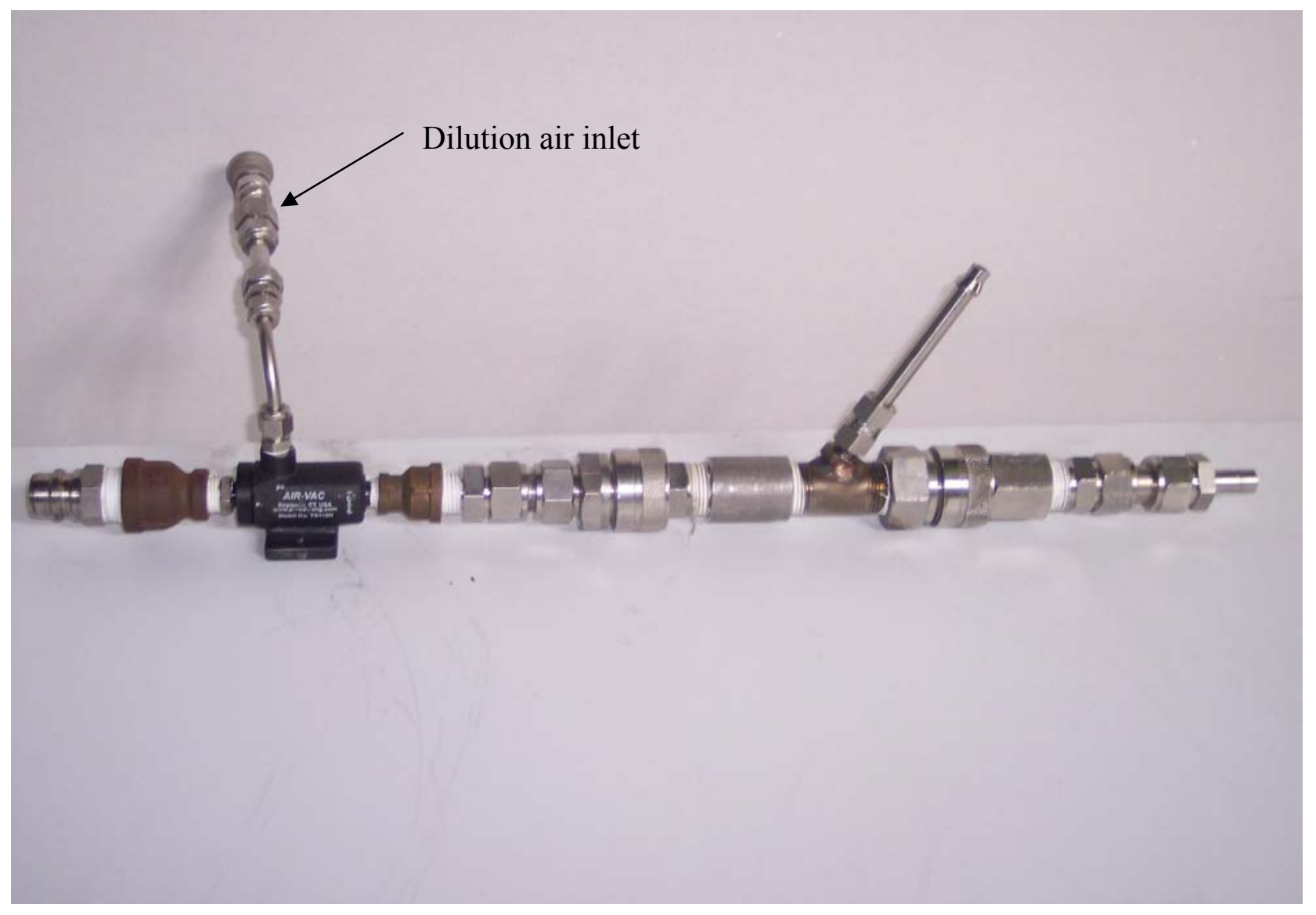

Figure 4.2: Ejector Diluter

\subsection{Particle Generation and Number Sizing}

Test Aerosols were generated by a TSI Model 3480 Electrospray Aerosol Generator and the size distributions were measured with a TSI Model 3936 Scanning Mobility Particle Sizer.

\subsubsection{Aerosol Generator}

The TSI Model 3480 Electrospray Aerosol Generator was used extensively in this project for experimental verification of the losses in the denuder as well as for the calibration of the SMPS. The aerosol generator produces high concentrations of 
monodisperse aerosols of diameters $15 \mathrm{~nm}, 30 \mathrm{~nm}$ and $70 \mathrm{~nm}$ from a specially prepared sucrose solution. [33, 34] Figure 4.3 shows the 3480 Electrospray Aerosol Generator.

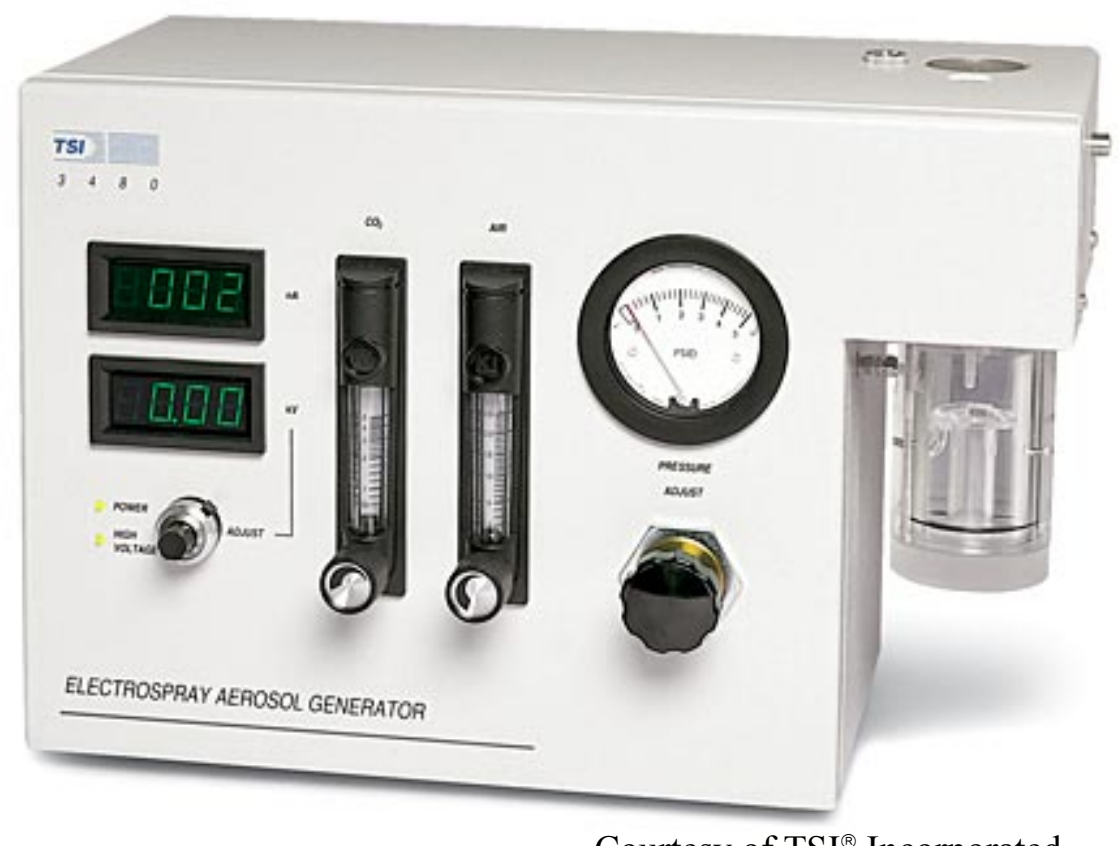

Courtesy of TSI ${ }^{\circledR}$ Incorporated

Figure 4.3: TSI Model 3480 Electrospray Aerosol Generator [34]

The sample sucrose solution is stored in a $1 \mathrm{ml}$ cone shaped vial and kept in the cylindrical pressure chamber. A platinum wire and a 25 micron capillary are kept immersed in the solution. A differential pressure of $25.5 \mathrm{KPa}$ (3.7 psi) is applied using the pressure regulator which causes the charged solution to be pulled through the capillary. The voltage is adjusted till a cone jet mode is observed through the viewing window which indicates particle generation. On exiting the capillary the solution forms droplets which are then mixed with a sheath flow of hepa filtered air and $\mathrm{CO}_{2}$ which causes evaporation leaving behind the charged droplets. The primary droplets are then 
transported to the electrospray chamber through an orifice plate where the charge is neutralized by a Polonium (Po-210) ionizer.

The equilibrium charge distribution generated by the ionizer is calculated based on a theoretical model developed by Wiedensohler (1986) which is an approximation of the Fuchs Diffusion Theory (1963) for particles in the submicrometer range. [34] A schematic of the Electrospray is shown in Figure 4.4. Appendix C gives the specifications of the aerosol generator.

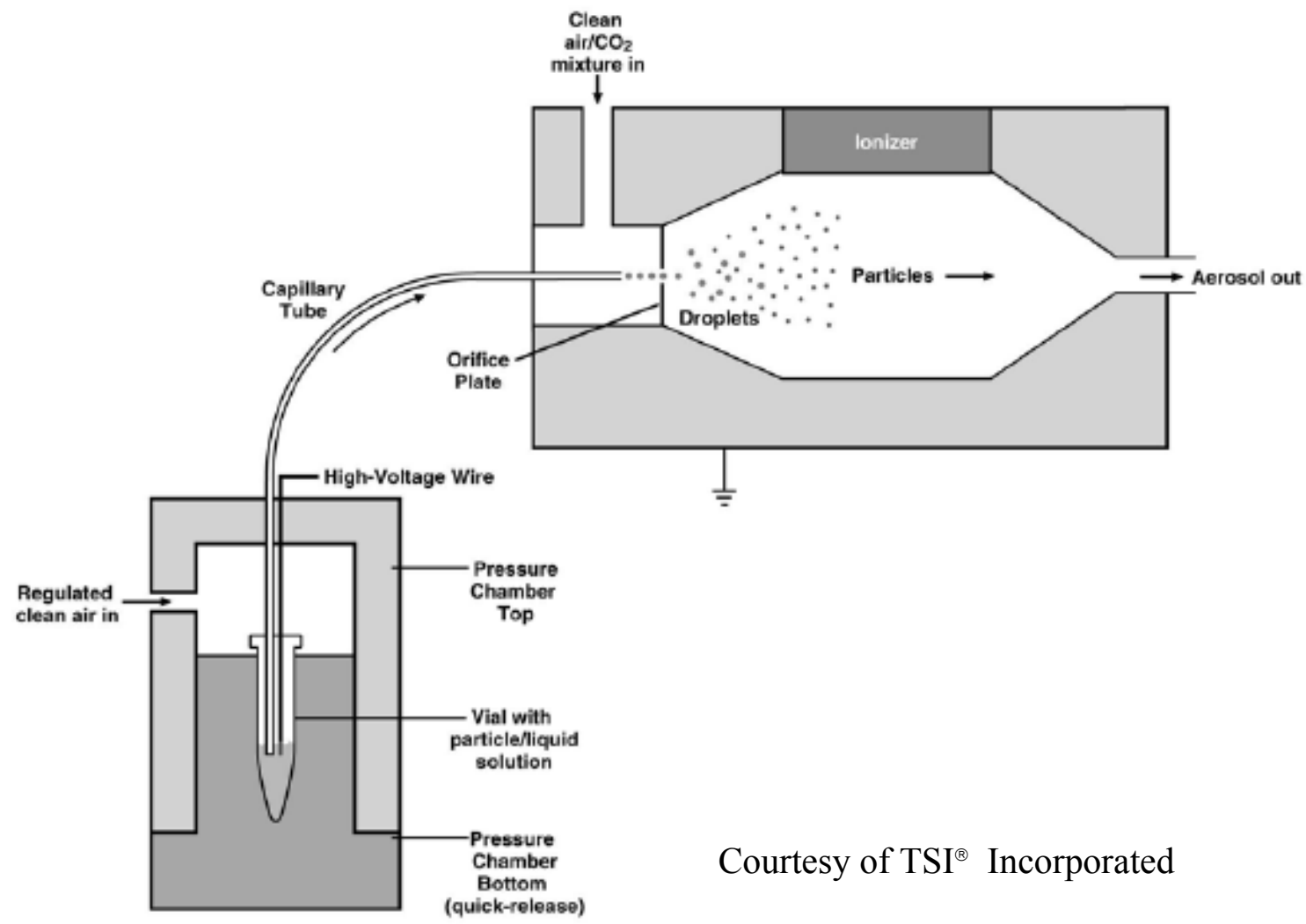

Figure 4.4: Schematic of TSI Model 3480 Electrospray Aerosol Generator [34] 


\subsubsection{Scanning Mobility Particle Sizer}

The TSI Series 3936 Scanning Mobility Particle Sizer ${ }^{\text {TM }}$ (SMPS ${ }^{\text {TM}}$ ) spectrometer was used to obtain the size distributions of the sample gas. The SMPS which uses a continuous fast scanning technique consists of two components, the Electrostatic Classifier and the Condensation Particle Counter. The classifier classifies the particles based on their electrical mobility and the CPC counts the particles [35, 36]. Figure 4.5 shows the SMPS system.
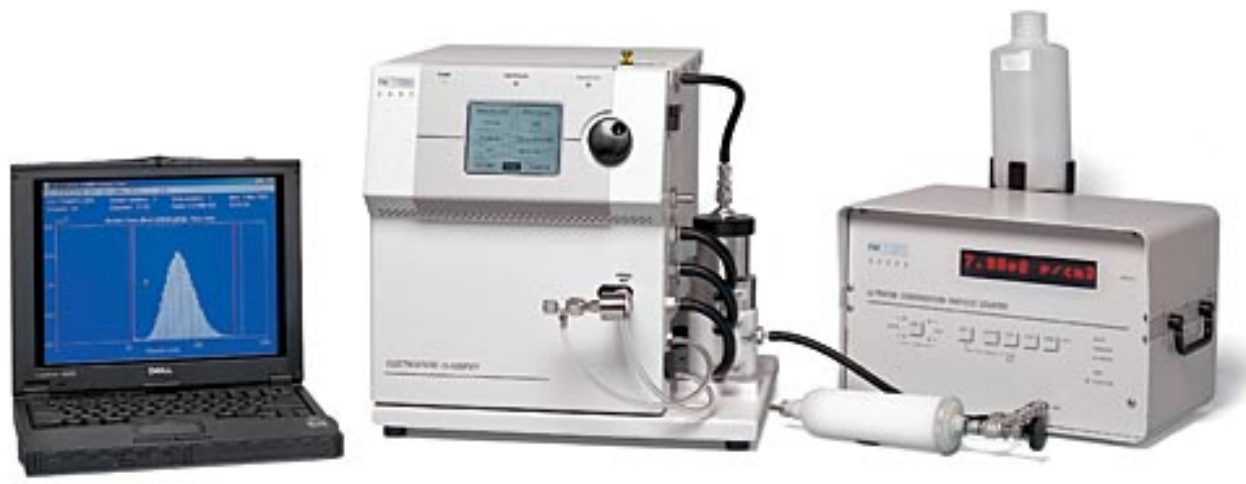

Courtesy of TSI ${ }^{\circledR}$ Incorporated

Figure 4.5: SMPS $3936^{\mathrm{TM}}$ [36]

The Model 3080 Electrostatic Classifier incorporates an impactor with a cut point diameter of 1 micrometer to remove the larger particles as they tend to have multiple charges and stripping these charges is difficult. The polydisperse aerosol which enters the instrument through the impactor then passes onto a bipolar charger containing a Krypton source $(\mathrm{Kr}-85)$ which exposes the sample stream to high concentrations of bipolar ions. The frequent collision between the ions and the particles causes an equilibrium state with a bipolar charge distribution. 
The polydisperse aerosol is then transported into the Differential Mobility Analyzer. The Long DMA, Nano DMA or the Radial DMA can be used with the classifier to generate a monodisperse aerosol stream. The TSI Model 3085 Nano DMA was used in this study for all experiments. Figure 4.6 shows the schematic of the classifier with the Nano DMA. The DMA consists of a central electric rod with a high negative voltage. The polydisperse aerosol flows between the outer cylinder and a sheath air. Charged particles are attracted towards the negatively charged central electrode through the sheath air curtain. Particles with higher electrical mobilities precipitate on the top portion of the rod and particles with low mobilities exit the DMA along with the bypass and excess air. Particle with a narrow range of electrical mobility exit the DMA as a monodisperse stream. During the up scan period, the voltage is increased exponentially and is decreased during the down scan. 


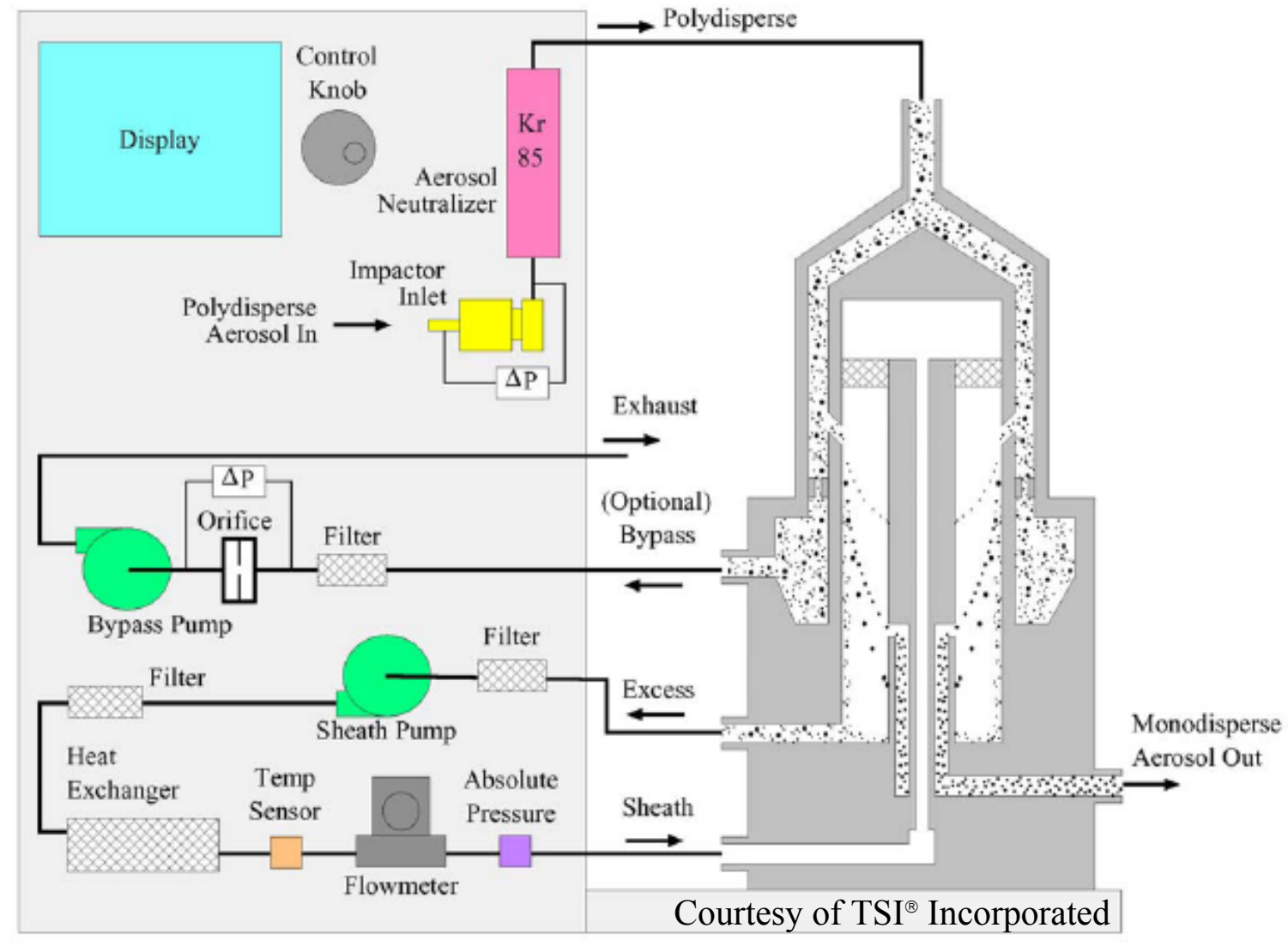

Figure 4.6: Schematic of Classifier with NDMA [36]

The monodisperse aerosol from the classifier then enters the CPC. A TSI Model 3025A Ultrafine Condensation Particle Counter was used for this project. The UCPC counts the number of particles in the aerosol stream and determines the number concentration in the sample. Supersaturated butanol vapors are condensed onto the particles to allow them to grow to detectable sizes. These particles are then counted by an optical detector [38]. The schematic of the UCPC is shown in Figure 4.7. 


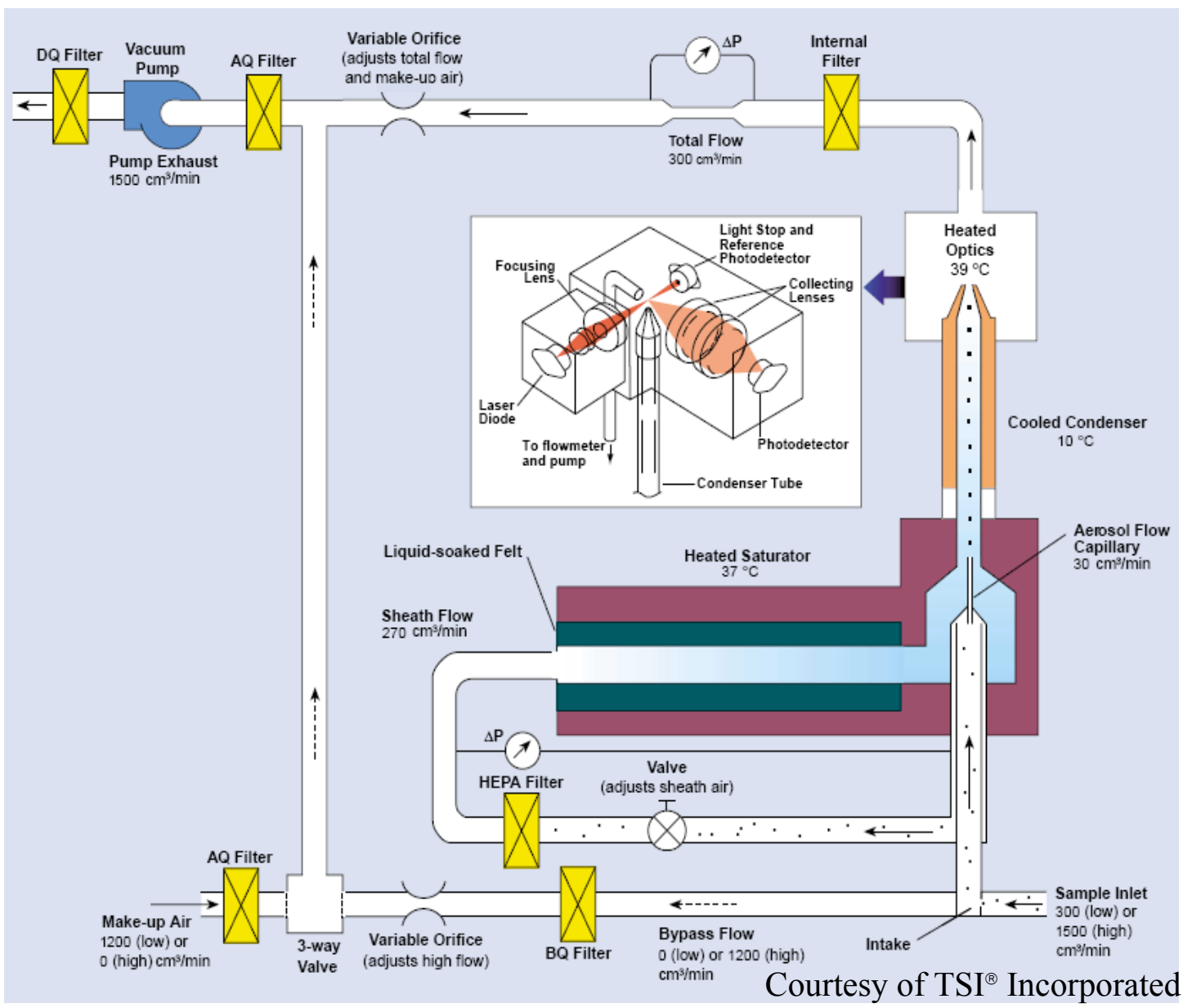

Figure 4.7: Schematic of 3025A UCPC [39]

The CPC and the EC together is used to generate particle size distributions. An analog BNC cable interfaces the instruments and the Aerosol Instrument Manager Software provided by the manufacturer is used to record data.

The SMPS is designed for data recording during steady state operations where the exhaust particle concentrations remain constant. For transient testing, the classifier is operated in the manual mode where a pre-selected particle size of interest is tracked over the entire transient operation.

Flow calibration of the SMPS system is necessary to ensure accuracy in the data. The flow calibrated system is further validated using test aerosols generated by the 
electrospray generator. Leak tests were performed on a daily basis by connecting a HEPA filter at the inlet and performing a full scan. Leak check can also be performed by setting the DMA voltage to zero. Ideally, at the zero voltage condition, no particles should exit the system. If any particles were detected above the noise level of the instrument, the manufacturer recommended procedures were used for troubleshooting. The SMPS specifications are given in Appendix B.

\subsubsection{SMPS and CPC Data Reduction}

The particle size distribution generated by the SMPS is based on raw counts transmitted from the CPC which assumes a single charge on a particle. In reality, this is not the case; particles do carry multiple charges and this result in discrepancies in the binning of the particles. The SMPS AIM software uses in-built algorithms based on the Fuchs-Gunn aerosol charging and a truncated triangular function [37] to correct the data for multiple charges.

For transient testing, particles of interest are tracked over time with the $\mathrm{CPC}$ and the classifier operating in a single particle mode at a corresponding DMA voltage. The AIM CPC software from TSI is used for recording the concentration variation of particles against time, but the software does not include any algorithms for data reduction. Single particle charge correction based on the transfer function, efficiencies of the CPC and the impactor and the dilution ratio have to be applied to the raw CPC data.

Two programs developed in MathCAD, were used for reduction of the CPC data and for dilution ratio correction of the SMPS data. The final SMPS data from steady state tests are presented as a lognormal distribution of the normalized concentrations of 
particles $/ \mathrm{cm}^{3}(\mathrm{dN} / \mathrm{d} \operatorname{logDp})$ against the particle diameter, and the transient testing data as the time based concentration variation for the particle diameters of interest. A sample CPC and SMPS reduction program is given in Appendix A.

\subsection{Test Procedure}

This section presents the test procedures adopted for the verification of the thermal denuder, and the test cycles over which the DDC Series60 diesel engine was exercised to study the influence of the TD on the particle size distributions.

\subsubsection{Validation Tests}

Validation tests were performed on the denuder to determine the optimal operating conditions and to quantify the losses associated with the denuder.

\subsubsection{Leak Test}

Leak test of the TD is essential to guarantee that no further dilution takes place within the two stages of the TD and that no particle losses occur. The leak test was performed under pressurized conditions and vacuum conditions to determine the loss of pressure against time. In the first test the denuder was pressurized to $40 \mathrm{KPa}$ (5.8 psi) and $50 \mathrm{KPa}$ (7.25 psi) and sealed off using needle valves at the inlet and outlet of the TD. In the second test, the denuder was subjected to vacuum conditions of $-40 \mathrm{KPa}(-5.8 \mathrm{psi})$ and $-50 \mathrm{KPa}(7.25 \mathrm{psi})$ using a vacuum pump and the loss of pressure with time was recorded. The results are discussed in detail in the next chapter 


\subsubsection{Temperature Profile Study}

A temperature profile study was required to determine the temperature profile across the heated section of the denuder at different flow rates and different set temperatures. The study is made at set temperatures of $125^{\circ} \mathrm{C}, 175^{\circ} \mathrm{C}, 200^{\circ} \mathrm{C}, 275^{\circ} \mathrm{C}$ and $300^{\circ} \mathrm{C}$ and flow rates of 1.0, 3.0 and $5.0 \mathrm{lpm}$ for each set temperature. The purpose of the study was to determine a temperature gradient across the tube cross section at a given wall temperature and a given sample flow rate in order to prevent unexpected sample transformations due to uncontrolled condensation and nucleation. The core aerosol temperature was registered by 7 J-type thermocouples fixed at regular intervals along the length of the heated section, and the corresponding time signatures by the data acquisition system. The temperature was controlled by a CNi3254-C24 1/32 DIN Micromega Autotune PID temperature controller at the end of the heated section. The flow rate maintained by the vacuum pressure pump was set using the Gilibrator bubble flow meter and checked at the end of each experiment. The results are discussed in the next chapter.

\subsubsection{Verification using Laboratory Aerosols}

Experimental verification of the TD requires tests using laboratory aerosols to determine the particle losses and penetration efficiencies associated with the volatilization tube.

\subsection{Diffusion Losses (DL)}

Diffusion losses have been established as the principal loss mechanism for ultrafine particles in transport tubes and are more pronounced when the flow is turbulent. The operational flow rate based on temperature profile studies for the current design was 
$5 \mathrm{lpm}$ which would yield a tube Reynolds number of 136, which is well within the laminar flow regime.

Preliminary experiments were conducted using laboratory test aerosols generated by the Model 3480 Electrospray Aerosol Generator to determine losses due to diffusion and thermophoresis. Test aerosols were generated using sucrose solution of various concentrations to yield particles of diameters $15 \mathrm{~nm}, 30 \mathrm{~nm}$ and $70 \mathrm{~nm}$.

The study was conducted with the denuder vertically oriented and operated under ambient temperature conditions which inhibits the inertial losses and thermophoretic losses. The flow rates were set to 1, 3 and $5 \mathrm{lpm}$ and the diffusion losses were studied at each flow rate for $15 \mathrm{~nm}, 30 \mathrm{~nm}$ and $70 \mathrm{~nm}$ sucrose particles. The flow rates were periodically checked to ensure that they were within $2 \%$ of the set values. The distributions upstream and downstream of the denuder were recorded with the SMPS and the diffusion losses calculated as

$$
\operatorname{DL}(\%)=\left(\frac{\mathrm{DU}-\mathrm{DD}}{\mathrm{DU}}\right) * 100
$$

where, DL is the Diffusion Loss,

DU is the Upstream Distribution and

DD is the Downstream Distribution.

The results are presented in the next chapter and discussed in detail.

\subsection{Thermophoretic Losses (TL)}

Thermophoretic losses are more important in the adsorber section because the wall temperature would be lower than the incoming gas temperature which would cause a particle drift towards the walls. An attempt was made to quantify the thermophoretic 
losses in the denuder at set temperatures of $100^{\circ} \mathrm{C}, 200^{\circ} \mathrm{C}$ and $300^{\circ} \mathrm{C}$ using $\mathrm{NaCl}$ test aerosols. The denuder was vertically oriented to prevent losses due to inertial impaction and the adsorber section empty without the activated charcoal. Flow rates were set to 1,3 and $5 \mathrm{lpm}$ for each of the three temperature conditions. Results could not be obtained due to clogging of the capillary due to coagulation of the solution.

The experiment was repeated with the DDC Series 60 engine as a particle generator. A heated line was used to transport the exhaust to the ejector diluter. There was no repeatability in the data collected for back to back tests; hence the results are not discussed.

\subsection{Inertial Losses (IL)}

Inertial losses occur because particles are unable to follow the streamlines due to their inertia. Since the flow rates selected are low $(\leq 5 \mathrm{Lpm})$ and the denuder operation is vertical these losses can be safely neglected.

\subsubsection{Electrostatic Losses}

Electrostatic losses are eliminated by electrically grounding the denuder. 


\subsubsection{Engine Testing}

Real-time measurements of the total, volatile and non volatile concentrations in the diesel exhaust using a thermal denuder was studied on a 1992 DDC Series 60 diesel engine run under steady state and transient conditions. The engine test conditions were consistent with the Code of Federal Regulations. The fuel used was low sulfur D2 fuel during the steady state testing and a reference fuel (MT000) from Flint Hill Resources with an API gravity of 30.6, for the transient testing. Raw exhaust sampling methodology was adopted with a probe in the exhaust transfer tube collecting the sample isokinetically. Isokinetic sampling ensures a representative sample is drawn from the exhaust gases. The raw exhaust was transferred using a heated line maintained at $191^{\circ} \mathrm{C}\left(375^{\circ} \mathrm{F}\right)$ to the ejector diluter. The heated line was maintained at the set temperature using a CNi3254C24 1/32 DIN Micromega autotune PID temperature controller in order to prevent condensation of the heavier hydrocarbons.

Baseline stabilization of the SMPS and UCPC was done on a daily basis before the start of each testing. Short lengths of tygon tubing were used for particle transfer from the sampling probes to the SMPS and at the end of each test day, particle free air was drawn through the denuder at the operational conditions and the size distribution measured to determine if the denuder itself was producing any particles. 


\subsubsection{Steady State Testing}

The TD operation was studied using six engine operating conditions at which the exhaust aerosol chemistry were respectively highly carbonaceous, highly volatile and having mixed characteristics. Engine maps were done prior to testing on each day to decide the operating set points. The steady state set points are shown in Table 4.2.

Table 4.2 Steady State Set Points for 92 DDC S60

\begin{tabular}{|c|c|c|}
\hline Mode & $\begin{array}{c}\text { Speed in } \\
\text { Rpm }\end{array}$ & $\begin{array}{c}\text { Torque in N-m } \\
\text { (ft-lb) }\end{array}$ \\
\hline R100 & 1810 & $1386(1022)$ \\
\hline R50 & 1810 & $759(560)$ \\
\hline R25 & 1810 & $380(280)$ \\
\hline I100 & 1210 & $1782(1314)$ \\
\hline I50 & 1220 & $956(705)$ \\
\hline I25 & 1220 & $475(350)$ \\
\hline
\end{tabular}

The engine was warmed up for at least 20 minutes till the engine oil temperature reached $191^{\circ} \mathrm{C}\left(375^{\circ} \mathrm{F}\right)$ before collecting data. The denuder was maintained at $200^{\circ} \mathrm{C}$, $300^{\circ} \mathrm{C}$ and $400^{\circ} \mathrm{C}$ and the upstream and downstream data was collected with the SMPS. Data was also recorded for two different ejector diluter settings of $413.68 \mathrm{KPa}$ (60 psi) and $551.58 \mathrm{KPa}(80 \mathrm{psi})$ for each denuder temperature for the different modes of engine operation. The Gilian Gilibrator was used to verify the set flows between tests. The heated line was maintained at $191^{\circ} \mathrm{C}\left(375^{\circ} \mathrm{F}\right)$ and the sample was pulled through the denuder at a flow rate of $5 \mathrm{lpm}$. The SMPS was operated in the low flow mode with an 
upscan time of 120 seconds and a downscan time of 30 seconds. At least two samples each were collected upstream and downstream of the denuder.

\subsubsection{Transient Testing}

Transient data were collected to study the influence of the thermal denuder. The upstream and downstream denuder data was collected at two different temperature settings of $300^{\circ} \mathrm{C}$ and $400^{\circ} \mathrm{C}$. The DDC S60 engine was exercised through the HeavyDuty Federal Test Procedure transient cycle and data was collected at a constant dilution air pressure setting of $413.68 \mathrm{KPa}$ (60 psi), for the ejector diluter, which would correspond to a dilution ration of 70 .

The FTP Cycle consists of four segments- New York Non Freeway (NYNF), Los Angeles Non Freeway (LANF), Los Angeles Freeway (LAFY) and the fourth, a repeat of the NYNF segment [31].

The cycle consists of motoring segments and the average speed is about $30 \mathrm{~km} / \mathrm{h}$ (18.6 mph) with a distance of $10.3 \mathrm{~km}$ (6.4 miles) traveled in 1200 seconds. The FTP Cycle is shown in Figure 4.8 


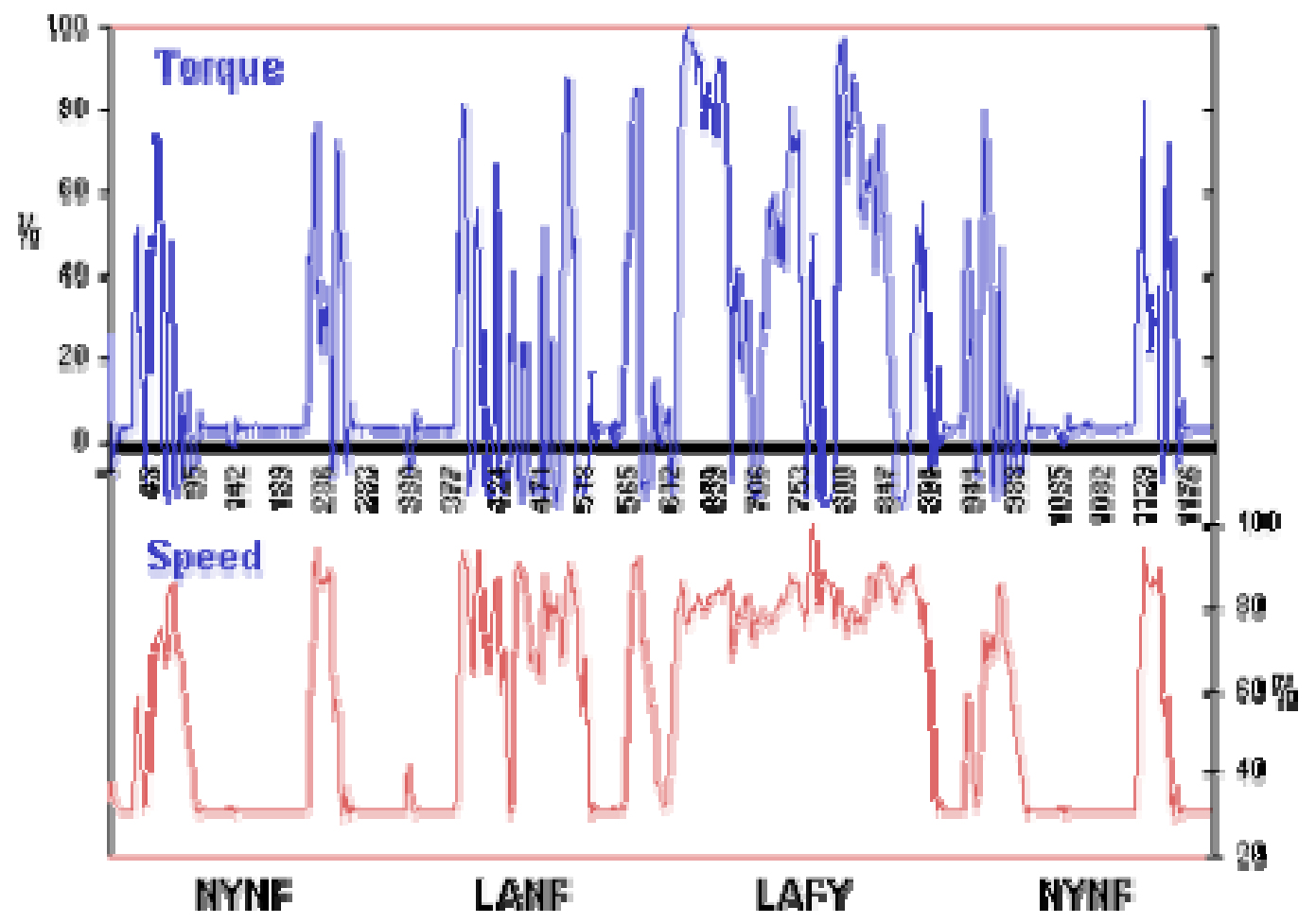

Figure 4.8 US FTP Cycle [31]

Concentration variations of $70 \mathrm{~nm}, 30 \mathrm{~nm}$ and $15 \mathrm{~nm}$ particles were recorded with the CPC when the engine was operated through the FTP Cycle. The CPC data are presented as a time-based concentration variation and is presented in the next chapter. 


\subsubsection{Crankcase Emissions}

The crankcase emissions were also studied using the TD in accordance to the 2007 PM regulations, which stipulate that the crankcase emissions should be treated the same as other exhaust emissions. The crankcase gases were vented through a downward directed draft tube for the DDC S60 engine. The oil used was Shell Rotella 15W-40.

Size distributions were first obtained for the crankcase gases under steady engine operating conditions. Based on the distribution graphs, the SMPS was operated in the manual mode tracking the particle concentration variation over the FTP cycle.

The sample was transferred from the crankcase vent on the engine side with a heated line maintained at $191^{0} \mathrm{C}\left(375^{\circ} \mathrm{F}\right)$ to the ejector diluter. The dilution air pressure was maintained at $413.68 \mathrm{KPa}(60 \mathrm{psi})$ and the denuder at $300^{\circ} \mathrm{C}$. The unconditioned and conditioned crankcase emissions data were collected with atleast two samples each. 


\section{RESULTS AND DISCUSSIONS}

\subsection{Introduction}

This chapter discusses the results of tests performed with the thermal denuder. The results of the validation tests to determine the operating characteristics are described and the influence of the thermal denuder on exhaust particle size distributions are discussed in detail.

All SMPS data are presented as normalized concentrations of particles $/ \mathrm{cm}^{3}$ against the particle diameter and the CPC data as a time varying concentration distribution of particles of interest for the entire cycle of operation. Size distributions were studied on a 1992 DDC S60 engine exercised over steady state and transient operation, with the data collected upstream and downstream of the TD for characterizing the volatile and non-volatile fractions. The sample was diluted with an ejector diluter with the dilution air pressures maintained at 60 psi and 80 psi, which resulted in dilution ratios of 70 and 104 respectively.

\subsection{Leak Test}

A leak test of the TD was performed to ensure that no further dilution takes place inside the TD and affect the size distributions. The whole system was pressurized with compressed air, and also put under vacuum to study the loss of pressure. The loss of pressure read by a gauge was recorded at regular intervals and plotted. Figures 5.1 and 5.2 present the results of the leak test. 


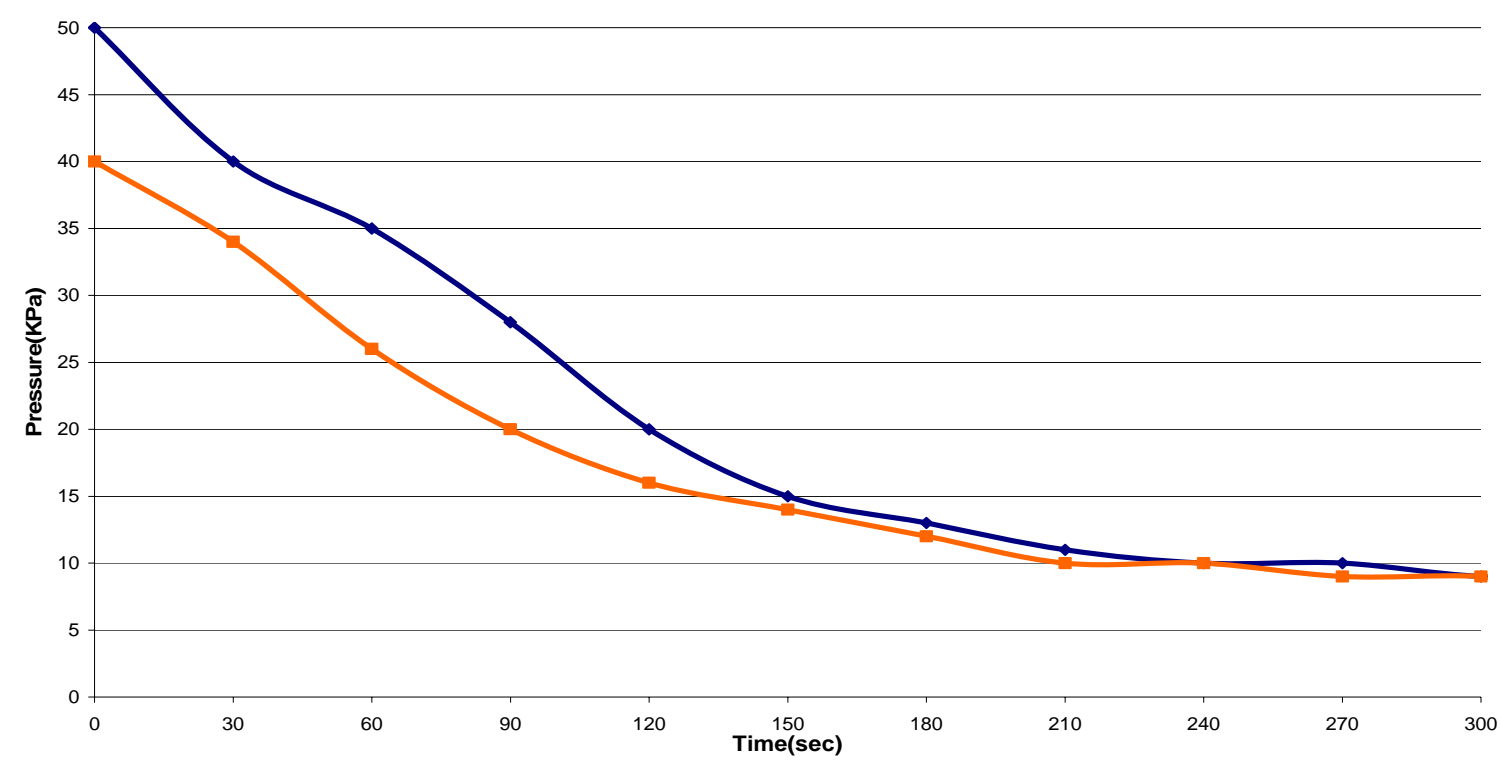

Figure 5.1: TD under Pressure

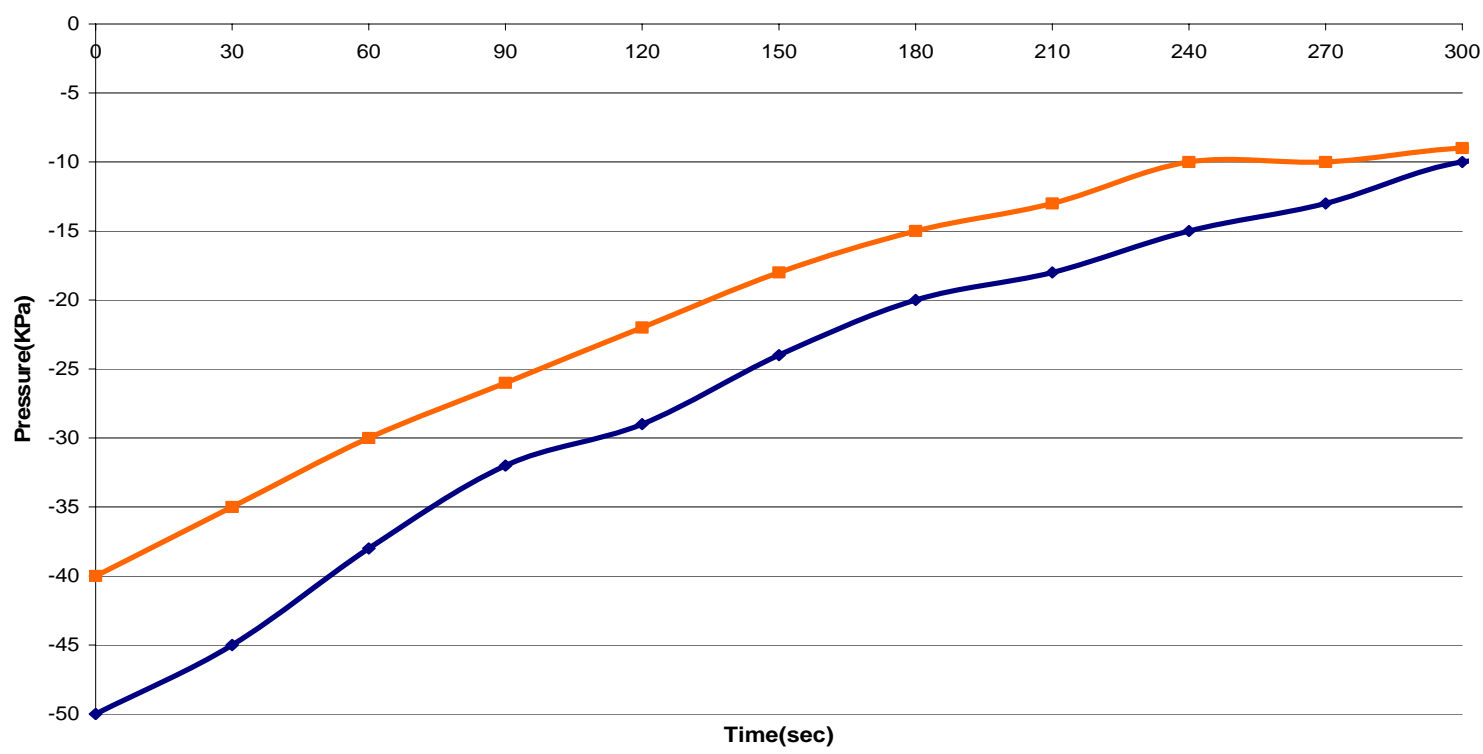

Figure 5.2: TD under Vacuum

The denuder was unable to hold the high pressures and within 300 seconds came down to $10 \mathrm{KPa}(1.45 \mathrm{psi})$ under pressure or $-10 \mathrm{KPa}(-1.45 \mathrm{psi})$ under vacuum, and stabilized. The leak was detected in the weld between the end plate and the second concentric tube which separates the cooling air jacket and the activated charcoal chamber 
in the adsorber stage. It was not possible to rectify the leak without cutting in half the adsorber. At the operating flow rate of $5 \mathrm{lpm}$, the pressure drop across the length of the denuder would be less than $3 \times 10^{-4} \mathrm{KPa}$ and since the pressure in the TD during the tests remained stable at $10 \mathrm{KPa}(1.45 \mathrm{psi})$, nothing further was done.

\subsection{Temperature Profile Study}

The temperature profile study was conducted to determine the flow rates at which the profile in the desorber would yield a positive gradient without any irregularities. The data acquisition system recorded the temperature data from the $7 \mathrm{~J}$-type thermocouples along the length of the desorber section. Data was collected for temperatures of $125^{\circ} \mathrm{C}$, $175^{\circ} \mathrm{C}, 200^{\circ} \mathrm{C}, 275^{\circ} \mathrm{C}$ and $300^{\circ} \mathrm{C}$ for flow rates of 1,3 and $51 \mathrm{pm}$. (Figures 5.3, 5.4 and

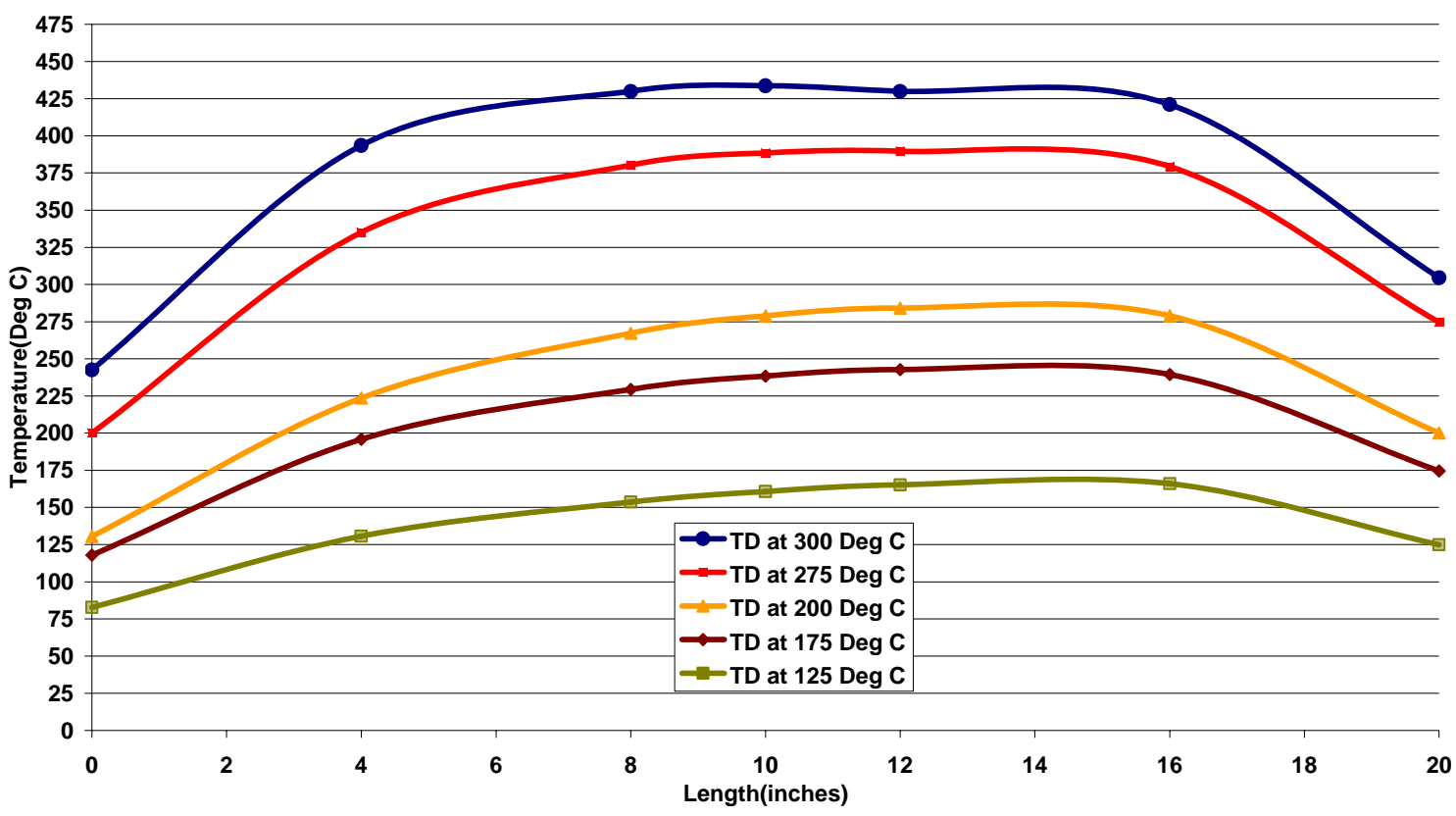

Figure 5.3: Temperature profile at $1 \mathrm{lpm}$ 


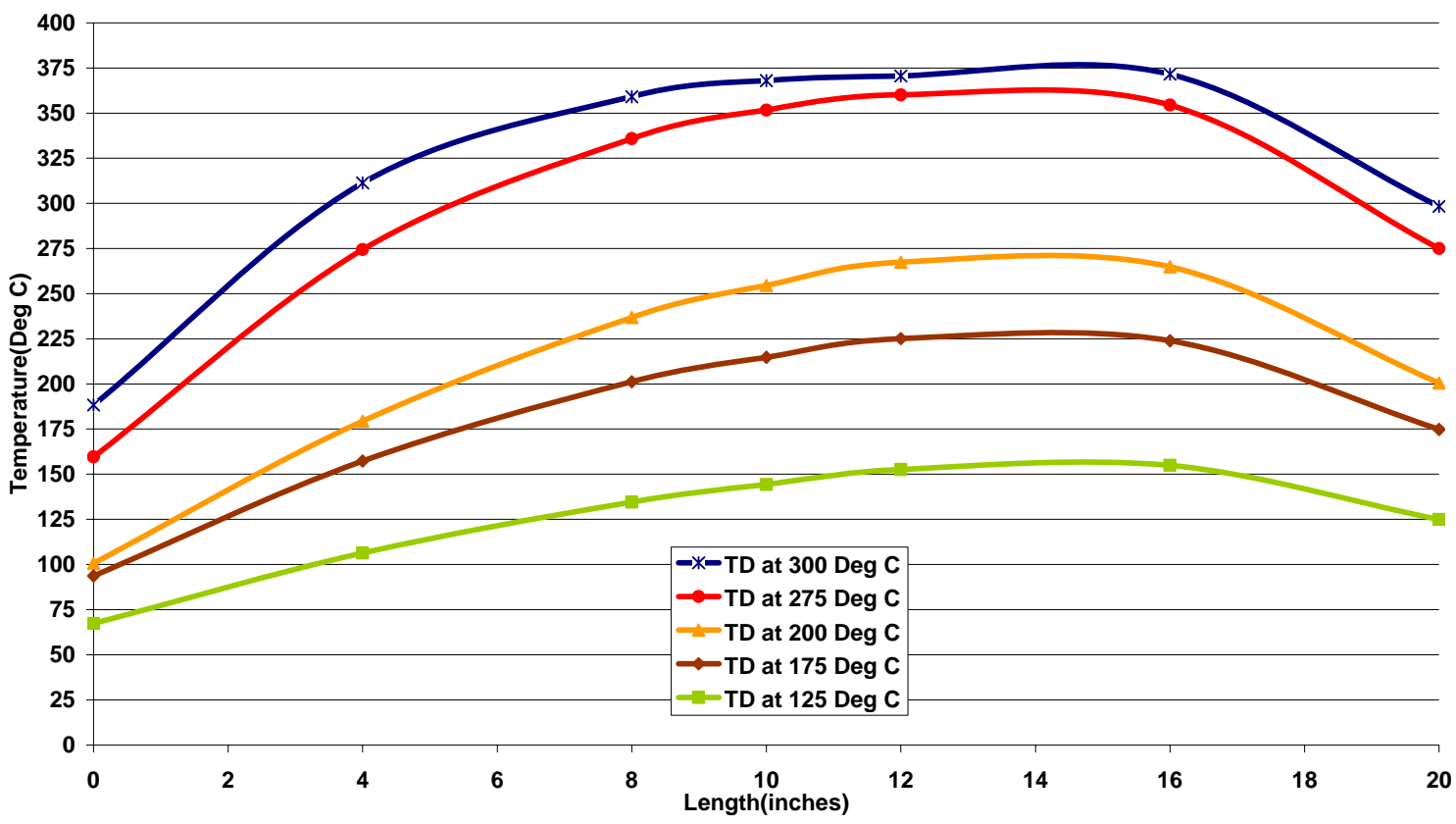

Figure 5.4: Temperature profile at $3 \mathrm{lpm}$

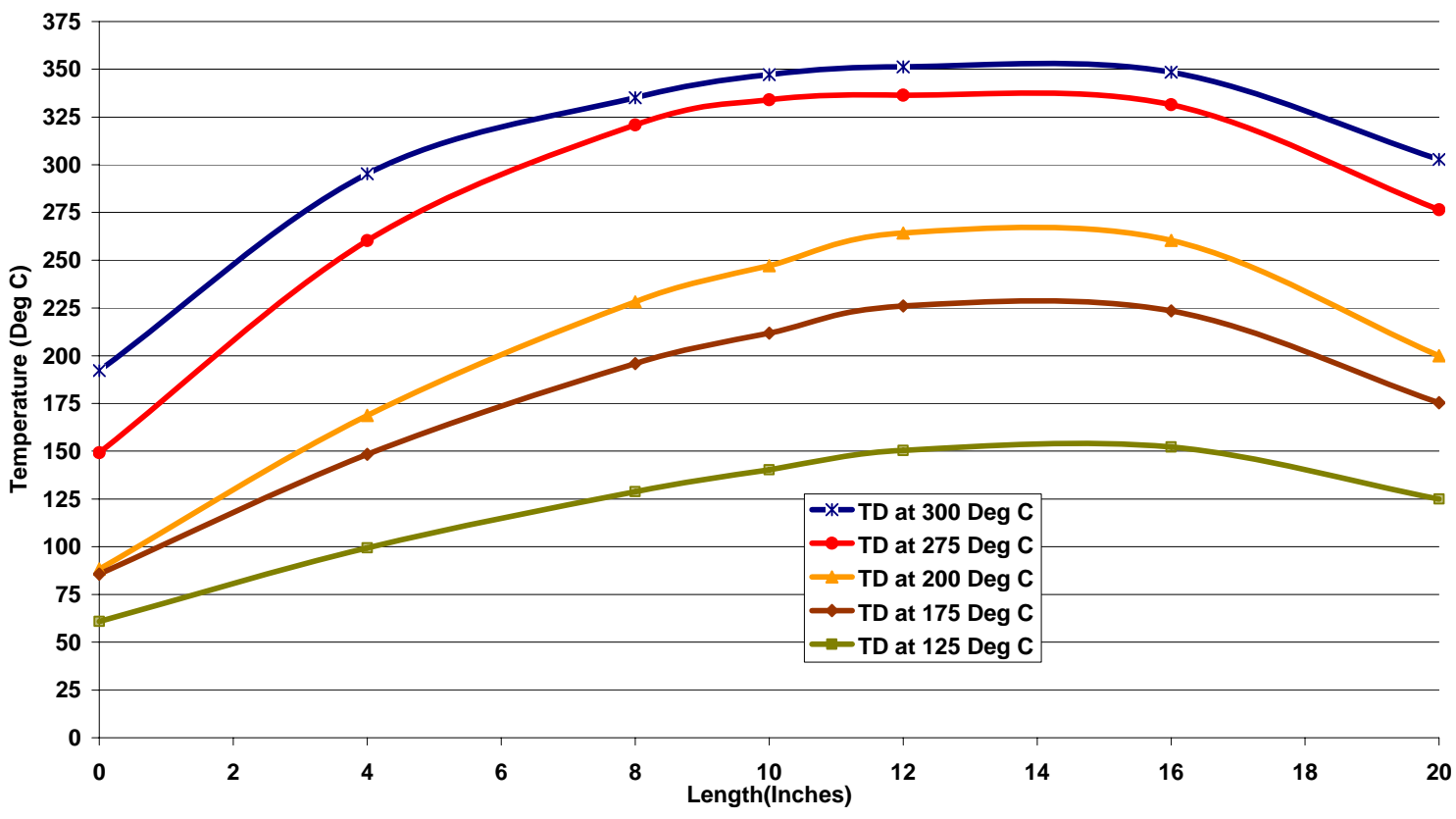

Figure 5.5: Temperature profile at $5 \mathrm{lpm}$ 
The flow rates were set using a vacuum pump and a needle valve with the flows measured using the Gilian Gilibrator and the temperatures with an Omega temperature controller with a fast thermal response. The temperatures were controlled based on the core aerosol temperature reading from the thermocouple at the end of the heated section.

The profile revealed positive gradients at all selected flow rates, however overshooting of the set value of $300^{\circ} \mathrm{C}$ by $125^{\circ} \mathrm{C}$ at $1 \mathrm{lpm}$ (Figure 5.3) and by $75^{\circ} \mathrm{C}$ at 3 lpm (Figure 5.4), midway into the desorber section was observed. The heating is achieved by the heating tape based on the input from the thermocouple at the end of the heating tube. The temperature controller supplies power to the heating tape wound uniformly around the tube, till the thermocouple reads the set value. At low flow rates the heated gas takes much longer to reach the thermocouple that inputs the value to the controller, which explains the overshooting midway into the desorber section. Based on the results of the temperature profile study, the operating flow rate for the denuder was determined as $5 \mathrm{lpm}$. 


\subsection{Diffusion Loss Study}

All transport tubes are subject to particle loss due to Brownian diffusion. The loss due to diffusion in the denuder was studied using test aerosols generated by a particle generator. The penetration of $15 \mathrm{~nm}, 30 \mathrm{~nm}$ and $70 \mathrm{~nm}$ sucrose particles at $51 \mathrm{pm}, 3 \mathrm{lpm}$ and $1 \mathrm{lpm}$ were measured by operating the SMPS in the manual mode and tracking the particle concentrations for a period of 200 seconds. The study was conducted under ambient conditions to negate thermophoretic losses and with the adsorber stage empty. The denuder was vertically oriented to avoid inertial losses. Upstream and downstream concentrations were recorded for each particle size and different set flow rates and the penetration or the transport efficiencies calculated as a percentage based on the equation given below.

Penetration Efficiency $(\%)=100-\left[\left\{\frac{\mathrm{DU}-\mathrm{DD}}{\mathrm{DU}}\right\} * 100\right]$

The results are summarized in Table 5.1 and the results plotted in Figure 5.6 
Table 5.1 Diffusion Loss Summary

\begin{tabular}{|c|c|c|c|c|}
\hline \multicolumn{5}{|c|}{ Diffusion Losses } \\
\hline \multirow{3}{*}{ Flow(Ipm) } & Diameter(nm) & $\begin{array}{c}\text { Inlet } \\
\text { Concentration } \\
(\# / c c)\end{array}$ & $\begin{array}{c}\text { Diffusion } \\
\text { Losses } \\
(\%)\end{array}$ & $\begin{array}{c}\text { Penetration } \\
\text { Efficiency } \\
(\%)\end{array}$ \\
\hline \multirow{3}{*}{5} & 70 & 17200 & 5.4 & 94.6 \\
\cline { 2 - 5 } & 30 & 11500 & 6.1 & 93.9 \\
\cline { 2 - 5 } & 15 & 2980 & 17.4 & 82.6 \\
\hline \multirow{3}{*}{3} & 70 & 29200 & 9.3 & 90.8 \\
\cline { 2 - 5 } & 30 & 19100 & 15.1 & 84.9 \\
\cline { 2 - 5 } & 15 & 4020 & 21.1 & 78.9 \\
\cline { 2 - 5 } & 70 & 67300 & 43.7 & 56.3 \\
\cline { 2 - 5 } & 30 & 34400 & 66.4 & 33.6 \\
\hline
\end{tabular}

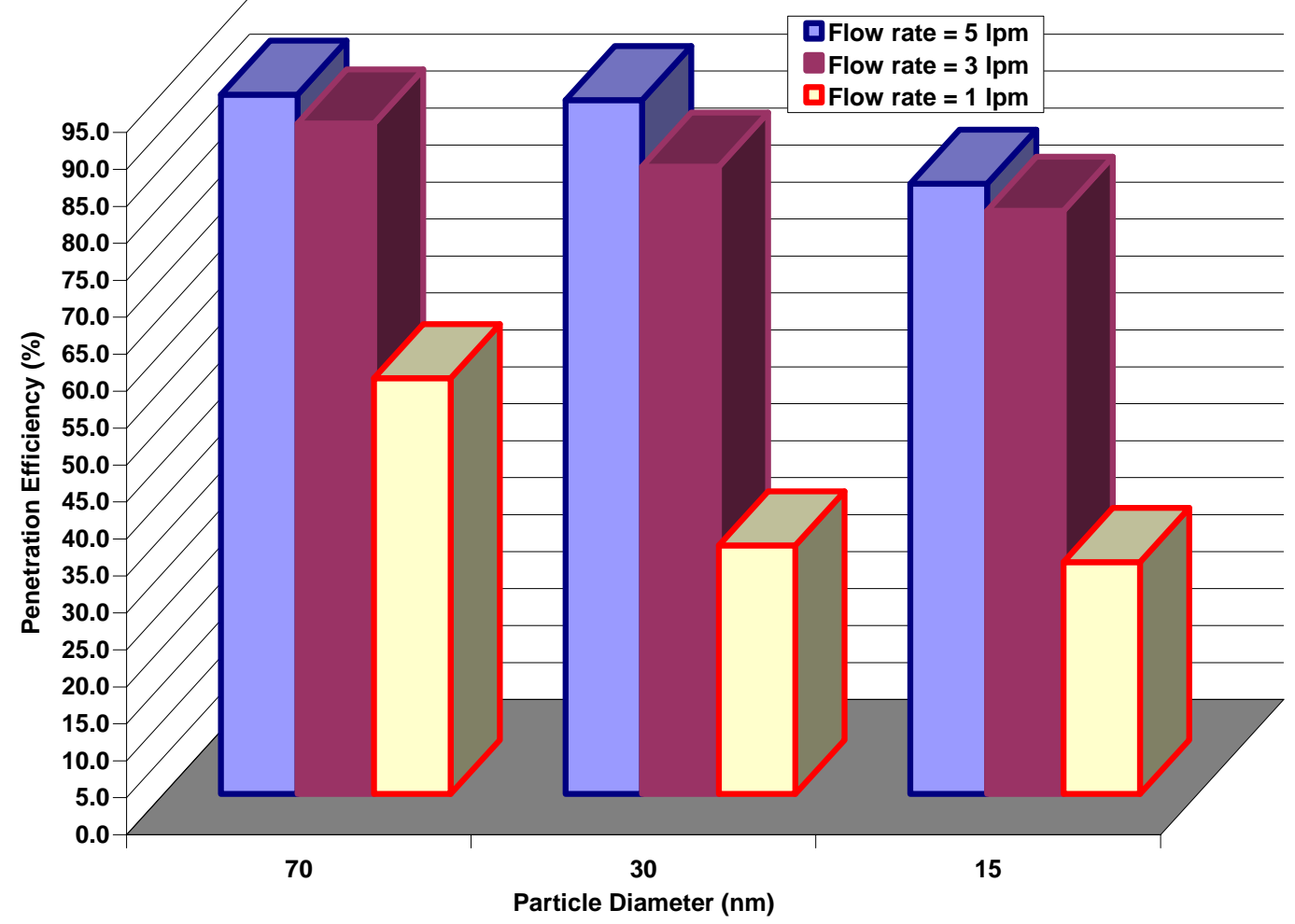

Figure 5.6: Penetration Efficiency Curve at different Flow rates 


\subsection{Steady State Testing}

The influence of the thermal denuder on exhaust particle size distributions was studied using the following engine operating conditions, dilution ratios and denuder temperatures.

Table 5.2 Steady State Test Matrix

\begin{tabular}{|c|c|c|c|c|c|c|}
\hline \multirow{3}{*}{ Mode } & \multicolumn{3}{|c|}{ Dilution Ratio $=70$} & \multicolumn{3}{|c|}{ Dilution Ratio $=104$} \\
\hline & \multicolumn{3}{|c|}{ TD Temperature } & \multicolumn{3}{|c|}{ TD Temperature } \\
\hline & $200^{\circ} \mathrm{C}$ & $300^{\circ} \mathrm{C}$ & $400^{\circ} \mathrm{C}$ & $200^{\circ} \mathrm{C}$ & $300^{\circ} \mathrm{C}$ & $400^{\circ} \mathrm{C}$ \\
\hline $\begin{array}{c}\mathrm{R} 25 \\
1810 \mathrm{rpm} / 380 \mathrm{~N}-\mathrm{m}\end{array}$ & $x$ & $\mathbf{x}$ & $\mathbf{x}$ & $x$ & $\mathbf{x}$ & $\mathbf{x}$ \\
\hline $\begin{array}{c}125 \\
1220 \mathrm{rpm} / 475 \mathrm{~N}-\mathrm{m}\end{array}$ & $\mathbf{x}$ & $x$ & $\mathbf{x}$ & & & \\
\hline $\begin{array}{c}\mathrm{R} 50 \\
1810 \mathrm{rpm} / 759 \mathrm{~N}-\mathrm{m}\end{array}$ & $\mathbf{x}$ & $\mathbf{x}$ & $\mathbf{x}$ & & & \\
\hline $\begin{array}{c}\mathrm{I50} \\
1220 \mathrm{rpm} / 956 \mathrm{~N}-\mathrm{m}\end{array}$ & $\mathbf{x}$ & $\mathbf{x}$ & & & & \\
\hline $\begin{array}{c}\mathrm{R} 100 \\
1810 \mathrm{rpm} / 1386 \mathrm{~N}-\mathrm{m}\end{array}$ & & $\mathbf{x}$ & $\mathbf{x}$ & & $\mathbf{x}$ & $\mathbf{x}$ \\
\hline $\begin{array}{c}I 100 \\
1210 \mathrm{rpm} / 1782 \mathrm{~N}-\mathrm{m}\end{array}$ & & $x$ & $x$ & & $x$ & $\mathbf{x}$ \\
\hline
\end{tabular}

\subsubsection{Ejector Diluter at 413.68 KPa (60 psi)}

The dilution air pressure to the ejector diluter was maintained at $413.68 \mathrm{KPa}(60$ psi), corresponding to a dilution ration of 70 . In the first test the engine was run at $25 \%$ of the load at rated speed corresponding to $1810 \mathrm{rpm}$ and torque of $380 \mathrm{~N}-\mathrm{m}(280 \mathrm{ft}-\mathrm{lb})$. The results are shown in Figure 5.7 


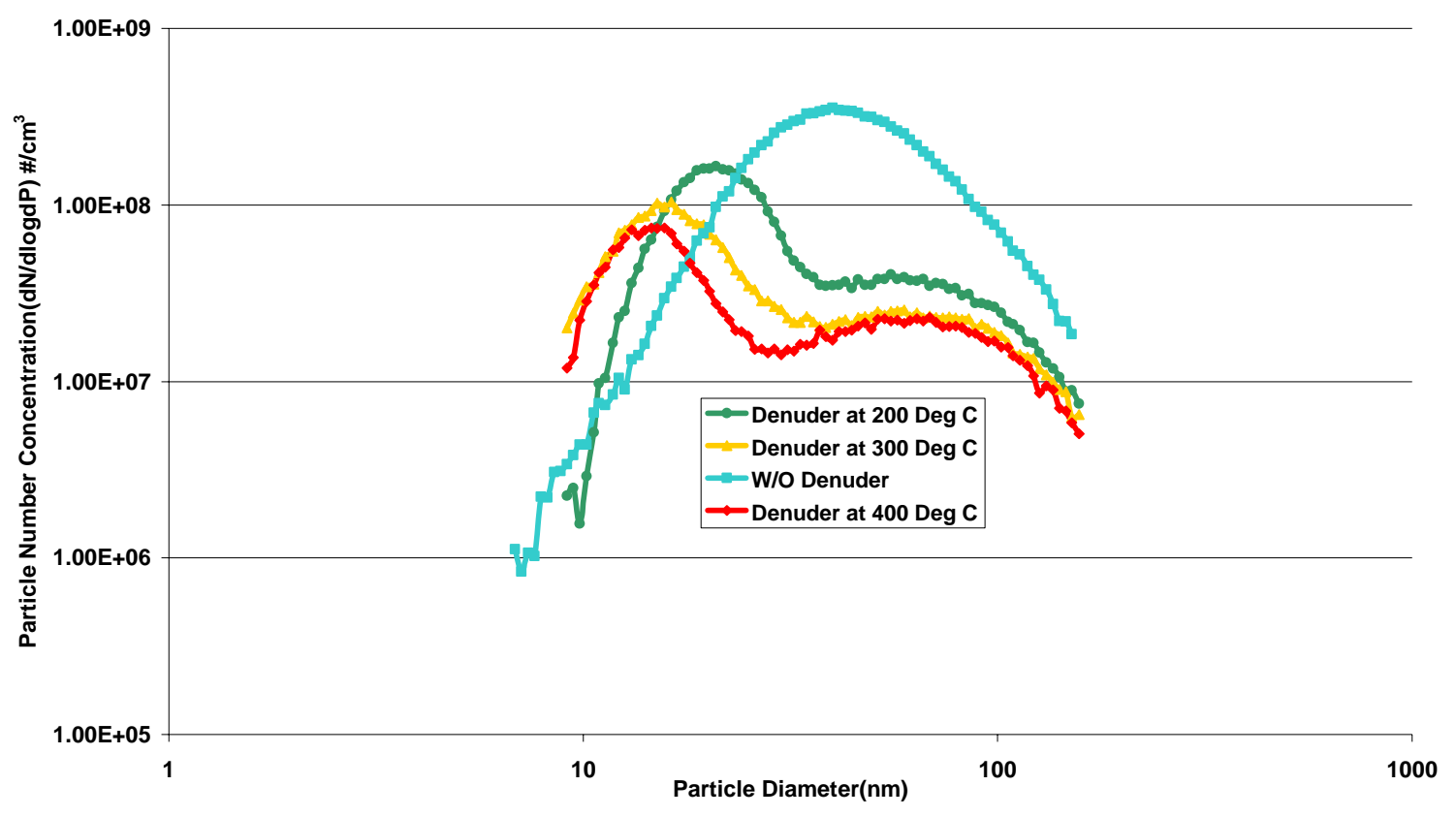

Figure 5.7: Particle Size Distribution for 1992 DDC S60 Operating at 25\% Load at Rated Speed and Different Denuder Temperatures $(D R=70)$

The size distribution without the denuder was characterized by a CMD of $40 \mathrm{~nm}$ with a peak concentration of $3.5 \times 10^{8} \# / \mathrm{cm}^{3}$. Data was collected for denuder temperatures of $200^{\circ} \mathrm{C}, 300^{\circ} \mathrm{C}$ and $400^{\circ} \mathrm{C}$.

A significant influence on the particle size distribution was observed with increasing temperatures. A shift in the size distribution occurs with increasing denuder temperatures with the CMD occurring at $20.9 \mathrm{~nm}$ at $200^{\circ} \mathrm{C}, 15.7 \mathrm{~nm}$ at $300^{\circ} \mathrm{C}$ and $14.6 \mathrm{~nm}$ at $400^{\circ} \mathrm{C}$.

Obviously the volatile organics contribute to the larger CMD in the tests without the denuder. With the increasing temperatures, the organics are desorbed from the residuals which could be ash, carbonaceous soot etc, of nanoparticle size. 
Measurements were repeated with the denuder maintained at $400^{\circ} \mathrm{C}$ to see if the peak at the lower end of the distribution was affected. Tests were also repeated with fresh activated charcoal on a different day, but no significant change was observed.

A reduction in the total concentration from $8.2 \times 10^{7} \# / \mathrm{cm}^{3}$ to $2.2 \times 10^{7} \# / \mathrm{cm}^{3}$ was achieved by increasing the denuder temperature to $400^{\circ} \mathrm{C}$.

In the next set of experiments the engine was run at $25 \%$ of the load at intermediate speed. The result is shown in Figure 5.8

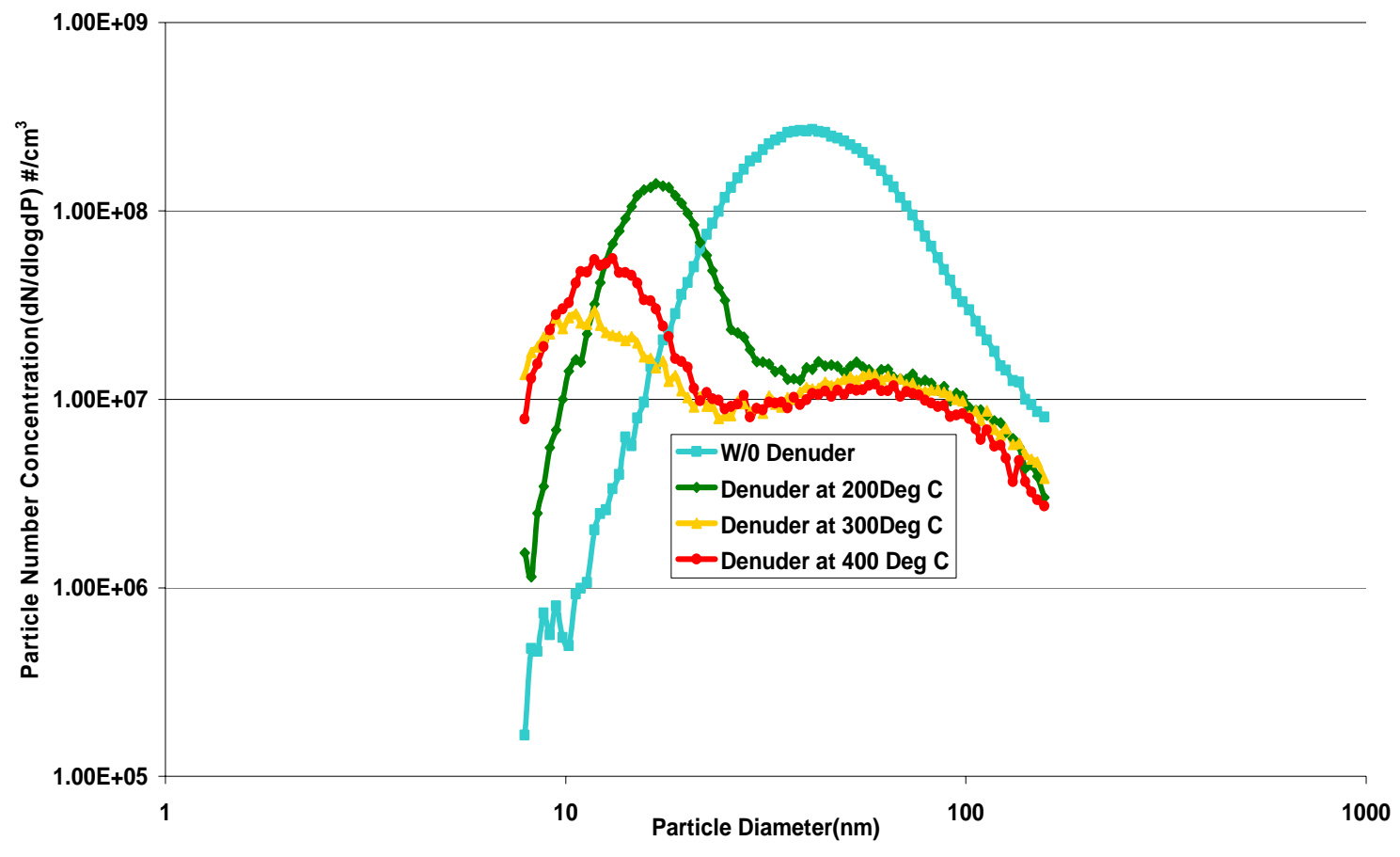

Figure 5.8: Particle Size Distribution for 1992 DDC S60 operating at 25\% Load at Intermediate Speed and Different Denuder Temperatures $(\mathrm{DR}=70)$

The corresponding engine speed was $1220 \mathrm{Rpm}$ and the torque, $474.5 \mathrm{~N}-\mathrm{m}$ (350 ft-lb). The Count Median Diameter (CMD) for the distribution upstream of the denuder was $41.4 \mathrm{~nm}$ with a maximum concentration of $2.7 \times 10^{7} \mathrm{\#} / \mathrm{cm}^{3}$. A strong dependence of 
the particle distribution on temperatures was again observed at different denuder temperature settings with a CMD of $12.2 \mathrm{~nm}$ at $400^{\circ} \mathrm{C}$. An overall reduction in the total concentration from $7.5 \times 10^{7} \# / \mathrm{cm}^{3}$ to $1.4 \times 10^{7} \# / \mathrm{cm}^{3}$ was documented. Again the larger CMD of the distribution without the denuder can be attributed to the organics, which are volatilized at higher denuder temperatures.

The engine was run at $50 \%$ of the load at rated speed to further study the effect of the denuder. This set point relates to a medium load condition with an engine speed of $1810 \mathrm{rpm}$ and torque of $759 \mathrm{~N}-\mathrm{m}(560 \mathrm{ft}-\mathrm{lb})$. Figure 5.9 shows the results.

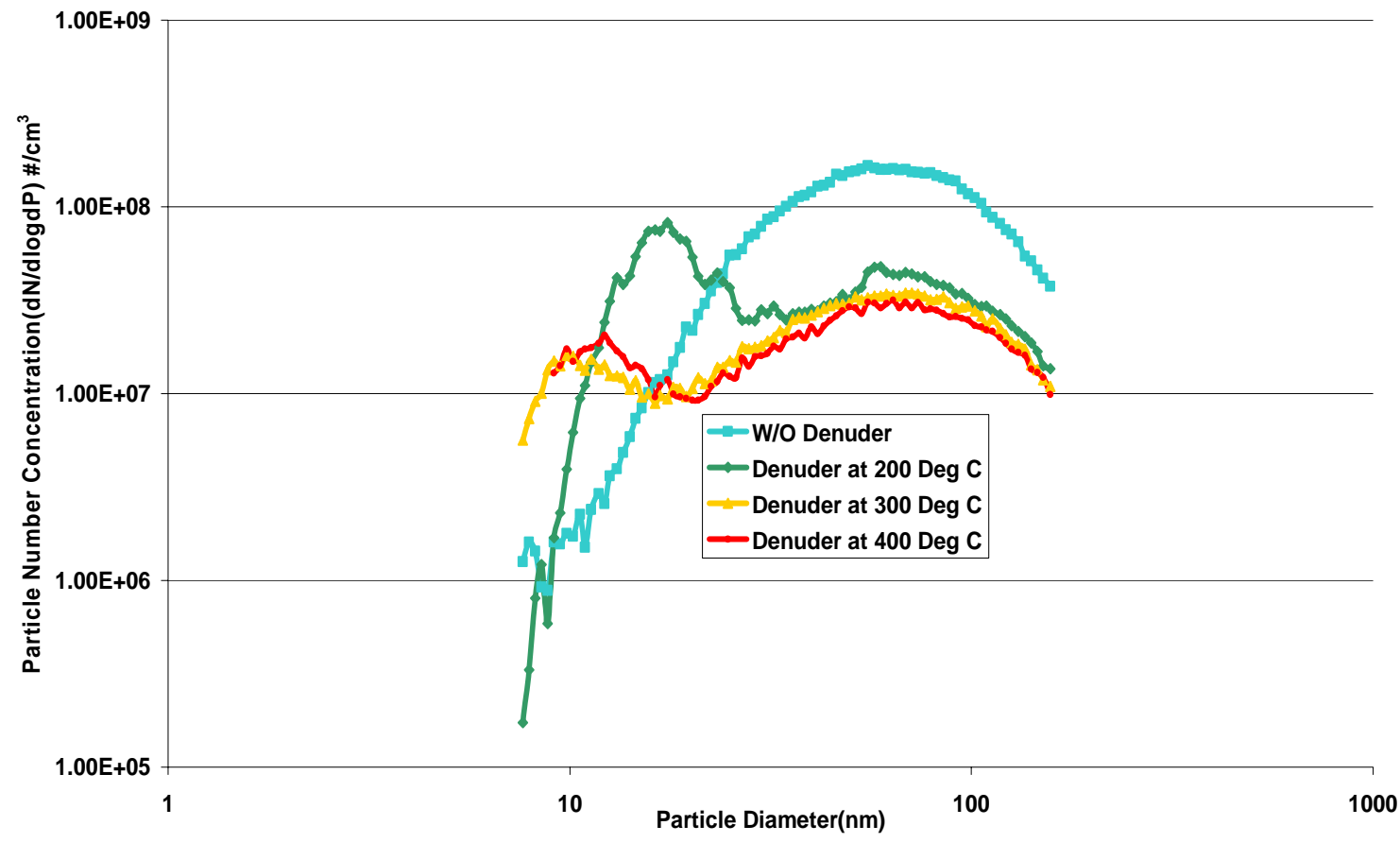

Figure 5.9: Particle Size Distribution for 1992 DDC S60 operating at $50 \%$ Load at Rated Speed and Different Denuder Temperatures $(D R=70)$ 
The size distribution without the TD exhibits a lower total concentration compared to the $25 \%$ load conditions. Increasing the denuder temperature removes the volatiles but higher concentrations of solid PM was observed, compared to the $25 \%$ load conditions.

Though a reduction in the total concentration was observed for the exhaust conditioned at $200^{\circ} \mathrm{C}$ and $300^{\circ} \mathrm{C}$, there was not much reduction when the denuder temperature was raised to $400^{\circ} \mathrm{C}$. The nanoparticle peak was observed again around $10 \mathrm{~nm}$ for the conditioned exhaust.

With the engine running at 50\% load at intermediate speed, distributions were obtained upstream and downstream of the denuder. The result is plotted in Figure 5.10.

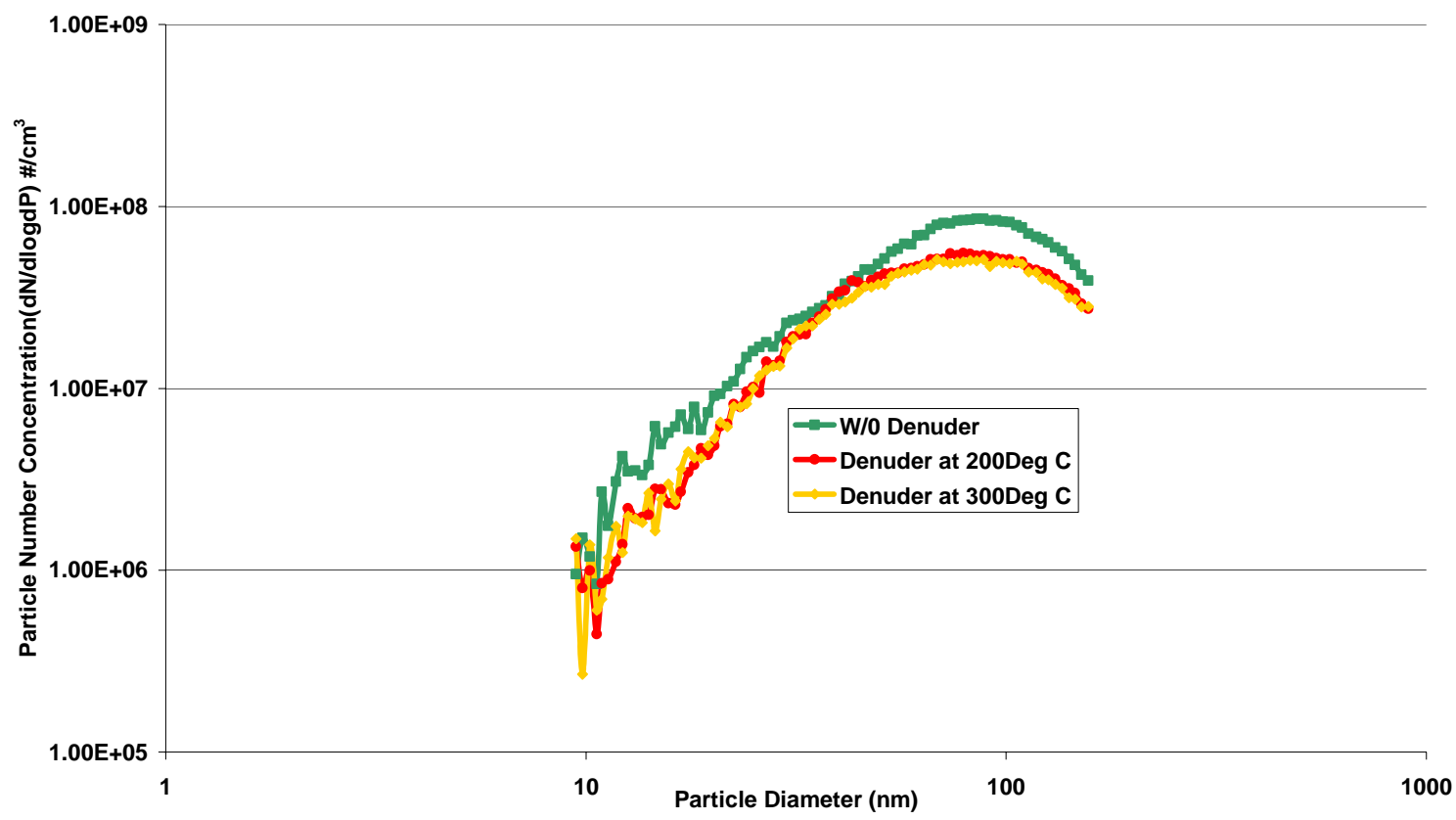

Figure 5.10: Particle Size Distribution for 1992 DDC S60 Operating at 50\% Load at Intermediate Speed and Different Denuder Temperatures $(\mathrm{DR}=70)$ 
The corresponding setpoints were $1220 \mathrm{rpm}$ and $955.85 \mathrm{~N}-\mathrm{m}$ (705 ft-lb). The upstream distribution showed a CMD of $88.2 \mathrm{~nm}$ with a maximum concentration of $8.5 \times 107 \# / \mathrm{cm}^{3}$. With the denuder at $200^{0} \mathrm{C}$, a reduction from $2.9 \times 10^{7} \# / \mathrm{cm}^{3}$ to $2.1 \times 10^{7}$ $\# / \mathrm{cm}^{3}$ in the total concentration was observed. Further increase in the denuder temperature to $300^{\circ} \mathrm{C}$ did not yield any change in the distribution, hence $400^{\circ} \mathrm{C}$ data was not collected. Apparently, the organic fraction is less at the specified engine operating condition and distribution characteristics can be attributed to solid PM.

In the next set of experiments, the engine was run at $100 \%$ load at rated speed and $100 \%$ load at intermediate speed. Particle size distributions were collected upstream and downstream of the denuder at denuder settings of $300^{\circ} \mathrm{C}$ and $400^{\circ} \mathrm{C}$. The corresponding setpoints were $1810 \mathrm{rpm}$ and $1386 \mathrm{~N}-\mathrm{m}(1022 \mathrm{ft}-\mathrm{lb})$ and $1210 \mathrm{rpm}$ and $1782 \mathrm{~N}-\mathrm{m}$ (1314 $\mathrm{ft}-\mathrm{lb})$ respectively.

Figures 5.11 and 5.12 illustrate the influence of the denuder for the respective engine operating setpoints.

For the engine operating at rated speed, the peak concentration was $4.9 \times 10^{7} \mathrm{\#} / \mathrm{cm}^{3}$ at $85.1 \mathrm{~nm}$. There was no significant reduction with the denuder setting of $300^{\circ} \mathrm{C}$, but at $400^{\circ} \mathrm{C}$, the total particle number concentration was reduced to $7.08 \times 10^{6}$ from the denuder upstream concentration of $1.7 \times 10^{7} \# / \mathrm{cm}^{3}$ corresponding to a $58 \%$ reduction (Figure 5.11).

The general form of the distributions were identical, but of a lesser concentration with the removal of the volatile material at $400^{\circ} \mathrm{C}$. 


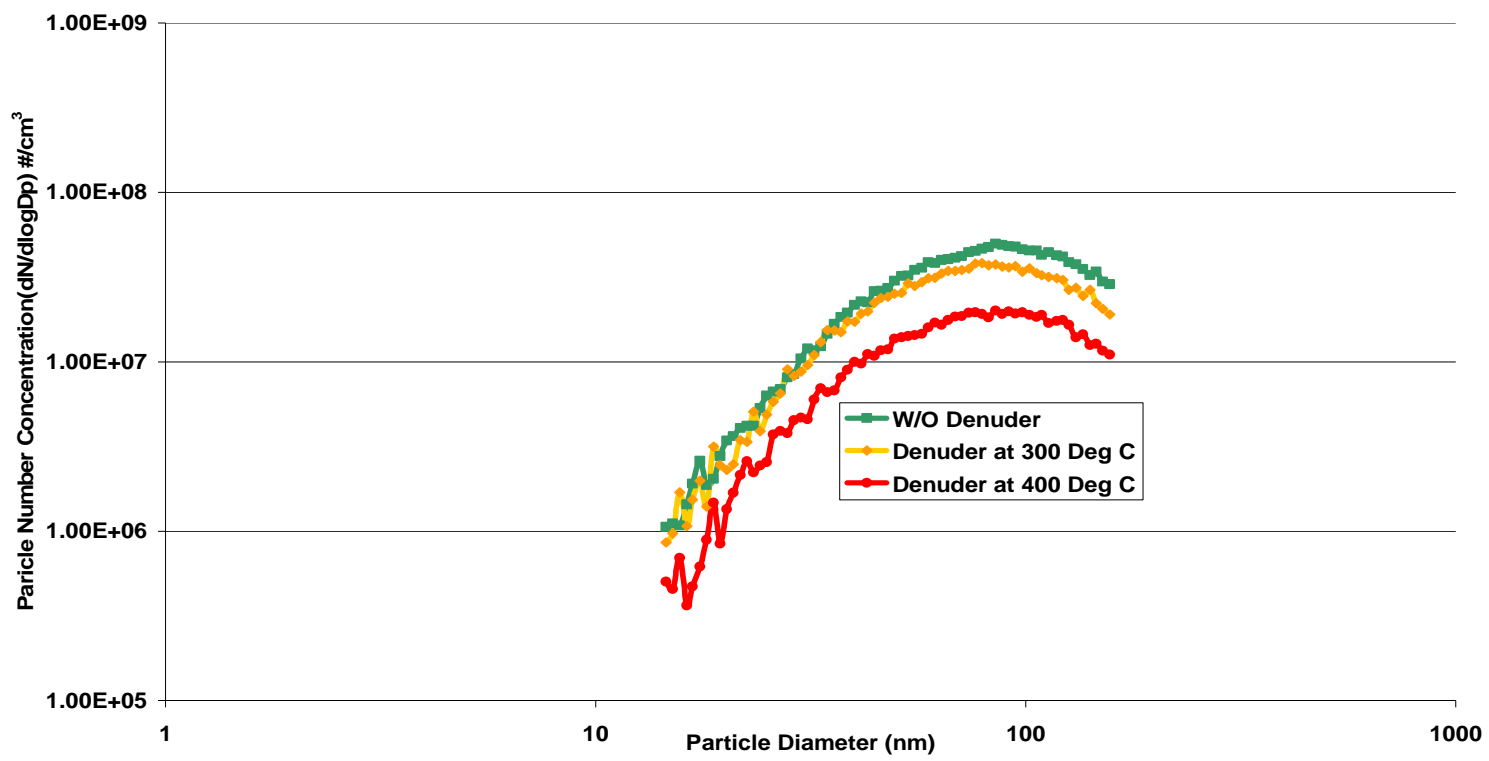

Figure 5.11: Particle Size Distribution for 1992 DDC S60 Operating at $100 \%$ Load at Rated Speed and Different Denuder Temperatures $(D R=70)$

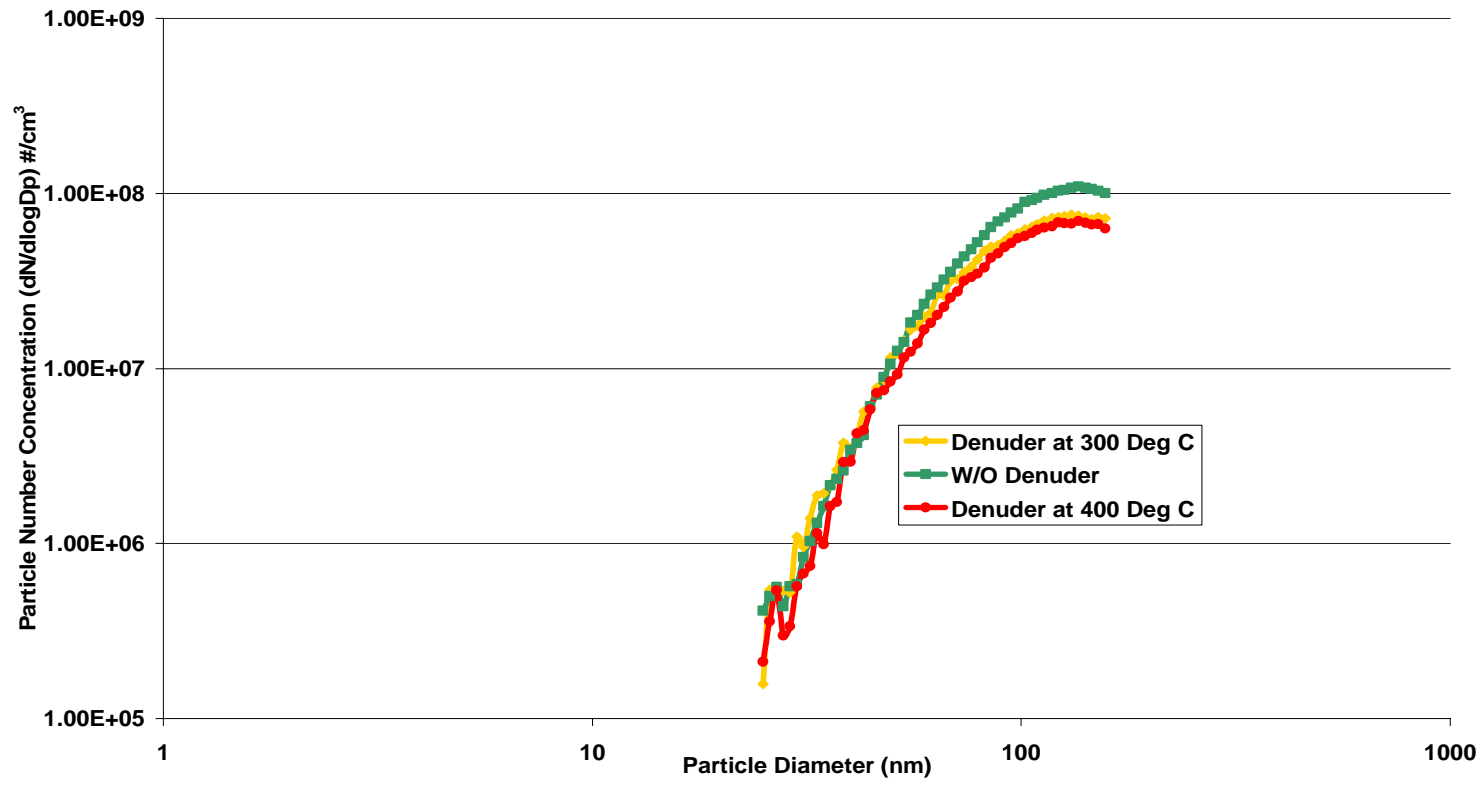

Figure 5.12: Particle Size Distribution for 1992 DDC S60 Operating at $100 \%$ Load at Intermediate Speed and Different Denuder Temperatures $(\mathrm{DR}=70)$ 
At $100 \%$ load and intermediate speed (Figure 5.12), accumulation mode particles were observed. The total concentration was $2.11 \times 10^{7} \# / \mathrm{cm}^{3}$ for the upstream denuder distribution which was reduced to $1.59 \times 10^{7} \mathrm{\#} / \mathrm{cm}^{3}$ at $300^{0} \mathrm{C}$ and $1.42 \times 10^{7} \mathrm{\#} / \mathrm{cm}^{3}$ at $400^{0} \mathrm{C}$. The reduction in the total concentration for the entire distribution was $29 \%$. The accumulation mode particles were mostly non-volatile with less organic fraction which was removed at denuder temperatures of $300^{\circ} \mathrm{C}$ and $400^{\circ} \mathrm{C}$.

\subsubsection{Ejector Diluter at $551.58 \mathrm{KPa}(80 \mathrm{psi})$}

At light and medium loads, the denuded sample exhibited peaks in the nanoparticle range, which could imply insufficient removal of the nuclei mode particles by the denuder. To verify whether the nanoparticle peak was of volatile nature, the dilution air pressure to the ejector diluter was increased to $551.58 \mathrm{KPa}$ (80 psi) which would match up to a dilution ration of 104.

The exhaust size distribution was studied at an engine operating condition of $25 \%$ load and rated speed corresponding to $1810 \mathrm{rpm}$ and $380 \mathrm{~N}-\mathrm{m}(280 \mathrm{ft}-\mathrm{lb})$. The result is shown in Figure 5.13. Even with the increased dilution ratio the nanoparticle peak around 10nm was still visible. 


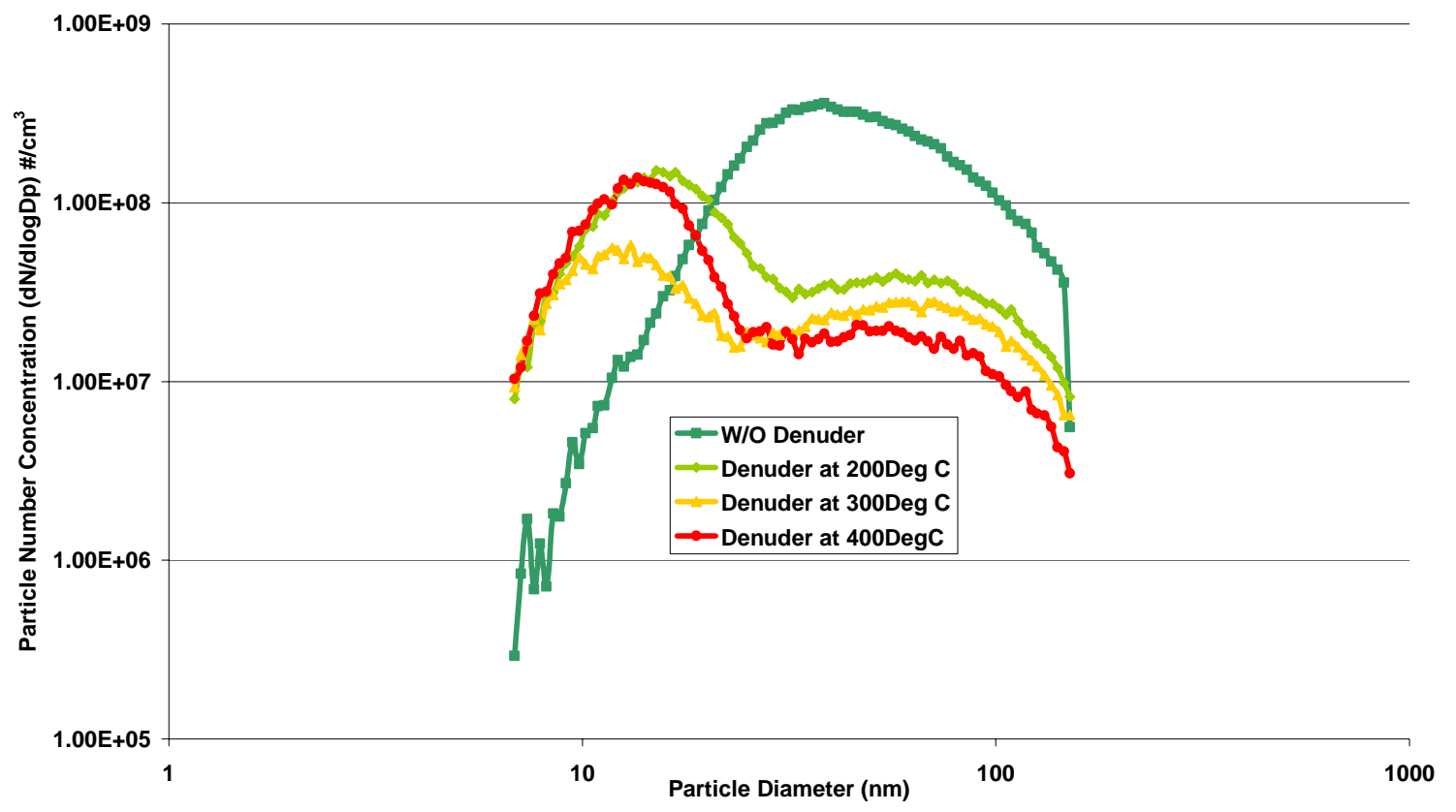

Figure 5.13: Particle Size Distribution for 1992 DDC S60 Operating at 25\% Load at Rated Speed and Different Denuder Temperatures $(D R=104)$

With the ejector dilution air pressure set to $551.58 \mathrm{KPa}(80 \mathrm{psi})$, the denuder influence on the diesel exhaust size distribution was evaluated again for operating setpoints of 100\% load at rated speed and intermediate speed (Figures 5.14 and 5.15). The corresponding setpoints were $1810 \mathrm{rpm}$ and $1386 \mathrm{~N}-\mathrm{m}$ (1022 ft-lb) and $1210 \mathrm{rpm}$ and $1782 \mathrm{~N}-\mathrm{m}(1314 \mathrm{ft}-\mathrm{lb})$ respectively.

The upstream and downstream distributions were recorded for denuder temperatures of $300^{\circ} \mathrm{C}$ and $400^{\circ} \mathrm{C}$. No changes were observed in the general form of the size distribution curve for either of the operating setpoints suggesting non-volatile nature of the particles in the exhaust. 


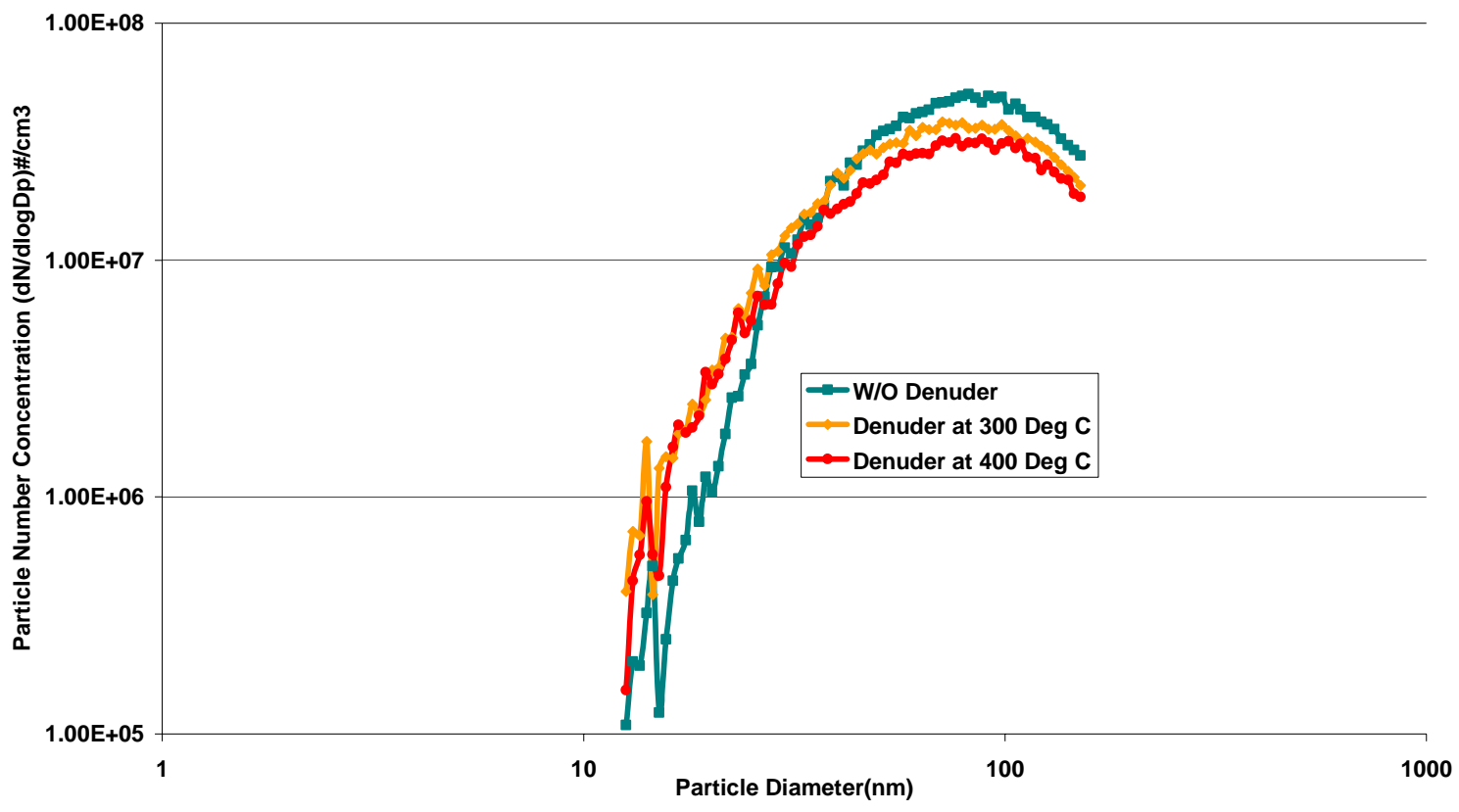

Figure 5.14: Particle Size Distribution for 1992 DDC S60 Operating at 100\% Load at Rated Speed and Different Denuder Temperatures $(D R=104)$

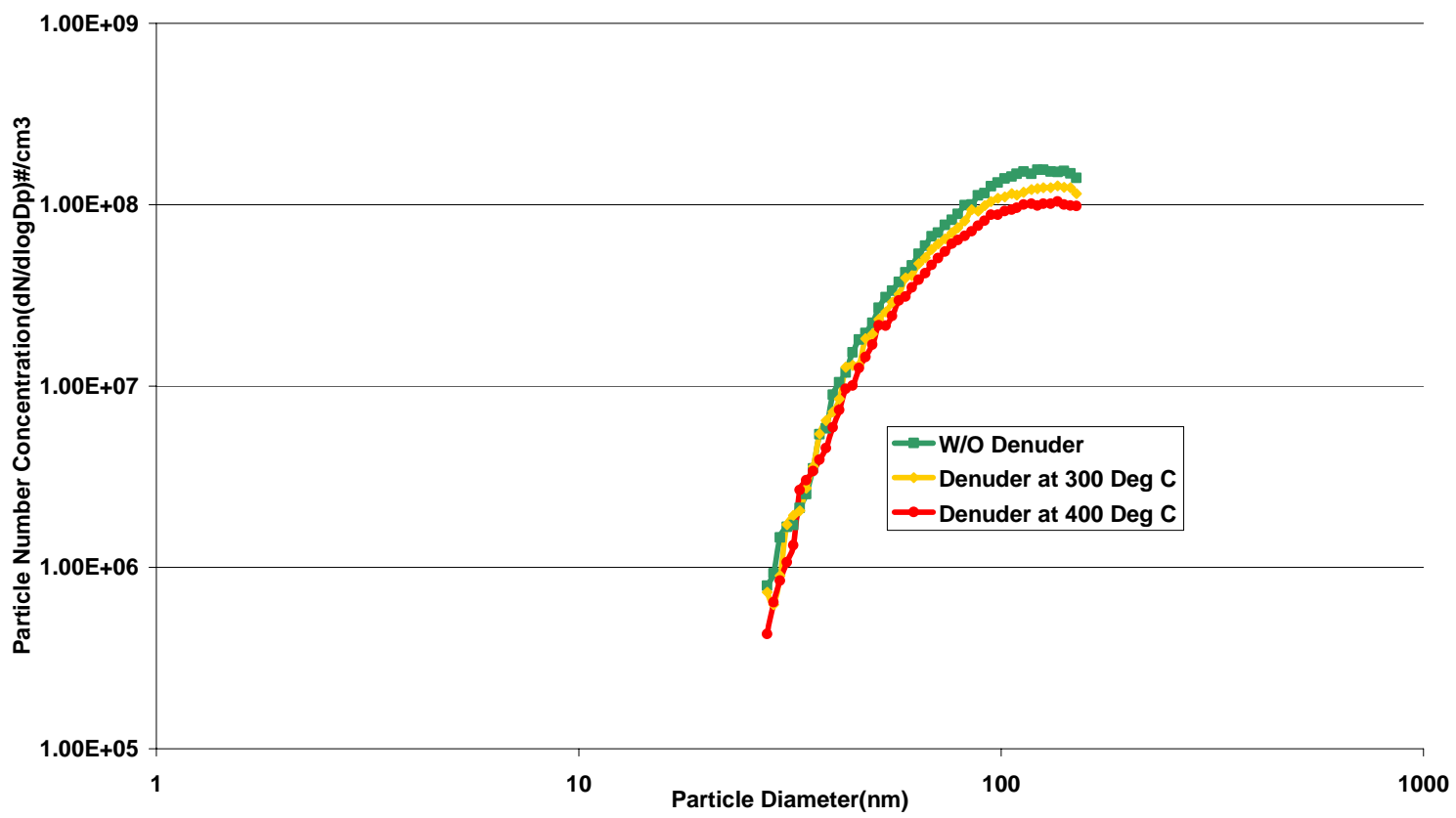

Figure 5.15: Particle Size Distribution for 1992 DDC S60 Operating at $100 \%$ Load at Intermediate Speed and Different Denuder Temperatures $(\mathrm{DR}=104)$ 


\subsection{Transient Testing}

The denuder performance was also evaluated with the engine operated through the Federal Test Procedure. The denuder flow rate was set to $5 \mathrm{lpm}$ and with temperature settings of $300^{\circ} \mathrm{C}$ and $400^{\circ} \mathrm{C}$. The SMPS was operated in the manual mode tracking particles $15 \mathrm{~nm}, 30 \mathrm{~nm}$ and $70 \mathrm{~nm}$ for each temperature setting. For all the transient testing the ejector diluter air pressure was maintained at 60 psi corresponding to a dilution ratio of 70 .

\subsubsection{Denuder at $300^{\circ} \mathrm{C}$}

For the 70nm particle over the FTP cycle, volatile behavior was observed only during the start and end corresponding to the New York Non Freeway phase (NYNF) of the FTP Cycle (Figure 5.16), which was removed by the denuder at $300^{\circ} \mathrm{C}$.At higher load conditions for the Los Angeles Non Freeway (LANF) and the Los Angeles Freeway (LAFY) segments, the SOF fraction is less as indicated by the graph. At the denuder

temperature of $300^{\circ} \mathrm{C}$, the total concentration reduction was from $4.81 \times 10^{9} \mathrm{\#} / \mathrm{cm}^{3}$ to $2.72 \times 10^{9} \mathrm{\#} / \mathrm{cm}^{3}$.

Volatile behavior to a greater extent was observed for the $30 \mathrm{~nm}$ particles over the transient cycle. The total concentration without the denuder was $3.03 \times 10^{9} \mathrm{\#} / \mathrm{cm}^{3}$ and with the denuder at $300^{\circ} \mathrm{C}$, the concentration was $5.79 \times 10^{8} \mathrm{\#} / \mathrm{cm}^{3}$.

Results are shown in Figure 5.17. 


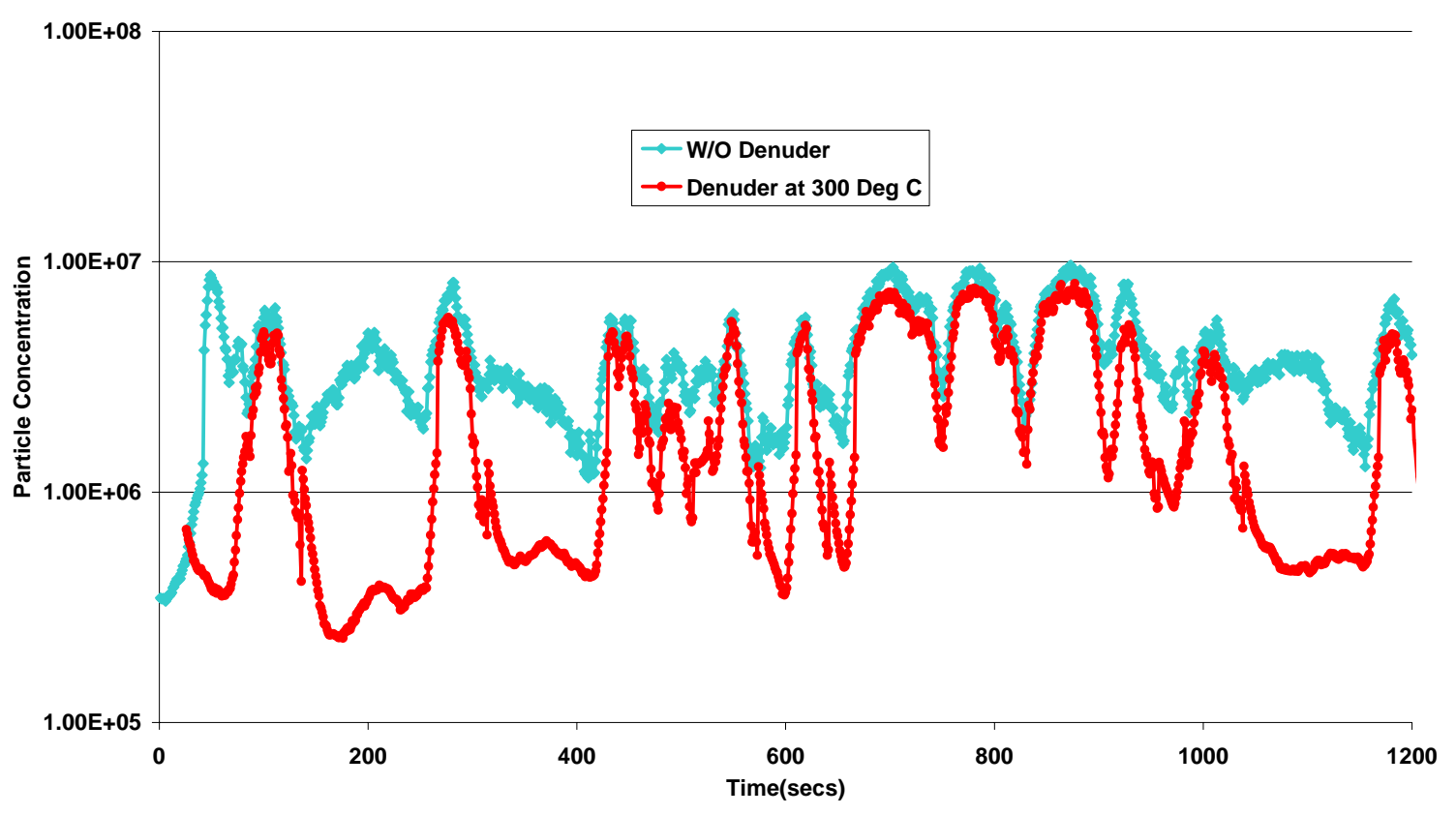

Figure 5.16: Concentration Variation for 70nm Particle over the FTP Cycle-

Denuder at $300^{\circ} \mathrm{C}$

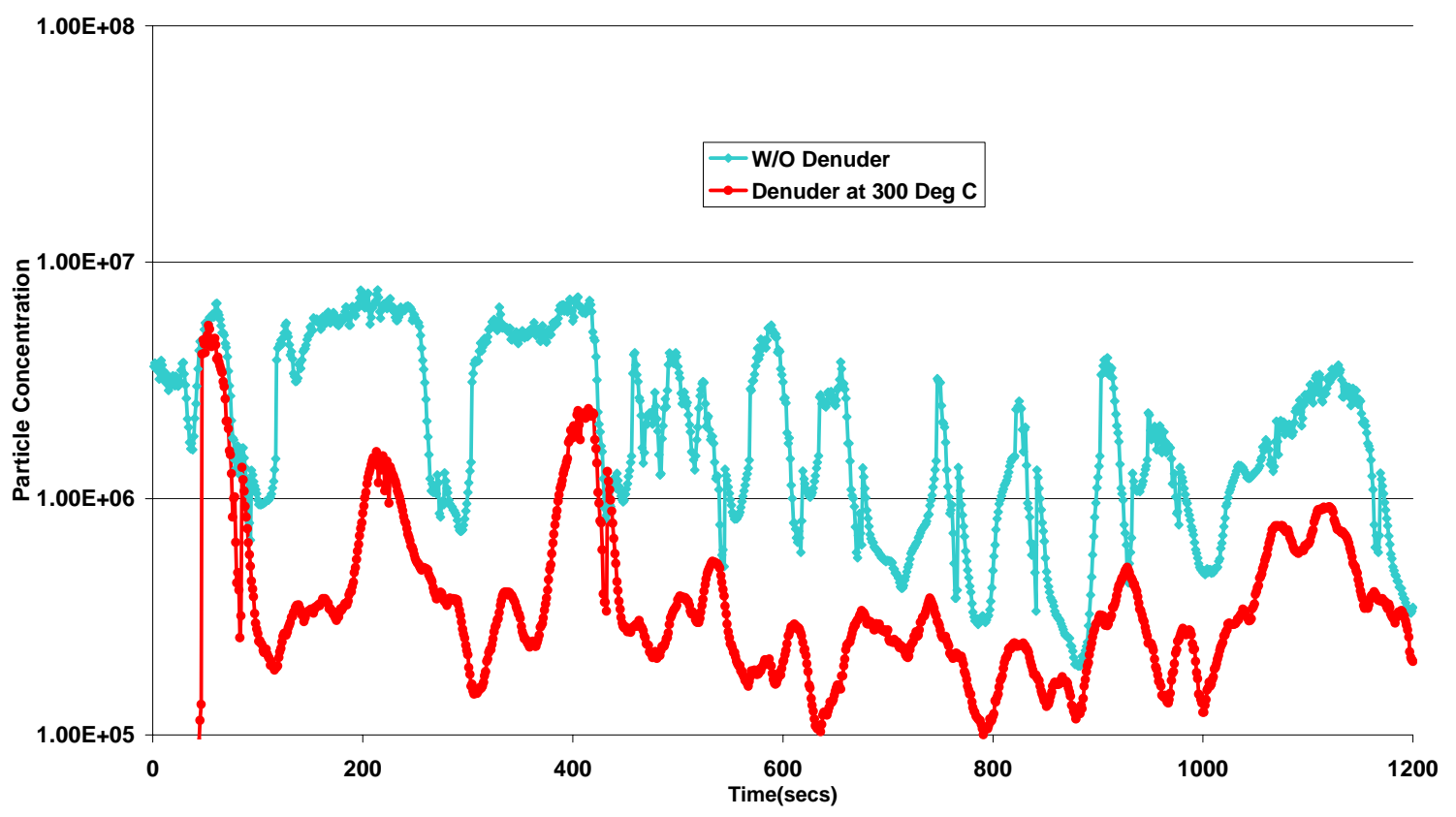

Figure 5.17: Concentration Variation for 30nm Particle over the FTP Cycle-

Denuder at $300^{\circ} \mathrm{C}$ 
For the $15 \mathrm{~nm}$ particle the total concentration was $3.85 \times 10^{9} \# / \mathrm{cm}^{3}$ without the denuder and $1.16 \times 10^{9} \mathrm{\#} / \mathrm{cm}^{3}$ with the denuder at $300^{\circ} \mathrm{C}$. The upstream and downstream denuder data is plotted in Figure 5.18

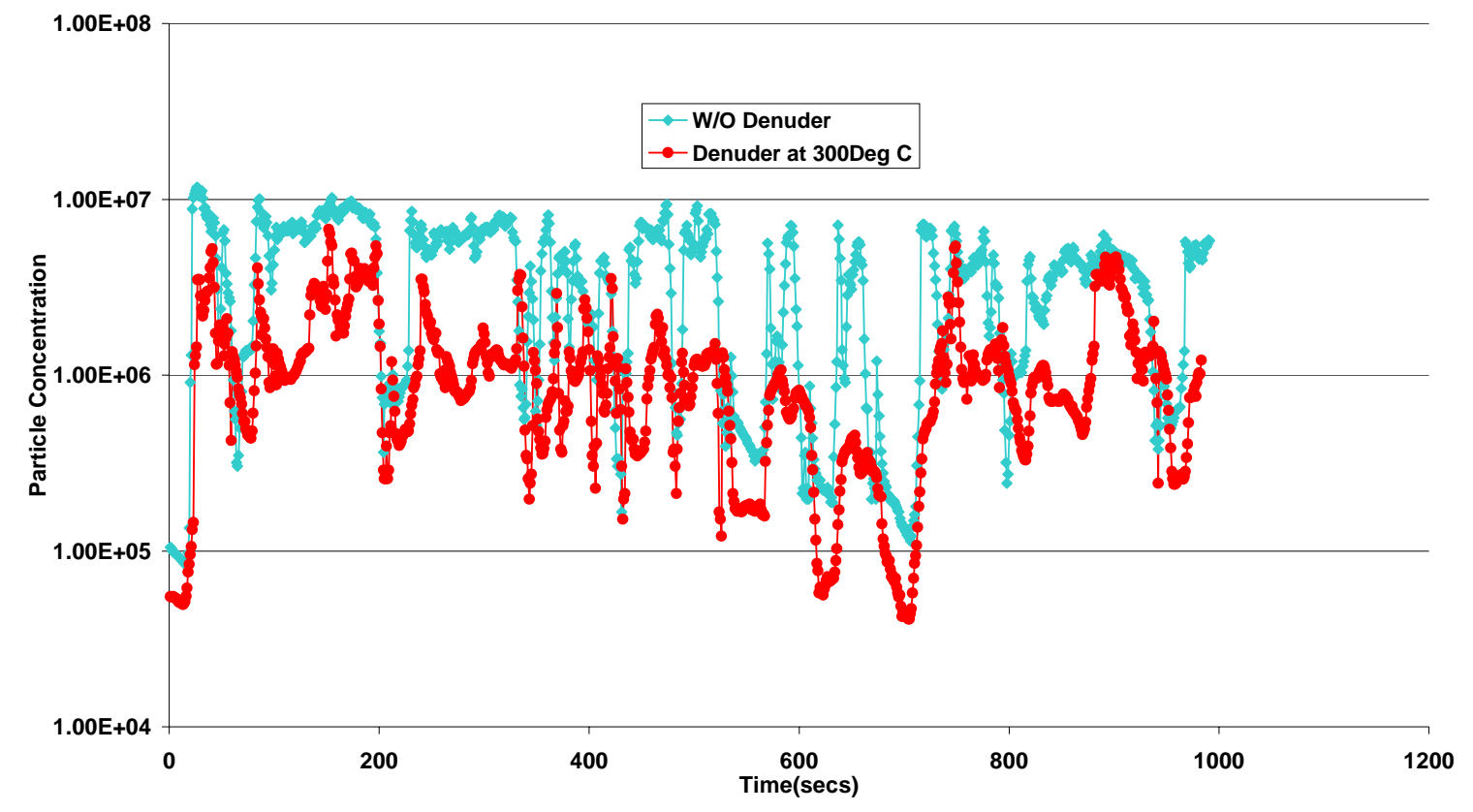

Figure 5.18: Concentration Variation for 15nm Particle over the FTP Cycle-

Denuder at $300^{\circ} \mathrm{C}$ 


\subsubsection{Denuder at $400^{\circ} \mathrm{C}$}

The total particle concentration over the transient cycle was $4.37 \times 10^{10} \# / \mathrm{cm}^{3}$, $3.77 \times 10^{10} \# / \mathrm{cm}^{3}$ and $1.63 \times 10^{10} \# / \mathrm{cm}^{3}$ for $70 \mathrm{~nm}, 30 \mathrm{~nm}$ and $15 \mathrm{~nm}$ respectively. The total concentrations measured after the denuder maintained at $400^{\circ} \mathrm{C}$ were $2.03 \times 10^{10} \# / \mathrm{cm}^{3}$, $4.01 \times 10^{9} \# / \mathrm{cm}^{3}$ and $3.08 \times 10^{9} \# / \mathrm{cm}^{3}$ respectively for $70 \mathrm{n}, 30 \mathrm{~nm}$ and $15 \mathrm{~nm}$. The results are plotted in Figures 5.19, 5.20 and 5.21.

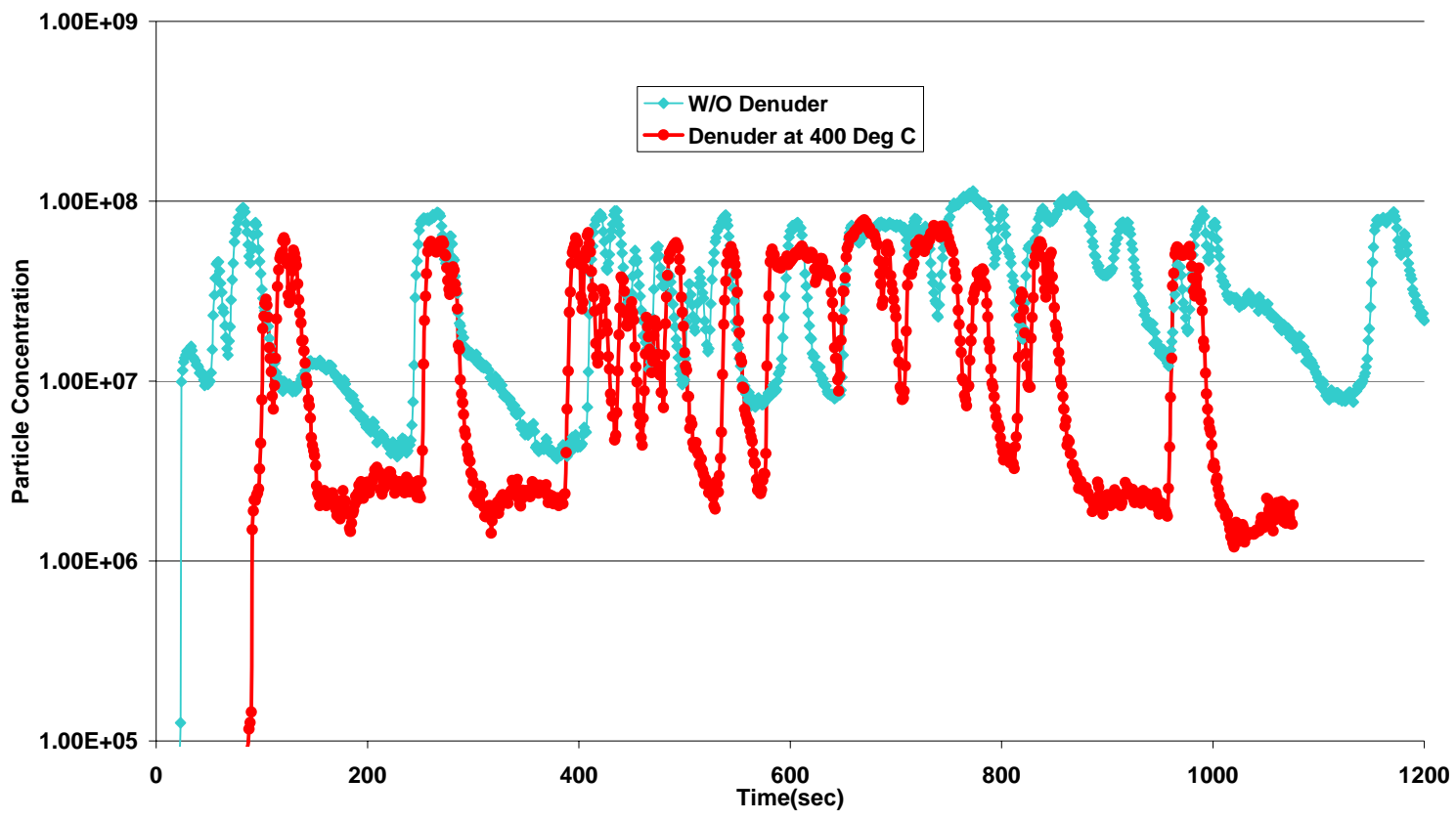

Figure 5.19: Concentration Variation for 70nm Particle over the FTP Cycle-

Denuder at $400^{\circ} \mathrm{C}$ 


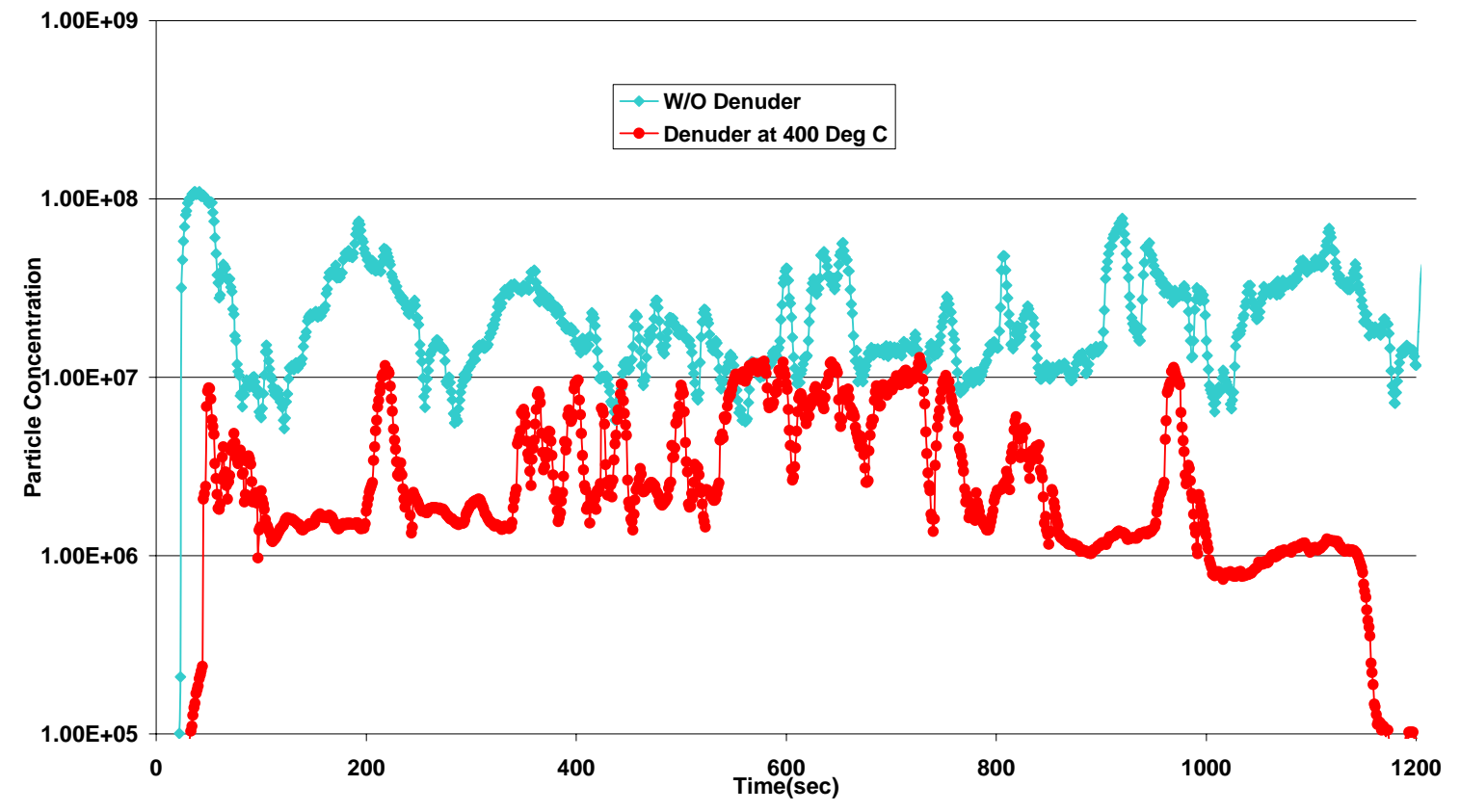

Figure 5.20: Concentration Variation for 30nm Particle over the FTP Cycle-

\section{Denuder at $400^{\circ} \mathrm{C}$}

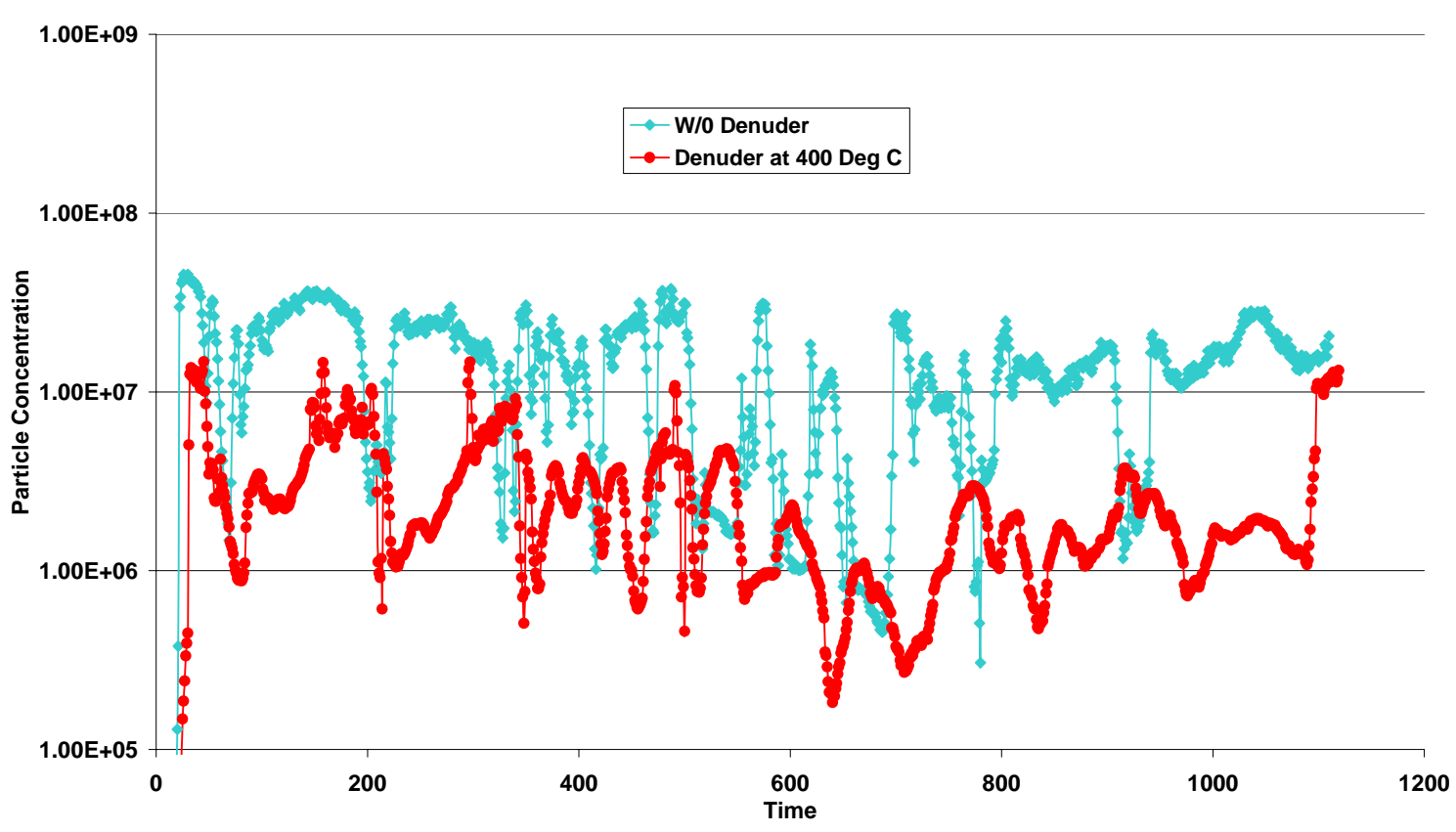

Figure 5.21: Concentration Variation for 15nm Particle over the FTP Cycle-

Denuder at $400^{\circ} \mathrm{C}$ 


\subsection{Crankcase emissions}

The effect of the denuder was also studied on crankcase emissions from the DDC S60 diesel engine. The crankcase gases were vented to the atmosphere using a rubber tube from the downward directed breather for the DDC S60 engine. The heated line maintained at $191^{\circ} \mathrm{C}\left(375^{\circ} \mathrm{F}\right)$ was connected in the stream with a probe drawing the sample to the ejector diluter. The dilution air pressure to the ejector diluter was maintained at $414 \mathrm{KPa}(60 \mathrm{psi})$ corresponding to a dilution ration of 70.

Baseline steady state tests were conducted with the engine running at idle conditions and $50 \%$ load and $75 \%$ load at rated speed. The corresponding set points were $600 \mathrm{rpm}$ and $0 \mathrm{~N}-\mathrm{m}(0 \mathrm{ft}-\mathrm{lb})$ for idle, $1810 \mathrm{rpm}$ and $760 \mathrm{~N}-\mathrm{m}(560 \mathrm{ft}-\mathrm{lb})$ for $50 \%$ load at rated speed conditions and $1810 \mathrm{rpm}$ and $1139 \mathrm{~N}-\mathrm{m}(840 \mathrm{ft}-\mathrm{lb})$ for $75 \%$ load conditions at rated speed.

Accumulation mode particles were observed for all the operating setpoints with the particle size distribution shifting towards the upper end of the spectrum with increasing oil temperatures. The engine oil temperatures were changing from $75^{\circ} \mathrm{C}$ $\left(167^{0} \mathrm{~F}\right)$ for idle to $104^{0} \mathrm{C}\left(220^{0} \mathrm{~F}\right)$ for $75 \%$ load at rated speed.

At idle condition the peak was observed at $118 \mathrm{~nm}$ with a maximum peak concentration of $3.02 \times 10^{5} \# / \mathrm{cm}^{3}$. For the engine operating at $50 \%$ and $75 \%$ load conditions at rated speed, the CMD was at 136nm. The results are shown in Figure 5.22.

Since the particle size distribution was shifting with changes in the engine oil temperatures, it was decided to study the concentration variation of particles of interest over a transient cycle. 


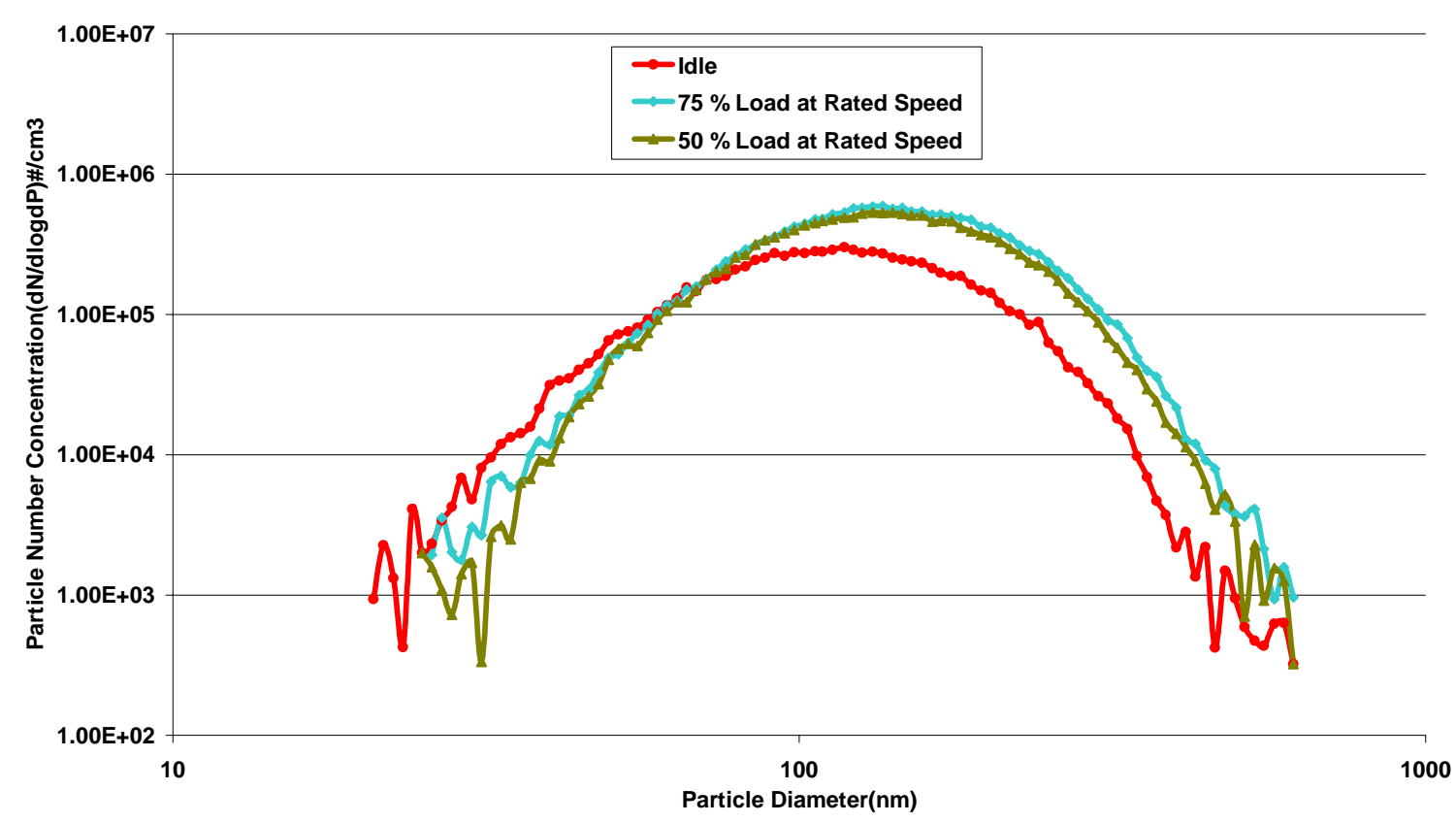

Figure 5.22: Particle size distributions for Crankcase Emissions under Different Engine Operating Conditions

Based on the SMPS data, $118 \mathrm{~nm}$ and $136 \mathrm{~nm}$ particles were tracked from the crankcase emissions gases over the FTP cycle to study the influence of the denuder. Total concentrations without the denuder were $3.49 \times 10^{9} \# / \mathrm{cm}^{3}$ and $5.16 \times 10^{9} \# / \mathrm{cm}^{3}$ for $118 \mathrm{~nm}$ and $136 \mathrm{~nm}$ respectively. Downstream of the denuder maintained at $300^{\circ} \mathrm{C}$, the concentrations were $1.59 \times 10^{9} \# / \mathrm{cm}^{3}$ and $9.28 \times 10^{8} \# / \mathrm{cm}^{3}$ for $118 \mathrm{~nm}$ and $136 \mathrm{~nm}$ respectively. The $136 \mathrm{~nm}$ particle exhibited higher concentrations than the $118 \mathrm{~nm}$ particle over the FTP cycle in the without TD tests. Downstream of the denuder, at a temperature of $300^{\circ} \mathrm{C}$, the $136 \mathrm{~nm}$ particles show lesser concentrations which can be attributed to the volatile lube oil fraction from the lube oil sump.

The results are plotted in Figures 5.23 and 5.24. 


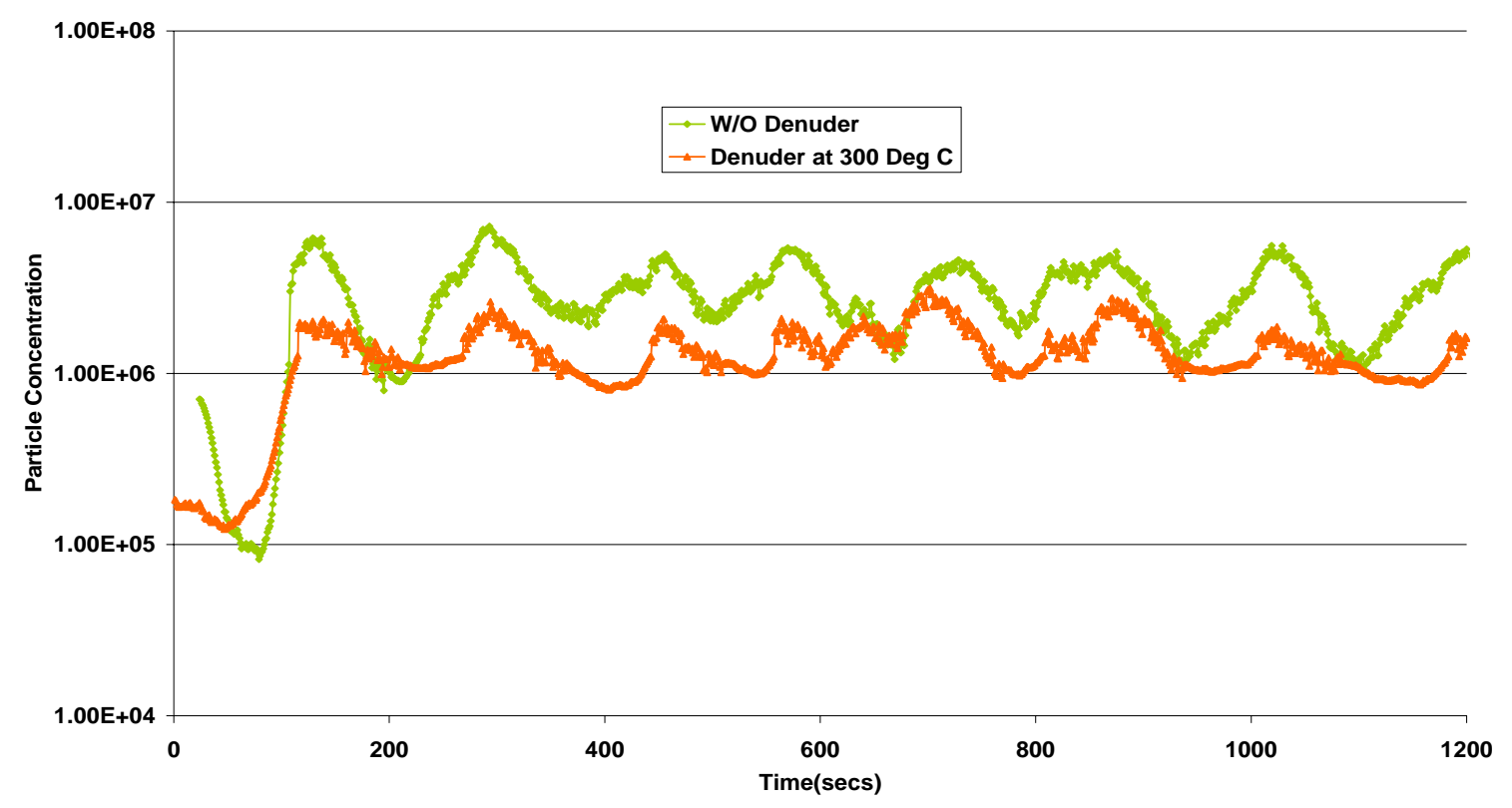

Figure 5.23: Concentration variation of $118 \mathrm{~nm}$ Particle in the Crankcase Emissions over the FTP Cycle

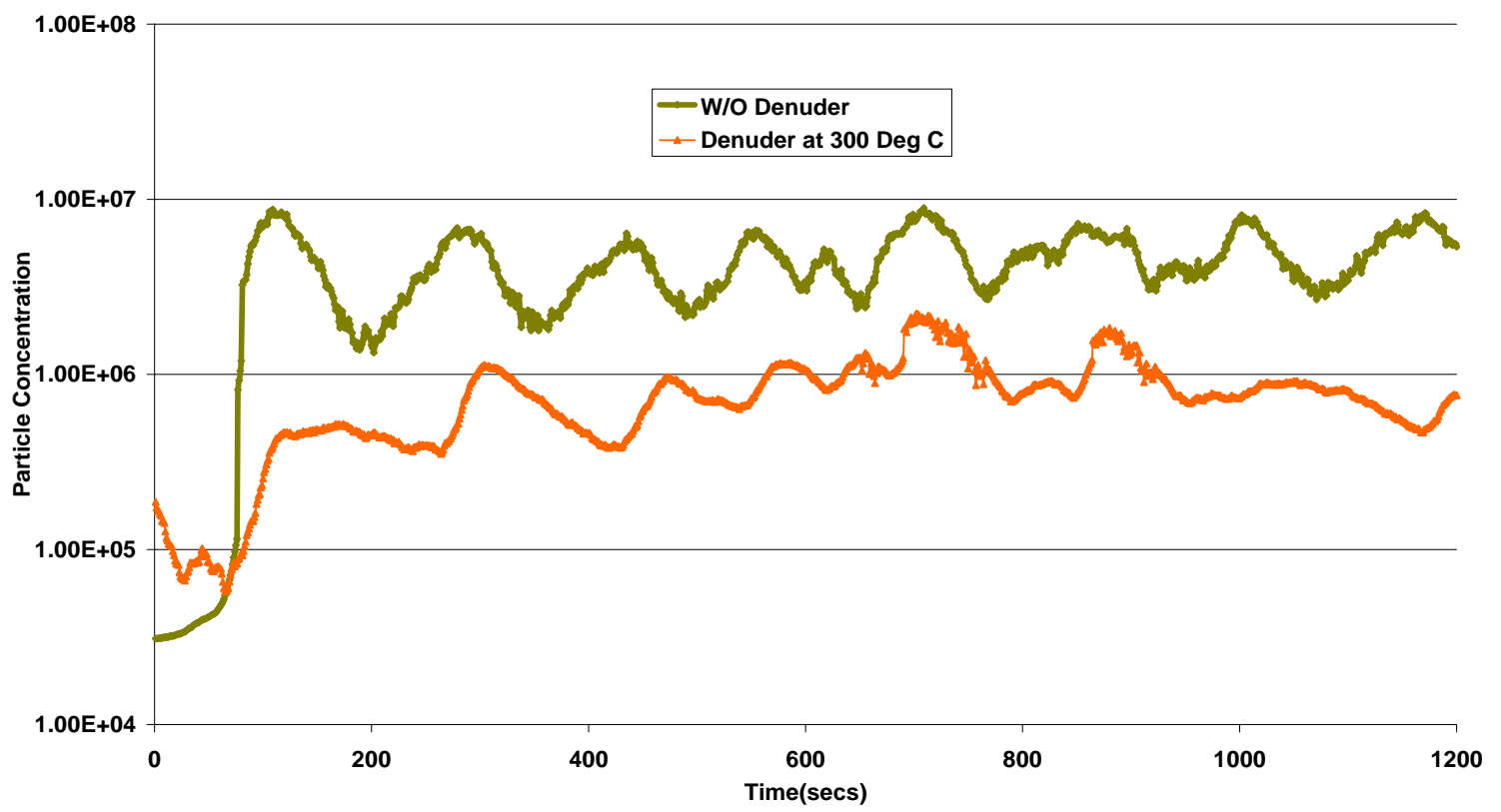

Figure 5.24: Concentration variation of 136nm Particle in the Crankcase Emissions over the FTP Cycle 


\section{CONCLUSIONS AND RECOMMENDATIONS}

\subsection{Conclusions}

A thermal denuder was developed and tested to understand the volatile and nonvolatile particle distribution in the diesel exhaust. The optimum operating characteristics were determined experimentally. The Scanning Mobility Particle Sizer was used to collect data from a 1992 DDC S60 engine that was operated over different steady state and transient cycles. Particle concentrations and size distributions were determined with and without the denuder. Particle size measurements were conducted at different dilution ratios and thermal denuder temperatures.

During steady state testing, nanoparticle peaks in the size distribution curves were observed towards the lower end of the spectrum with a Count Median Diameter around $10 \mathrm{~nm}$. Tests performed to determine the nature of these particles at higher dilution ratios and with fresh activated charcoal on different days lead to the conclusion that these particles could be ultrafine particles in the exhaust which were not volatile. Even at higher denuder temperatures of $400^{\circ} \mathrm{C}$ and higher dilution ratios, these particles does not disappear. These residual particles could be comprised of a non-volatile carbonaceous core and/or condensed organics of low volatility. The higher volatility fraction is reduced by the use of the denuder leaving behind nuclei mode particles that are now centered at $10 \mathrm{~nm}$. As expected, a high volatile fraction in the exhaust was observed at light loads and medium loads.

At high load conditions for the engine running at rated speed and intermediate speed, the distributions reveal mostly non-volatile fractions with very less organic fractions. For these engine operating conditions, no significant changes were observed for 
the upstream and downstream denuder size distribution curves even at high set temperatures of $400^{\circ} \mathrm{C}$ suggesting the non-volatile nature of the particles in the exhaust.

Crankcase particle size distributions reveal accumulation mode particles with Count Median Diameters around 136nm and the size distributions change with the changes in the engine oil temperatures.

Due to limitations, the efficiency of the denuder cannot be attributed to be $100 \%$, but efficient removal of the volatile material was observed with the thermal denuder design.

\subsection{Recommendations}

The thermal denuder effect was characterized on diesel engine exhaust. However, the current design needs to be optimized further. The particle losses in the tube should be studied with a non volatile particle generator, such as the CAST to correct the data for losses. Higher flow rates should be experimented and the particle removal efficiency studied.

A design with different sets of sorbents could help in studying the volatile fraction better. Simultaneous data collection using the SMPS, a hydrocarbon analyzer and a PM filter would further throw light on the exhaust chemistries.

With an improved design, the thermal denuder can form a critical component in the particle measurement methodology to throw light on the number concentrations and to speciate the volatile and non volatile fractions in the exhaust. The sensitivity of the current PM measuring technique can be enhanced with a thermal denuder to prevent the formation of negative and positive artifacts in the sample stream. 


\section{REFERENCES}

1. McMillan, M. H., Cui, M., Gautam, M., Keane, M., Ong, T., Wallace, W., and Robey, E., (2002) "Mutagenic Potential of Particulate Matter from Diesel Engine Operating on Fischer-Tropsch Fuel as a Function of Engine Operating Conditions and Particle Size," SAE 2002-01-1699.

2. Holmen, B. A., and Ayala, A., (2002) "Ultrafine PM Emissions from Natural Gas, Oxidation-Catalyst Diesel, and Particle-Trap Diesel Heavy-Duty Transit Buses," Journal of Environmental Science and Technology, Vol. 36, pp 5041-5050.

3. Khalek, I. S., Kittelson, D. B., Graskow, B. R., and Wei, Q., (1998) "Diesel Exhaust Particle Size: Measurement Issues and Trends," SAE 980525.

4. Kittelson, D. B., (1998) "Engines and Nanoparticles: A Review," Journal of Aerosol Science, Vol. 29, No. 5/6, pp 575-588.

5. Gautam, M., Clark, N. N., Mehta, M., Boyce, J. A., Rogers, F., and Gertler, A., (2003) "Concentrations and Size Distributions of Particulate Matter Emissions from a Class-8 Heavy-duty Diesel Truck Tested in a Wind Tunnel," SAE 200301-1894.

6. Cheng, Y. S., Yeh, H. C., and Smith, S. M., (2001) "Deposition of Ultrafine Particles in Human Tracheobronchial Airways of Adults and Children," Journal of Aerosol Science, Vol. 3, pp 697-709.

7. Donaldson, K., Li, X. Y., and Mac Nee, W., (1998) "Ultrafine (Nanometer) Particle Mediated Lung Injury," Journal of Aerosol Science, Vol. 29, No. 5/6, pp $\underline{553-560 .}$

8. "The Lungs in Health and Disease," (1997) National Institute of Health publication No. 97-3279.

9. Matter, U., Siegmann, H., C., and Burtscher, H., (1999) "Dynamic Field Measurements of Submicron Particles from Diesel Engines," Journal of Environmental Science and Technology, Vol.33, pp 1946-1952. 
10. UK Particle Measurement Programme-Heavy Duty Methodology Development Final Report, July 2002.

11. Report of the GRPE Particle Measurement Programme (PMP) - Government Sponsored Work Programmes, July 2003.

12. Kittelson, D., Johnson, J., Watts, W., Wei, Q., Drayton, M., and Paulsen, D., (2000) "Diesel Aerosol Sampling in the Atmosphere," SAE 2000-01-2212.

13. Mills, A. F., HEAT AND MASS TRANSFER, John Wiley and Sons, New York, NY, 1999.

14. Hinds, W. C., AEROSOL TECHNOLOGY- PROPERTIES, BEHAVIOR AND MEASUREMENT OF AIRBORNE PARTICLES, John Wiley and Sons, New York, NY, 1999.

15. Kittelson, D. B., and Khalek, I. S., (1999) "Formation of Nanoparticles during Exhaust Dilution," EFI members conference, January 18-20, 1999.

16. Mayer, A., Matter, U., Scheidegger, Czerwinski, J., Wyser, M., Kieser, D., and Weidhofer, (1998) "VERT: Diesel Nano-Particulate Emissions: Properties and Reduction Strategies," SAE 980539.

17. Koutrakis, P., Fasano, A. M., Slater, J. L., and Spengler J. D., (1989) "Design of a Personal Annular Denuder to Measure Atmospheric Aerosols and Gases," Journal of Atmospheric Environment, Vol.23, pp 2767-2773.

18. Coutant, R. W., Callahan, P. J., and Kuhlman, M. R., (1989), "Design and Performance of a High-Volume Compound Annular Denuder," Journal of Atmospheric Environment, Vol. 23, pp 2205-2211.

19. Koutrakis, P., Sioutas, C., Ferguson, S. T., and Wolfson, J. M., (1993), "Development and Evaluation of a Glass Honeycomb Denuder/Filter Pack System to Collect Atmospheric Gases and Particles," Journal of Environmental Science and Technology, Vol.27, pp 2497-2501.

20. Eatough, D. J., Obeidi, F., Pang, Y., Ding, Y., Eatough, N. L., and Wilson, W. E., (1999), "Integrated and real-time diffusion denuder sampler for PM2.5," Journal of Atmospheric Environment, Vol.33, pp 2835-2844. 
21. Ding, Y., Pang, Y., and Eatough, D. J., (2002), "High-Volume Diffusion Denuder Sampler for the Routine Monitoring of Fine Particulate Matter: I. Design and Optimization of the PC-BOSS," Journal of Aerosol Science and Technology, Vol.36, pp 369-382.

22. Ding, Y., Pang, Y., Eatough, D. J., Eatough, N. L., and Tanner, R. L., (2002), "High-Volume Diffusion Denuder Sampler for the Routine Monitoring of Fine Particulate Matter: II. Field Evaluation of the PC-BOSS," Journal of Aerosol Science and Technology, Vol.36, pp 383-396.

23. Abdul-Khalek, I. S., and Kittelson, D. B., (1995), "Real Time Measurement of Volatile and Solid Exhaust Particles Using a Catalytic Stripper," SAE-950236.

24. Burtscher, H., Baltensperger, U., Bukowiecki, N., Cohn, P., Huglin, C., Mohr, M., Nyeki, S., Schmatloch, V., Streit, N., and Weingartner, E., (2001), "Separation of volatile and non-volatile aerosol fractions by thermodesorption: instrumental development and applications," Journal of Aerosol Science Vol.32, pp 427-442.

25. http://www.tsi.com/documents/3065.pdf.

26. http://www.dekati.com/brochures/denudermainos.pdf.

27. Fierz, M., and Burtscher, H., "Separation of solid and volatile fraction by thermodesorption and hot dilution," PMP report CH6.

28. Madl, P., (2003), "Instrumental development and application of a thermodenuder".

29. Khalek, I. A., (2005), "2007 Diesel Particulate Measurement Research,” Draft Final Report, E-66 Project-Phase I.

30. http://www.dekati.com/brochures/Dekatidiluter.pdf.

31. http://www.dieselnet.com.

32. http://www.bgiusa.com/agc/critical.htm.

33. Model 3480 Electrospray Aerosol Generator Instruction Manual, P/N 1933793, 
Revision D, October 2003.

34. http://www.tsi.com/products/eag.aspx.

35. http://www.tsi.com/models/3936.aspx.

36. Model 3936 Scanning Mobility Particle Sizer ${ }^{\mathrm{TM}}$ (SMPS) Spectrometer Instruction Manual, P/N 1933796, Revision, February 2005.

37. Series 3080 Electrostatic Classifiers-Instruction Manual, P/N 1933792, Revision F, March 2005.

38. Model 3025A Ultrafine Condensation Particle Counter Instruction Manual, P/N 1933762, Revision I, July 2002.

39. http://www.tsi.com/products/cpc3025a.aspx.

40. Aerosol Instrument Manager ${ }^{\circledR}$ Software for Scanning Mobility Particle Sizer ${ }^{\mathrm{TM}}$ (SMPS) Spectrometer Instruction Manual, P/N 1930038, Revision C, February 2005. 


\section{APPENDICES}

\section{APPENDIX A- CPC AND SMPS REDUCTION PROGRAM}

\section{CPC reduction Program}

\section{Particle Concentration Calculation when using DMA and CPC at a single diameter}

Input Dp (Particle Diameter in $\mathrm{nm})$

$\mathrm{Dp}:=15 . \mathrm{nm}$

Number of Charges on Particle

$\mathrm{N}:=1$

Dilution Ratio

DR := 104

Input Sheath Flow Rate

$\mathrm{QC}:=3.0 \mathrm{lpm}$

Input Aerosol Flow Rate

Qa:=0.3.1pm

$$
\begin{aligned}
& \text { CONSTANTS } \\
& \eta \equiv 1.81 .104 . \text { dyne sec } / \mathrm{cm} 2 \\
& \mathrm{~T} \equiv 295 \mathrm{~K} \\
& \mathrm{~nm} \equiv 10^{-9} \mathrm{~m} . \\
& \mathrm{kB} \equiv 1.38 .10^{-2} 3 \text { joule } / \mathrm{K} \\
& \mathrm{lpm} \equiv \text { liter } / \mathrm{min}^{-12} \text { farad } / \mathrm{m} \\
& \mathrm{E} 0 \equiv 8.854187817 .10^{-1} \\
& \lambda \mathrm{atm} \equiv 0.066 .10^{-4} . \mathrm{cm}^{-19} \\
& \mathrm{qe} \equiv 1.60217733 .10^{-19} \\
& \mathrm{qa} / \mathrm{qc}=
\end{aligned}
$$




\section{Slip Correction}

$\mathrm{Cc}(\lambda \mathrm{Dp}):=1+\lambda / \mathrm{Dp}[2.514+0.800 \mathrm{e}(-0.55[\mathrm{Dp} / \lambda])$

Particle Mobility

$\mathrm{Zp}(\mathrm{Dp}):=[1 / 3+$.qe $\{[\mathrm{Cc}(\lambda \mathrm{atm}, \mathrm{Dp})] /[\pi .(\eta . \mathrm{Dp})]\}$

Guesses for mathcad root function

TOL: $=0.0001$

$\mathrm{x}:=\operatorname{lnm}$.

$\mathrm{y}:=1 \mathrm{~nm}$.

Dplus $:=\operatorname{root}[\{\mathrm{Zp}(\mathrm{Dp}) / \mathrm{Zp}(\mathrm{x})\}-\{1+(\mathrm{qa} / 2 . \mathrm{qc})\}, \mathrm{x}]$

Dminus $:=\operatorname{root}[\{\mathrm{Zp}(\mathrm{Dp}) / \mathrm{Zp}(\mathrm{x})\}-\{1-(\mathrm{qa} / 2 . \mathrm{qc})\}, \mathrm{x}]$

Dminus $=$

Dplus $=$

FWHM := Dplus-Dminus

\section{FWHM =}

Tf $:=\log (\mathrm{FWHM} / \mathrm{Dp}+1)$

Transfer Function

\section{$\mathrm{Tf}=$}

Fuchs / Gunn Aerosol Charging

$\mathrm{a}:=\mid \begin{array}{lllll}-26.3328 & 2.3197 & -0.0003 & -2.3484 & -44.4756\end{array}$ $\begin{array}{lllll}-35.9044 & 0.6175 & -0.1014 & 0.6044 & 79.3772\end{array}$ $\begin{array}{lllll}-21.4608 & 0.6201 & 0.3073 & 0.4800 & -62.8900\end{array}$

$\begin{array}{lllll}7.0867 & -0.1105 & -0.3372 & 0.0013 & 26.4492\end{array}$

$\begin{array}{lllll}-1.3088 & -0.1260 & 0.1023 & -.1553 & -5.7480\end{array}$

$\begin{array}{lllll}0.1051 & 0.0297 & -0.0105 & 0.0320 & 0.5049\end{array}$

$\mathrm{F}(\mathrm{N}, \mathrm{Dp}):=10 \exp \left[\sum_{i=0}^{5} a i, N+2\left(\log \left(\frac{D p}{n m}\right)^{i}\right)\right.$

Probability of Charge $\mathrm{N}$ on particle dia Dp

\section{$\mathrm{f}(\mathrm{N}, \mathrm{Dp})=$}




\author{
Select Raw CPC file \\ RawCPC:=C:I..।UTD-1 tracking15nm.txt \\ Select Output reduced file \\ Reduced:= C:I..। UTD-1rd tracking15nm.txt \\ RawCPC.DR/Tf.f(N, Dp)
}

\title{
Reduction Program for SMPS
}

Input Dilution Ratio

DR :=104

$$
\begin{aligned}
& \text { Select Raw data File } \\
\text { Raw }= & \text { C }: 1 . . . \text { UTD at } 300 \text { Deg C.txt }
\end{aligned}
$$

Rowsize $:=\operatorname{rows}($ Raw $)$

$\mathrm{N}:=$ Row size- 26

Raw1 :=submatrix(Raw, 1, N, 1, 2)

Rawcount Raw1 $1^{<2>}$

Size Raw $1^{<1>}$

$\mathrm{C}:=$ Rawcount.DR

Reduced :=augment(Size , C)

Select output reduced data file

REDUCED $=C: \mid \ldots .$. UTD-rd at 300 Deg C.txt

Reduced 


\section{APPENDIX B- TSI MODEL 3936 SCANNING MOBILITY PARTICLE SIZER SPECIFICATIONS}

\section{SLPS Spcoiliatione}

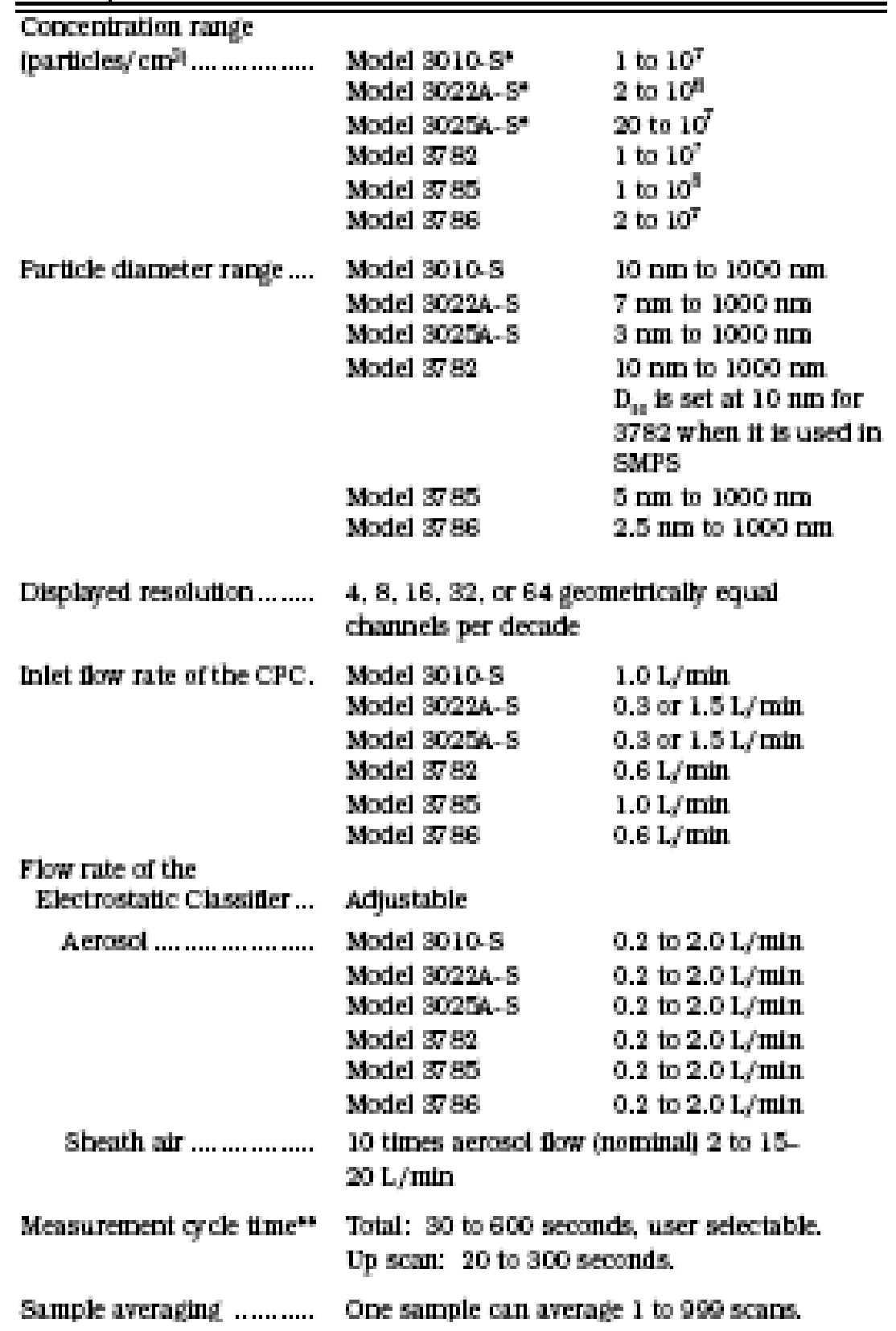




\section{APPENDIX C- TSI MODEL 3480 ELECTROSPRAY AEROSOL GENERATOR SPECIFICATIONS}

\begin{tabular}{|c|c|}
\hline Mode of operation & $\begin{array}{l}\text { Generation of aerosols from liquid solutions or suspersions using an } \\
\text { electros pray method. }\end{array}$ \\
\hline Capillary dimension & $25 \mu \mathrm{m}, 250 \mathrm{~mm}$ length \\
\hline Particle type & $\begin{array}{l}\text { Solids or nonvolatile liquids soluble in } 20 \mathrm{mM} \text { ammonium acetate } \\
\text { solution in ultrapure water or } 0.05 \% \text { trifluorocetic acid in ultrapure } \\
\text { water. Suspensions in some solvents up to a particle size of } 100 \mathrm{~nm} \text {. }\end{array}$ \\
\hline Initial droplet diameter & $150 \mathrm{~nm}$ nominal \\
\hline Particle generation rate & $>10^{\prime}$ particles $/ \mathrm{cm}^{3}$ \\
\hline Particle size range & 2 to $100 \mathrm{~nm}$ \\
\hline Liquid conductivity & $0.2 \mathrm{~S} / \mathrm{m}$ nominal \\
\hline Liquid flowrate & $66 \mathrm{~nL} / \mathrm{min}$ nominal \\
\hline Differential pressure & 0 to 5 psi ( 3.7 psi nominal) \\
\hline \multicolumn{2}{|l|}{ Flowrates } \\
\hline Air & 0.2 to $2.5 \mathrm{~L} / \mathrm{min}(1 \mathrm{~L} / \mathrm{min}$ nominal $)$ \\
\hline $\mathrm{CO}$ & 0.05 to $0.5 \mathrm{~L} / \mathrm{min}(0.1 \mathrm{~L} / \mathrm{min}$ nominal $)$ \\
\hline Aerosol & 0.25 to $3 \mathrm{~L} / \mathrm{min}$, determined by the sum of air and $\mathrm{CO}_{2}$ flowrates \\
\hline Ionizert & $\begin{array}{l}\text { Bipolar, Po-210, } 5 \text { millicurie, half-life of } 138 \text { days, shipped } \\
\text { separately }\end{array}$ \\
\hline Front panel displays & LED, 3.5 digit voltage and current displays \\
\hline \multicolumn{2}{|l|}{ Ports } \\
\hline Air inlet & $1 / 4$ in. OD Swagelok connection \\
\hline $\mathrm{CO}$, inlet & $1 / 4$ in. OD Swagelok connection \\
\hline Aerosol outlet & $1 / 4$ in. OD Stainless Steel tube \\
\hline Voltage range & $\begin{array}{l}+0.5 \text { to }+3.5 \mathrm{kV} \text { ( } 2.0 \text { to } 2.5 \mathrm{kV} \text { nominal, negative high-voltage module } \\
\text { available) }\end{array}$ \\
\hline Current range & 0 to $2000 \mathrm{nA}$ (280 to $320 \mathrm{nA}$ nomiral) \\
\hline Dimensions (LWH) & $20.3 \mathrm{~cm} \times 40.4 \mathrm{~cm} \times 25.7 \mathrm{~cm}(8.0$ in. $\times 15.9$ in. $\times 10.1$ in. $)$ \\
\hline Weight & $6.8 \mathrm{~kg}(15 \mathrm{lb})$ \\
\hline Power requirements & 85 to 260 VAC, $50 / 60 \mathrm{~Hz}, 25 \mathrm{~W}$ maximum \\
\hline Fuse (not replaceable by user) & $2.5 \mathrm{~A}, 250 \mathrm{~V}$, type $5 \times 20 \mathrm{~mm}$ (not replaceable by operator) \\
\hline Environmental Conditions & $\begin{array}{l}\text { Indoor use } \\
\text { Altitude up to } 2000 \mathrm{~m}(6500 \mathrm{ft}) \\
\text { Ambient temperature } 10-50^{\circ} \mathrm{C} \\
\text { Ambient humidity } 0-90 \% \mathrm{RH} \text { non-condensing } \\
\text { Over-voltage category II } \\
\text { Pollution degree II }\end{array}$ \\
\hline
\end{tabular}

